\title{
Adaptive Lifelong Learning for an Inclusive Knowledge Economy
}
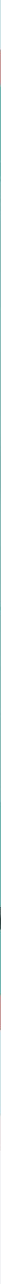

The Calhoun Center for Higher Education Innovation Virginia Tech Publishing The International Academic Forum Future Talent Council 
Copyright (C) 2020 Virginia Tech

Individual chapters (C) 2020 respective authors

Some rights reserved

\section{(c) (1) \& (2)}

This work is licensed under a Creative Commons Attribution 4.0 International (CC BY- NC-SA 4.0) License. Note to users: A Creative Commons license is only valid when it is applied by the person or entity that holds rights to the licensed work. Works may contain components (e.g., photographs, illustrations, or quotations) to which the rightsholder in the work cannot apply the license. It is ultimately your responsibility to independently evaluate the copyright status of any work or component part of a work you use, in light of your intended use. To view this license in full, visit: https://creativecommons.org/licenses/by/4.0/

First published 2020 by the Virginia Tech Calhoun Center for Higher Education Innovation in collaboration with The International Academic Forum, Future Talent Council, and Virginia Tech Publishing.

Virginia Tech Calhoun Center for Higher Education Innovation

Hillcrest Hall

Blacksburg, VA 24061

Virginia Tech Publishing

University Libraries at Virginia Tech

560 Drillfield Dr.

Blacksburg, VA 24061

The International Academic Forum

Sakae 1-16-26 - 201

Naka Ward, Nagoya, Aichi Prefecture

Japan 460-0008

Future Talent Council

Regeringsgatan 38

Stockholm, SE

DOI: https://doi.org/10.21061/adaptive-learning-report

Suggested Citation:

Calhoun Center for Higher Education, Virginia Tech. (2020). Adaptive Lifelong Learning Report for an Inclusive Knowledge Economy. doi:https://doi.org/10.21061/adaptive-learning-report

Graphics and illustrations: Olivia Menezes 


\section{Adaptive Lifelong Learning for an Inclusive Knowledge Economy}

\section{List of Co-Authors and Participants}

This report was compiled by 60 co-authors and contributors engaged with adaptive lifelong learning across different sectors. The team worked together remotely over 12 months and also met for a twoday, in-person workshop in October 2019. Starting in August 2020, the report will be further developed through working groups with different learning communities and stakeholders.

Amy Arnold, Virginia Tech

Andrew Lindsey, Alpha Corporation

Andrew McCoy, Virginia Tech

Anne Khademian, Virginia Tech

Barbara Lockee, Virginia Tech

Carol Adams, University of Lynchburg

Catherine Amelink, Virginia Tech

Chip Blankenship, Virginia Tech/UVA/GE

Christopher Glover, Beacon of Hope

Chrystal Harris, An Achievable Dream

Clayton Hoyle, Journeys

Colin Potts, Georgia Tech

Dale Pike, Virginia Tech

Dale Whittaker, University of Central Florida

Daniel Kjellsson, Future Talent Council

David Hare, GE Appliances

David Tegarden, Virginia Tech

David Tinapple, Arizona State University

David Ucko, Museums+more LLC
Eta Nahapetian, Fairfax County

Feng Hou, Maryville University of St. Louis

Glen Holmes, Virginia Tech

Jared Keyel, Virginia Tech

Jeff Garrett, Brookville High School

Jenna Joo, Ithaka $\mathrm{S}+\mathrm{R}$

Joel McPhee, Bank of America

John Boyer, Virginia Tech

John Flato, Future Talent Council

Jonothan Lister, An Achievable Dream

Joseph Haldane, IAFOR

Julie Greenwood, Arizona State University

Karen Eley Sanders, Virginia Tech

Karla Bruce, Fairfax County

Kate Lindsey, Alpha Corporation

Kimberly Carlson, Virginia Tech

Kristin Wingfeld, Academies of Louisville

Laura Hamilton, Beacon of Hope

Lisa McNair, Virginia Tech 
Manny Contomanolis, Northeastern University

Mark Kamlet, Carnegie Mellon University

Marsha Semmel, Marsha Semmel Consulting

Matthew Holt, Virginia Tech

Michael Richey, The Boeing Company

Mukul Kumar, Hult Business School

Nene Spivy, Children's Science Center

Owen Cardwell, University of Lynchburg

Rachel Holloway, Virginia Tech

Randy Swearer, Autodesk

Ralph Hall, Virginia Tech

Rebecca Clark-Stallkamp, Virginia Tech

Robert Mazer, Smart City Works

Robert Smith, The Boeing Company

Roger Reynolds, University of California San Diego

Scott Bess, Purdue University
Scott Weimer, Virginia Tech

Shahabedin Sagheb, Virginia Tech

Shari Garmise, APLU and USU

Sherrell Ashburn, An Achievable Dream

Sylvester Johnson, Virginia Tech

Taran Cardone, Virginia Tech

Todd Nicewonger, Virginia Tech

Tom Martin, Virginia Tech

Tom Quick, GE Appliances

Thanassis Rikakis, Virginia Tech

Thomas Skuzinski, Virginia Tech

Virginia Tech Student Participants: Alicia Gendell, Ariel Carter, Golder Baah, Mimi Dang, Sabrina Chin, Taha Shaikh

Workshop facilitator: Tom Martin 


\section{Workshop Sponsors}

The following Virginia Tech organizations supported the workshop and work on this report:

The Calhoun Center for Higher Education Innovation

The Center for Humanities

The Institute for Creativity, Arts, and Technology

The College of Agriculture and Life Sciences

The Pamplin College of Business

The College Access Collaborative

The Office of the Vice President for the National Capital Region

\section{Report Co-Publishers}

The publishing and dissemination of this report is a collaborative effort of:

The Calhoun Center for Higher Education Innovation

Editors: Thanassis Rikakis, Jared Keyel, Amy Arnold

Co-editor: Rebecca Clark-Stallkamp

Graphic Design: Olivia Menezes

The International Academic Forum (IAFOR)

Editor: Joseph Haldane

Future Talent Council (FTC)

Editors: Daniel Kjellsson and John Flato

Virginia Tech Publishing

Editors: Peter Potter, Robert Browder, Lauren Holt 


\section{CONTENTS}

EXECUTIVE SUMMARY

INTRODUCTION

Authors: Jared Keyel, Anne Khademian, Thanassis Rikakis

Contributors: Sylvester Johnson, Lisa McNair, Joseph Haldane, John Flato, Catherine Amelink

\section{CHAPTER I: The Integrative Professional and Personal Development Model (IPPD) and $21^{\text {st }}$ Century Knowledge}

Authors: Amy Arnold, Thanassis Rikakis

Co-authors: Jared Keyel, David Tegarden, Kimberly Carlson

Contributors: Robert Smith, Brock Avery

1.1 Lifelong Learning Needs in the $21^{\text {st }}$ Century Economy 13

1.2 Higher Education Evolves 17

1.3 Meeting the Talent Demand Through On-ramps 19

1.4 Integrative Professional and Personal Development Model 22

1.5 Characteristics of Integrative Development 29

1.6 Collective Responsibility for Integrative Professional and Personal Development 32

\section{CHAPTER II: Adaptive Approaches to Integrative Professional and Personal Development}

Authors: Thanassis Rikakis, Kimberly Carlson, Jared Keyel, Owen Cardwell

Co-authors: David Tegarden, Randy Swearer, Barbara Lockee, Feng Hou, Glen Holmes, Sylvester Johnson

Contributors: Taran Cardone, Mark Kamlet, Dale Whittaker, Colin Potts, Amy Arnold, John Boyer, Tazio Grivetti, Chip Blankenship, Michael Richey 
2.1 Adaptation and Integrative Development 37

2.2 Co-Creation Approaches to Learning 38

2.3 Understanding Learners' Personal and Relational Knowledge 42

2.4 Moving From Fixed Courses and Curricula to IPPD-based Adaptive Learning Platforms 43

2.5 Technological Tools for Aiding Adaptation 49

\section{CHAPTER III: Adaptive Learning Pathways: Examples from Higher Education, Industry, and Across Sectors}

Authors: Rebecca Clark-Stallkamp, Shari Garmise

Co-authors: Thanassis Rikakis, Amy Arnold, Jared Keyel

Contributors: Andrew McCoy, Chip Blankenship, Colin Potts, Chrystal Harris, David Hare, Jena Joo, Julie Greenwood, Kristin Wingfeld, Manny Contomanolis, Marsha Semmel, Mukul Kumar, Randy Swearer, Robert Smith, Scott Bess, Sherrell Ashburn, Tom Quick

3.1 Adaptive Pathways in Higher Education 60

3.2 Adaptive Pathways in Industry 64

3.3 Adaptive Pathways that Cross Sectors 65

3.4 On-Ramps and Off-Ramps 72

3.5 Expanded Access and Reduced Cost 73

3.6 Cross-sector, Learner-Centric Credentialing 74

\section{CHAPTER IV: Point of Need Learning and Inclusive Learning Societies}

Authors: Jared Keyel, Thanassis Rikakis, Anne Khademian

Contributors: Todd Nicewonger, Sylvester Johnson, Dale Whittaker, Michael Richey, Taran Cardone, Rebecca Clark-Stallkamp, Catherine Amelink, Ralph Hall, Matt Holt

4.1 Participatory Knowledge and Flatter Organizations 79

4.2 Communities of Integrative Learners as Pilots for Learning Societies 81

4.3 Point of Need Learning Platforms 84

4.4 Predictive Modeling of Practices Within an Inclusive Knowledge Economy 87 
Group 1: From School, to Manufacturing Employment, to Lifelong Learning 93

Group 2: Adaptive and Integrative Learning in Global Academia 94

Group 3: Adaptive and Integrative K-12 Preparation in Underserved Areas-Trusting the Young Learner 94

Group 4: Cross-Sector Summit on Adaptive Learning for an Inclusive Workforce at the Intersection of Humans and Technology 94

Group 5: Integrating IPPD Adaptive Learning in Current Higher Education Structures-Calhoun Discovery Program 95

Group 6: An Inclusive Workforce Development Workshop with Virginia Mayors-Focus on Industry 4.095

Group 7: Institutional Partnerships with Local Employers in Rural Settings 95

Group 8: Transdisciplinary Relational Knowledge for Integrative Development and Revaluing the Humanities and Arts 96

Group 9: Towards a Point-of-Need Platform for Inclusive and Sustainable Industry 4.096

\section{APPENDIX A: The Calhoun Discovery Program-A Pilot IPPD Curriculum}

Author: Thanassis Rikakis

Co-authors: Lisa McNair, Shahabedin Sagheb, Alkan Soysal, Mike Kretser, Robert Smith, Neal Henshaw Contributors: Michelle Kovac, Paul Knox, Paul Heilker, Tom Martin, Akshay Sharma, Lara Khansa, Mark Embree, Sylvester Johnson, James Ivory, Anne-Lise Velez, Nikki Lewis, Luke Lester, Chip Blankenship, John Tracy, Amy Arnold, Les Duffeld, Howard Haines

REFERENCES

\section{RESOURCES}

The Calhoun Center for Higher Education Innovation will host an iterative, online repository of examples, case-studies, and pilot programs related to the themes and practices explored in this report. These resources provide greater detail and context to a number of ongoing adaptive, lifelong learning projects that expand on the recommendations of the report and will inform the working groups. 
Authors will continue to add and update their contributions, which can be found at: https://honorscollege.vt.edu/cdp/Report/Resources.html

- $\quad$ KY Federation of Advanced Manufacturing Education (FAME) (David Hare)

- Adaptive Professional Development at GE (David Hare)

- The Academies of Louisville (Kristin Wingfeld)

- A Discussion of Ken Wilbur's AQAL Model (Owen Cardwell)

- A Pilot Study of an Experimental, Multimodal-Curricular Design (Kimberly Carlson, Buzz Williams, Thanassis Rikakis)

- The Myers Lawson School of Construction Cross-sector Curriculum (Andrew McCoy)

- Calhoun Discovery Program Assessment (Lisa McNair)

- Industry 4.0 for Sustainable Development Lab (Jared Keyel)

- Blockchain Revolution (Feng Hou)

- Modularizing the World: Redesigning World Regional Geography into Multiple Mini-Courses Format (John Boyer)

- Transdisciplinary Relational Contexts for Adaptive and Inclusive IPPD (Thanassis Rikakis, Sylvester Johnson, Roger Reynolds)

- Working through Differences: An on the ground exploration of the socio-cultural experiences of faculty and staff engaged in campus-wide, cross-disciplinary collaborations in higher education (Todd Nicewonger) 


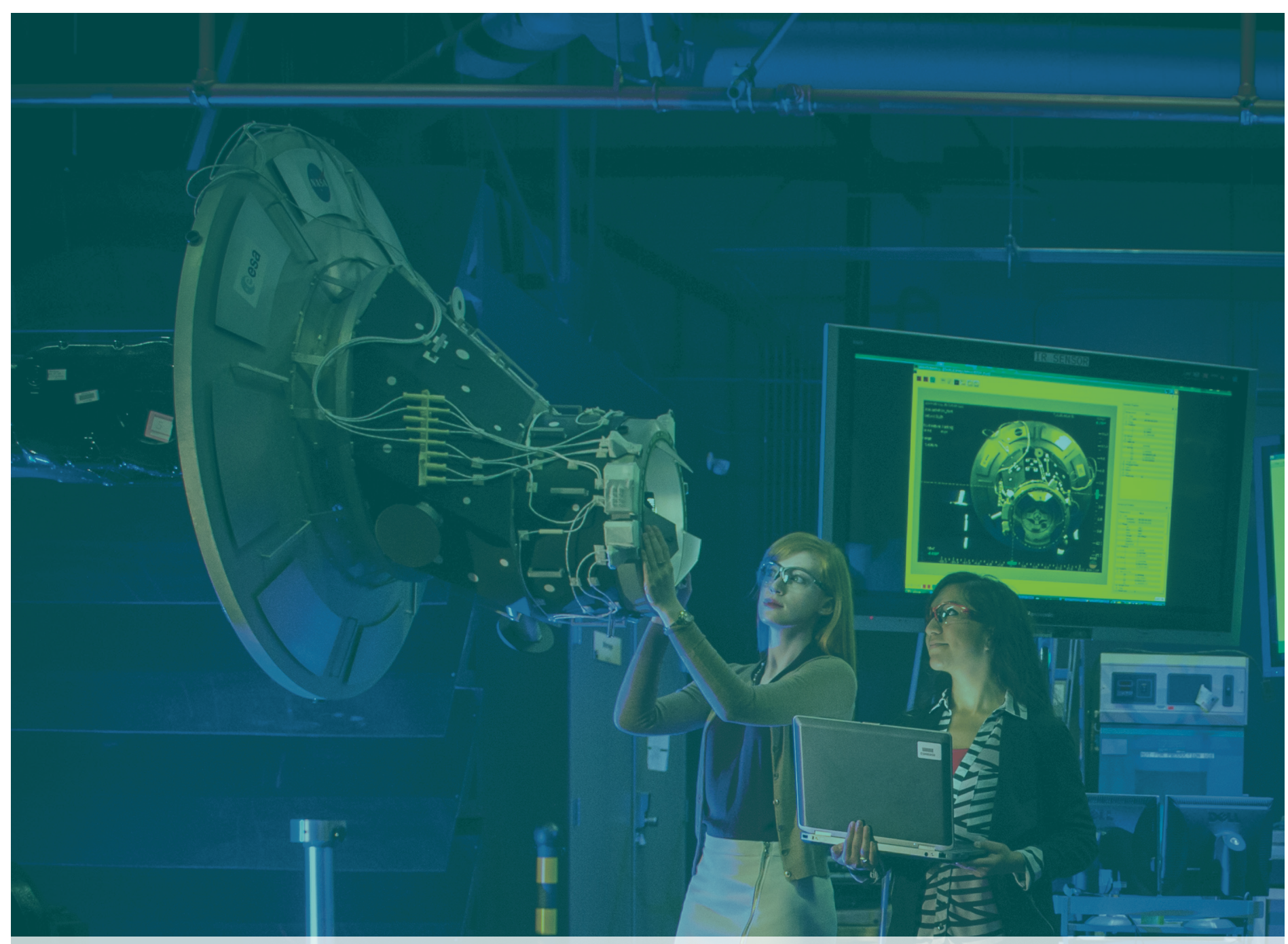

Executive Summary 


\section{EXECUTIVE SUMMARY}

$\mathrm{I}$

n January 2019 the Calhoun Center for Higher Education Innovation at Virginia Tech launched a multiyear project designed to explore the connections between adaptation and inclusiveness in learning. Our thesis was that a full-fledged commitment to adaptive learning has the potential to diversify the emerging knowledge economy while also making it more inclusive. Moreover, increased diversification and inclusiveness can enhance socioeconomic sustainability and enable our society to engage all pertinent voices when approaching complex problems.

To test this thesis, we first explored an adaptive and inclusive approach to defining what we mean by learning and knowing. A dynamic definition allowed us to then openly explore adaptation to specific aspects of learning including: i) How is learning realized? ii) When is learning delivered? iii) Who is included in learning?

Our first step was to bring together 60 individuals, each with significant direct experience with adaptive learning. These individuals came from 30 different organizations representing a range of sectors: higher education, $\mathrm{K}-12$ education, industry, and non-profit. Together, we collaboratively developed a three-stage plan:
- Stage 1: Record emerging practices in a preliminary report and discuss them during a twoday workshop in Washington, D.C. (March 2019-October 2019)

- Stage 2: Synthesize the outcomes of the research and discussions into a report that summarizes emerging practices and provides an agile framework of recommendations for further development of adaptive and inclusive lifelong learning. This report concludes the second stage. (November 2019-August 2020)

- Stage 3: Launch working groups to further explore and test the recommendations of this report. These working groups can be found at the end of this report. They are launching in August 2020 and are open to participation by entities and individuals interested in the project. (August 2020-August 2021)

While implementing the second stage of our project, a number of world events intervened, which only served to amplify the urgency of our mission. One such event, COVID-19, is already showing the speed with which scientific and technical knowledge can be developed, shared, and advanced as never before. This, of course, 
has profound implications for the development of life-saving treatments. At the same time, COVID-19 has laid bare the social disparities inherent in $21^{\text {st }}$ century socioeconomic structures and highlighted the challenges we face as a society in coordinating the handling of complex issues. Entire segments of the population are effectively excluded from participating in, and reaping the benefits from, the knowledge-based economy. Individual achievement is being disconnected from social progress. What is clear is that we must do a much better job of bringing together diverse individual perspectives and experiences if we expect to produce collective action that is both wise and equitable.

This report begins with an introduction that defines our meaning of inclusive knowledge and explains how our proposed definition expands some of the traditional understandings of knowledge. First and foremost, we conceptualize knowledge not as a fixed product or outcome-something stored in our brains, computers, books, or institutions that we access as needed. Nor do we separate the mind (cognition) from the body (action). Rather, we see knowledge as inclusive, dynamic, and evolving. This report takes a knowledge in action approach where knowledge is an emergent, pragmatic, situated, and historical process that is practiced collectively in the classroom, on the job, in the neighborhood, on the road, on the internet, and at home.

Our understanding of knowledge in action as relational comes from the fact that knowledge exists in many different contexts, and those contexts vary from one individual to the next. To have relational knowledge, we also need to account for personal knowledge; active and embodied knowledge-making by individuals. Because human beings have unique life experiences, their accumulat- ed knowledge, learning preferences, and pathways will also be unique. Adapting our learning practices to fit diverse needs and experiences will increase our capacity to be inclusive. Inclusive participation will benefit all learners as they discover how to engage with multiple perspectives. Over time, learners will come to value, leverage, and embody difference, which in turn will make them agile learners with the ability to intuitively combine their expertise with the diverse expertise of others, and structure collective intelligence for addressing complex societal tasks and challenges.

In Chapter I we review literature that establishes adaptive development of domain-specific, domain-general, and life skills as key to training diverse, versatile learners for a collaborative $21^{\text {st }}$ century economy. Learners who develop all three layers of skills in an interconnected fashion are able to transfer knowledge across different relational contexts. This in turn enables them to connect their diverse experiences to multiple professional pathways and collaborative contexts, as well as adjust their stock of skills to changing workforce needs.

Chapter I also highlights several organizations that have developed agile training frameworks in an effort to address $21^{\text {st }}$ century proficiencies. In some cases, organizations are also providing onramps for nontraditional learners who may be under or unemployed. A key takeaway is that co-creation processes enable learners who are at risk of being left behind to acquire integrative multilayer skills that are needed in the $21^{\text {st }}$ century economy.

Chapter II focuses on ways to adapt existing best practices to better serve the needs of learners as they develop and expand their multilayer skills across professional and personal contexts. As we explain, educators and employers must first acknowledge that learners already possess unique 
skill sets that simply need to be tapped into. Educators and employers must then find creative ways to partner with learners, enabling them to connect existing skill sets and aspirations to future career pathways and acquire the additional skills necessary for these individualized pathways.

The way we propose to facilitate this partnering is to structure learning experiences as networks of short modules that utilize different learning modalities and connect through multiple pathways to allow learners to develop skill proficiency and connectivity precisely when it is needed and in the most efficient customized manner. Structuring pathways of short modules allows just-in-time information to emerge in the course of learning such that a learner's pathways can change and evolve to reflect the new situation. Utilization of different learning modalities (e.g., experiential, theoretical, in-person, asynchronous, blended, etc.) helps to address the needs of a truly diverse body of learners and cover the full range of knowledge types. We conclude the chapter by discussing a number of existing and emerging technological tools and technology-assisted processes that facilitate adaptive learning. These include intelligent/cognitive tutors combined with interactive content; the Internet of Things and paired technologies such as augmented/virtual reality and robots for embodied interactive learning; and multidimensional data analytics for assessment of progress and adaptation of learning.

In Chapter III we survey a number of adaptive learning programs currently being implemented in academia, industry, and communities. As we show, these programs are increasing access to learning by employing multiple delivery modalities, alternative cost structures, holistic support mechanisms for diverse learners, transferability of learning, and transparency of learning outcomes across institutions. We show how these programs are mobilizing people to learn whenever and however they require it regardless of barriers that may exist at the individual, social, or cultural levels. We also consider new approaches to cross-sector learning and credentialing that increase access and reduce cost while allowing for the learning record to stay with the learner rather than with the institution.

In Chapter IV we propose advancing inclusive and integrative adaptive learning through cross-sector cooperative communities organized around transdisciplinary themes of societal impact. As envisioned, these communities value and engage all aspects of knowledge in action, rely on inclusive and non-hierarchical participation and promote integrative, multilayer skill development for all participants. We further propose expanding these communities by developing Point of Need Learning Platforms (PNLP) that allow diverse learners to explore the mapping of their existing skills to current and emerging training and employment pathways. PNLPs provide efficient individualized pathways for immediate learning needs while guaranteeing that learning is transferable to other contexts and situated within integrative professional and personal development. PNLPs contain interconnected, modular content that has been developed by all participating sectors and that accommodates all types and levels of learning need. Many of the modules integrate multi perspective learning and bring diverse learners together to explore complex problems. PNLPs use high dimensional analytics to continuously adapt to societal and individual needs and provide a lifelong learning record owned by the learner.

PNLPs can be developed by adopting, experimenting with, and evolving many of the recommendations presented in this report. The model of 
institutional change proposed in this report is the result of integrative discourse between a radical paradigm shift-inclusive transdisciplinary communities supported by PNLPs - and the gradual change processes embedded in existing institutions.

Appendix $A$ summarizes the Calhoun Discovery Program (CDP) at Virginia Tech. The CDP focuses on the development of versatile and collaborative lifelong learners through adaptive and integrative training of domain-specific, domain-general, and life skills. The learning is embedded in cross-sector transdisciplinary communities focused on sustainable and equitable socio-technical innovation.

In closing the report, we propose the establishment of nine Working Groups with learners and learning professionals working in and across sectors ( $\mathrm{K}-12$, Higher Education, Industry, etc.). Taking place in the second half of 2020 and Spring of 2021 , the groups will collect more information on emerging adaptive learning practices and engage participants in reflexive dialogue on their experiences with various learning models and approaches. The insights gained from these groups will be analyzed and incorporated into a draft of a cross sector PNLP for Industry 4.0 and Sustainable Development. The findings of the working groups will also be presented in a digital book published by Virginia Tech Publishing at the end of 2021.

We thank you for reviewing this report and welcome questions and suggestions as well as inquiries for participation in the working groups. Please contact us atcchei@vt.edu. 


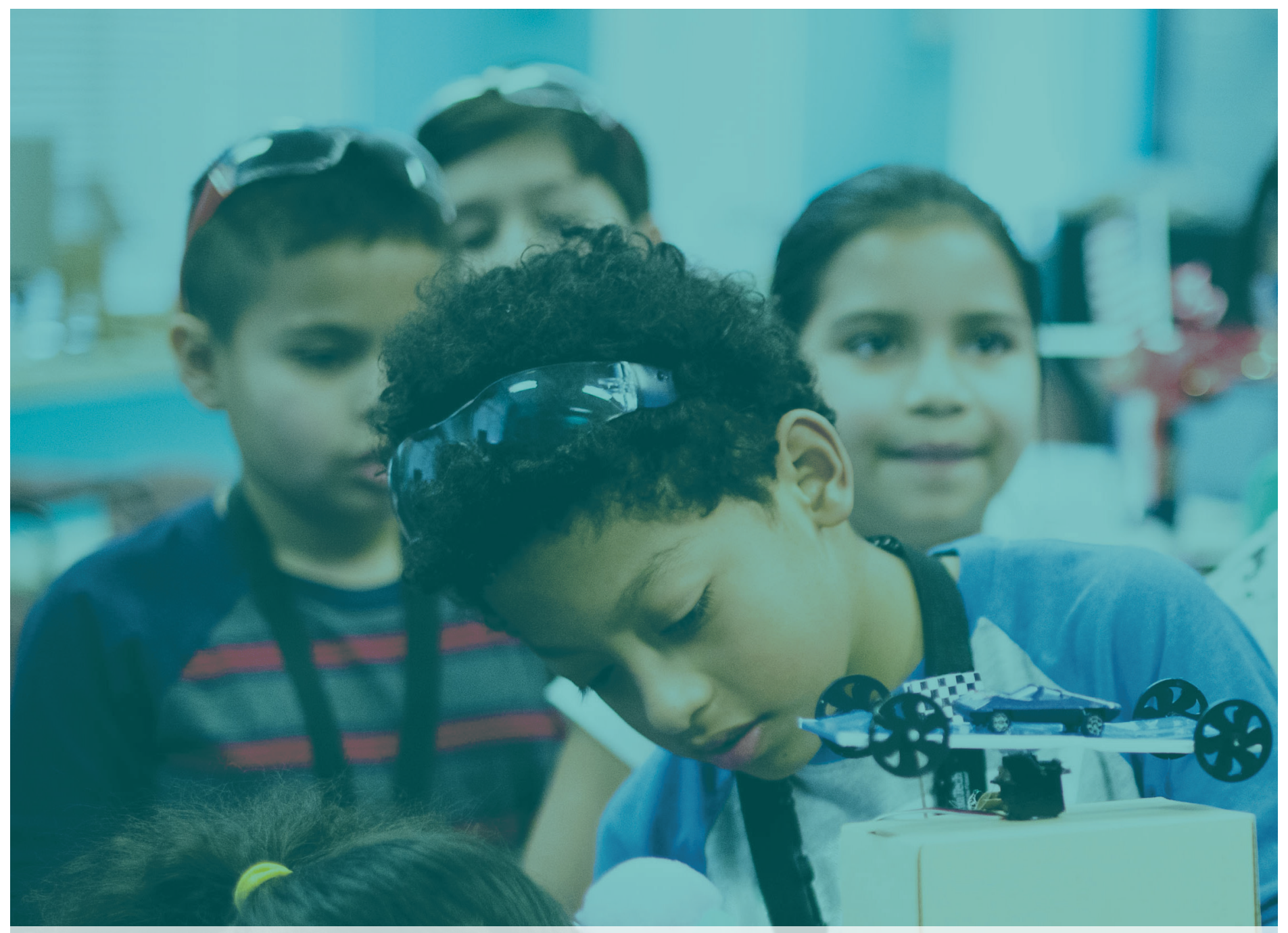

\section{Introduction:}

Inclusive Knowledge in Action

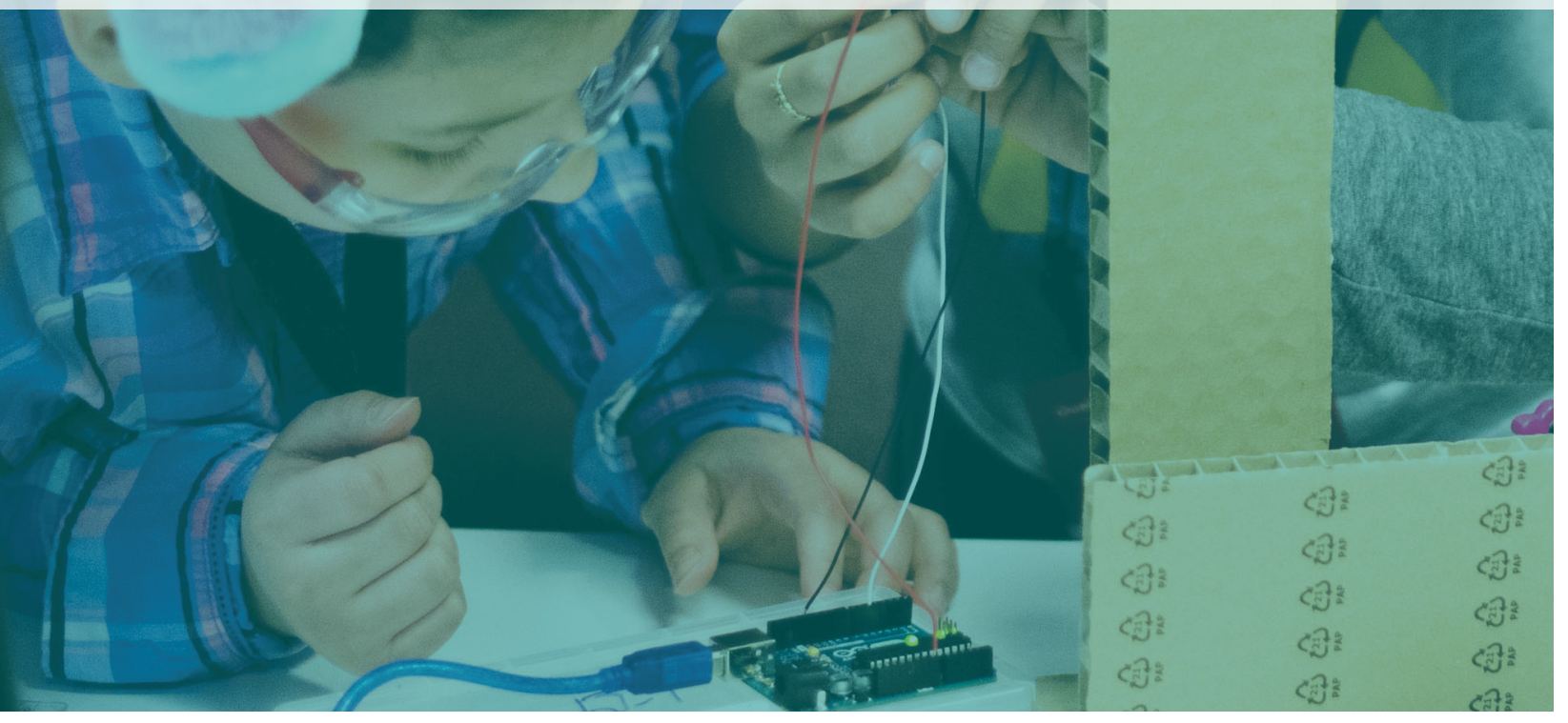




\section{INTRODUCTION}

Authors: Jared Keyel, Anne Khademian, Thanassis Rikakis

Contributors: Sylvester Johnson, Lisa McNair, Joseph Haldane, John Flato, Catherine Amelink

$\mathrm{T}$

This report addresses the globalized knowledge economy in the $21^{\text {st }}$ century; not only as it exists today, but the knowledge economy needed to meet the demands of tomorrow. This report proposes that in order for our knowledge economy to grow and be sustainable, it must be inclusive in ways that enable it to adapt to - and incorporate within it - the personal and professional growth of a large and diverse body of lifelong learners. In this introduction, we first define what we mean by inclusive knowledge and explain how our proposed definition expands some of the traditional understandings. We then show that an expansive and dynamic conceptualization of knowledge increases inclusion and promotes lifelong adaptive learning as a mindset and a practice.

\section{Inclusive Knowledge in Action}

The way we learn and know in today's world is deeply shaped by the informational and relational practices of educators and decision-makers across the educational enterprise. This begins in $\mathrm{K}-12$ schools and continues through higher education, on-the-job training, and continuing professional education. Within the established educational enterprise, longstanding learning practices approach knowledge in exclusionary ways. Top-down practices represent knowledge as discrete components of information, disciplinary-based, and siloed in terms of what individuals need to know, what constitutes expertise, and where they learn - such as classrooms and workplaces. This means that our traditional understanding of knowledge has been defined in terms of cognitive expertise developed and acquired through education, reading, and research that is largely held and protected by practicing professionals and degree-granting institutions.

In a similar fashion, we have come to view the organizations that make up the educational enterprise as repositories of knowledge and expertise tailored to a specific mission or mandate. Knowledge is often considered a product that organizations can have and that is stored within domain-specific databases, procedures, and protocols. In the higher education sphere, students enter schools and colleges to acquire specific subject matter knowledge that is organized according to varying levels of specialization. Students are tested at each level to ensure mastery of the knowledge, from which they ultimately move on, degrees in hand, ready to work in jobs that align with the specific knowledge they have acquired. 
In contrast to such understandings, this report takes a knowledge-in-action approach (Argyris \& Schön, 1978; Dewey 1933; Polanyi, 1958; Schön, 1983). Rather than conceptualize knowledge as a fixed product or outcome-something stored in our brains, computers, books, or institutions that we access as needed - and rather than separate the mind (cognition) from the body (action), we believe it is important to see knowledge as inclusive, dynamic, and evolving. Knowledge in action is an emergent, pragmatic, situated, and historical process. It is practiced collectively in the classroom, on the job, in the neighborhood, on the road, on the internet, and at home.

A fundamental component of knowledge in action is tacit knowledge that has been acquired through experience (Polanyi, 1958) rather than absorbed through verbal explanation or written form. Existing exclusive meritocratic approaches have largely ignored or overlooked expertise and knowledge that is acquired through our day-today activities - in business, in school, on the bus, playing sports, painting, or cleaning at home. Yet, anyone who knows the best driving routes across a city, the safest schools and best teachers, the experience of troubleshooting home computer network issues for friends and family, or the tactics to catch a particular kind of fish has tacit knowledge. Knowledge in action involves synergistic interactions of explicit, implicit, and tacit knowledge (Polanyi, 1967; Reber, 1989) combined with integrative cognitive, psychomotor, and affective learning (Anderson \& Krathwohl, 2001).

Knowledge in action is also relational and personal (Dewey 1933; Dourish, 2001; Polanyi, 1958). To understand knowledge as relational is to emphasize the importance of the historical, social, technical, cultural, and economic contexts in which knowledge is situated (Coghlan \& Brydon-Miller,

\section{Knowledge in action is an}

emergent, pragmatic, situated, and historical process practiced collectively in the classroom, on the job, in the neighborhood, and at home.

2014). When considered in these contexts, knowledge is not a set of rational, discoverable facts that can be neutrally applied to test an idea, do a task, or solve a problem. In fact, what we know cannot be distinguished from how we know it (Polanyi, 1958) or from the multiple interactions that give meaning to information. To have relational knowledge, we also need to account for personal knowledge - active and embodied knowledge-making by individuals. Individuals accumulate knowledge differently based on their mode(s) of participation, preferences, situational contexts, and goals. Each person brings the totality of the knowledge they have acquired across many different contexts to any new learning situation. To structure effective learning, we need to recognize that comprehensive personal knowledge accumulates in the person rather than the formalized curricula. Because everyone has different life experiences, their accumulated knowledge will be diverse, and their learning preferences and pathways may also be multiple. To include everyone and allow everyone to develop most effectively, adaptation of learning is imperative.

If we focus solely on knowledge as an outcome, we end up with clusters of knowledge defined by particular understandings of the world. This, in turn, leads to pre-set paths to expertise that invariably limit other possible paths that are otherwise able to emerge in adaptive situations. 


\section{Knowledge in action is}

relational and personal. It involves active and embodied personal knowledge-making by individuals in multiple contexts.

Such is true with disciplinary sets of scientific rules about the physics of the universe, homogeneous understandings of the relationship between social services and human behavior, and collective understandings of national identity. In this context, knowledge, beliefs, and convictions are seen as a given, set in stone, requiring compromise and negotiation to navigate differences, or the give and take of academic investigation and deliberation to make incremental adjustments. Alternatively, when we understand collective meaning as a way of knowing, the relational, diverse, and enacted nature of knowing comes to the fore, with opportunities for continuous adaptation and formulation of new ideas, techniques, and approaches. A pluralistic and dynamic knowledge-in-action discourse resists the creation of static knowledge structures and permanent hierarchies of knowledge power. In fact, by its very nature, this discourse is deconstructive. In view of these characteristics, it is perhaps more useful to understand knowledge in action not as a fixed outcome but as an active system of multiple ways of knowing that are dynamic and engage a multitude of process-product permutations.

Connecting highly individualized ways of knowing to collective ways of knowing is an ageold challenge. Institutional standardization can circumnavigate this issue by advancing homogeneity of collective knowing but homogeneous groups get stuck on local maxima (Page, 2007).
Heterogeneous groups can achieve global maxima and transformative change, but the connectivity of these groups is highly challenging (Eagle, Macy, $\&$ Claxton, 2010). The interrelation of dynamic personal knowledge of lifelong learners and the diverse, collective intelligence of learning societies may hold the key to solving this problem. Adaptive learning practices that address diverse, personal knowledge needs can promote inclusive participation.

This results in diverse relational contexts for all participants and encourages participants to embody difference. Learners that can embody multiple points of view become aware of the full complexity of societal problems and the need for collaborative approaches to complexity. Members with diverse expertise can then coalesce around complex societal tasks and challenges and share their knowledge intuitively with one another, including less experienced members, resulting in collective intelligence. This promotes the empowerment and mobility of individuals within and across organizations, and mitigates the loss of organizational memory (Harnecker, 2007). Collective intelligence also facilitates a flatter professional pyramid since the "expert" is a dynamic notion that emerges from context (Guattari, 1972). For example, while an experienced medical doctor might lead in making diagnoses, an experienced nurse or physical therapist might be most effective in promoting participatory health for patients (Sepkowitz, 2020). Collective intelligence can thus be conceptualized as a complex ecosystem where instructors are also learners and diverse participants inform the continuous adaptation of personal and relational knowledge. This, in turn, enables participants, as a group, to successfully navigate complex tasks and facilitate recovery from disruptions or systemic failures (Hutchins, 1995). As these intelligence ecosystems grow they 


\section{The interrelation of lifelong}

learners' dynamic personal

knowledge and learning

societies' diverse collective

intelligence may hold a key to

connecting the individualized to the collective.

can promote the realization of learning societies built upon the process of participation (UNESCO, 2008, 2019). Members of a learning society seek to embody process-oriented creation and dissemination of knowledge. As a result, participation in itself becomes a form of knowledge. We expect that the creation, building mechanisms, and function of learning societies as institutions of democratic governance will help acknowledge and address wider racial, gender, and socioeconomic inequalities (UNESCO, 2019).

Throughout history, educators have contemplated how to develop learning societies and rethink their approaches to the content and forms of learning to increase accessibility and inclusivity. Learning and education are inherently evolutionary; practices and approaches shift and respond to social, economic, and political changes over time (Whitney, 2010). The initial creation of universal primary and secondary education, for example, was a leap forward for inclusion. In the United States in the late 19th century, the Morrill Acts framed public education as a democratizing force in society by allowing for greater access to higher education for diverse populations (Geiger, 2015). These acts also allowed for the creation of land grant universities, like Virginia Tech, that attempted to expand education to new students and subjects. Efforts to expand access and inclusion of diverse learners and knowledge have taken place throughout the world. In the United Kingdom, for example, institutions founded in the 19th century, such as University College London and the London Mechanics' Institute (now, Birkbeck College, University of London), offered education to women and people from a much broader range of social backgrounds. Birkbeck College began as a pioneer in adult learning as well. More recently, the Open University was founded in the UK in 1969 with a commitment to modernization and growth in technological development. It was an early advocate and practitioner of increasing access to education through distance learning and was a precursor for online learning that is now vital in a university setting.

Like these earlier iterations and efforts to expand educational opportunities, we are proposing an adaptive approach to learning with the poten-

Figure I:

\section{Four Key Dimensions of Inclusive Knowledge Presented as Expansive Continua}

\author{
Outcome-focused \\ Institutionalized \\ Segregated \\ Standardized
}

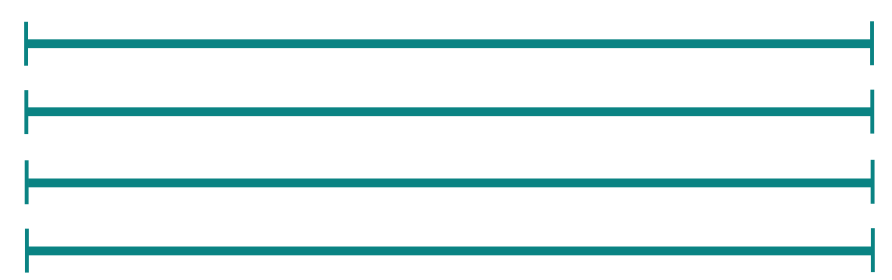

Process-focused

Personal

Integrative

Adaptive 
tial to create vastly more inclusive and accessible learning possibilities that leverage knowledge in all its dimensions. Rather than seeing differences as polarizing binaries (i.e., outcome focused vs process focused), adaptive learners and learning societies can explore the full space between the two notions, thus moving from the binary categorization to expansive continua (Dewey, 1906, 1933; Xenakis, 1971). In Figure I, we present, as continua, the four key dimensions of inclusive knowledge discussed in this introduction.

When we value the full spectrum of knowledge, adaptation becomes both a mindset and a mechanism. Individuals adapt in ways that enable them to engage and embody many different types of knowledge. Learning structures adapt to facili- tate the engagement and growth of different types of knowledge, and societies adapt to value and embrace the diverse personal knowledge of their members. Prior personal and relational knowledge becomes highly transferable to many new types of contexts and becomes stronger and deeper posterior knowledge (Tenenbaum et al., 2011). This deep inclusion and (re)valuing of a vast array of knowledge modes and practices increases a society's human capital (Spence \& Hlatshwayo, 2012). Consequently, those societies are able to find multi-perspective solutions to complex problems that promote socioeconomic sustainability (Morrar, Arman, \& Mousa, 2017). Knowledge becomes a "powerful tool for taking action" to "deepen democracy and to struggle for a fairer and healthier world" (Hall \& Tandon, 2017, p. 13). 


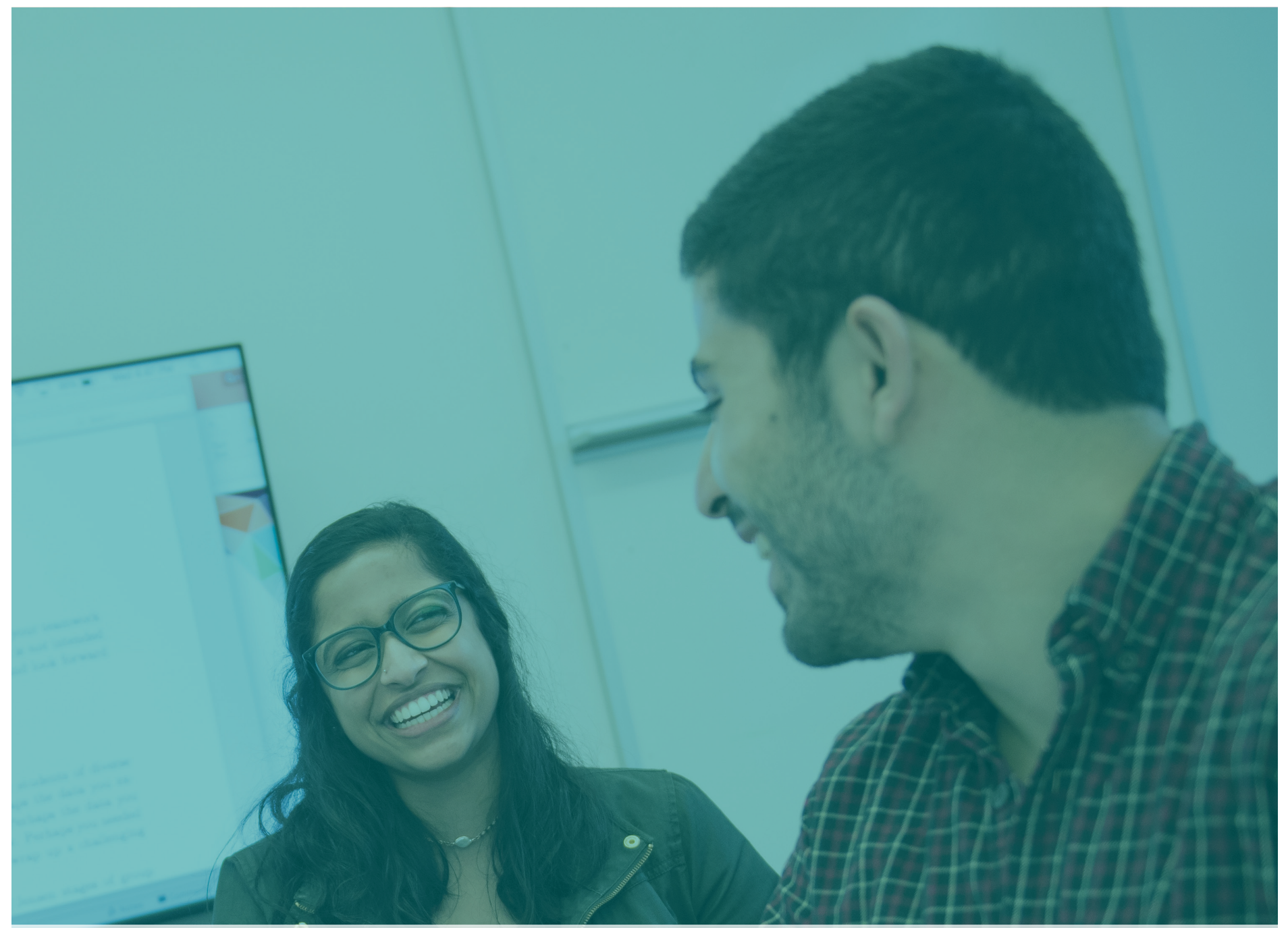

Chapter I:

The Integrative Professional and Personal Development Model (IPPD) and 21 st Century Knowledge 


\title{
CHAPTER I
}

\section{The Integrative Professional and Personal Development Model (IPPD) and 21 ${ }^{\text {st }}$ Century Knowledge}

\author{
Authors: Amy Arnold, Thanassis Rikakis \\ Co-authors: Jared Keyel, David Tegarden, Kimberly Carlson \\ Contributors: Robert Smith, Brock Avery
}

$\mathrm{I}$

$\mathrm{n}$ this chapter, we lay the foundation for the remainder of the report by establishing the basis for the claim made in the introduction, that a new framework for learning and training is necessary to meet the knowledge requirements of the $21^{\text {st }}$ century. Definite socioeconomic changes are influencing the global economy, and our society is at risk of not having the human capital or adaptive ability to navigate them. We show that sustainable growth of human capital requires integrative and continuous development of a wide range of skills tailored to the diverse interests, abilities, and capacities of each learner. We survey emerging frameworks of learning and training throughout higher education and industry that aim to address these needs. Finally, we propose a new model for Integrative Professional and Personal Development (IPPD) comprised of two main components, personal knowledge and relational knowledge. The personal knowledge is organized as a three-layer hierarchy: life skills, domain-general skills, and domain-specific skills. Diverse and dynamic relational knowledge provides the context for the development of integrative personal knowledge.

\subsection{Lifelong Learning Needs in the $21^{\text {st }}$ Century Economy}

It is no secret that the American labor market is in the midst of major structural change. The most notable change is the shift from tradable sector jobs to more non-tradable sector jobs. According to Spence and Hlatshwayo (2012), in the years leading up to the 2008 recession, $97 \%$ of employment growth occurred in the non-tradable sector-largely jobs in government, health care, and retail. Non-tradable jobs are jobs performed by a domestic workforce creating goods and services that cannot be traded internationally (Hlatshwayo \& Spence, 2014; Spence \& Hlatshwayo, 2012). Economists caution that growth in the non-tradable sector cannot continue forever. Standing in the way are restraints on government budgets, reduced public sector spending, and high levels of consumer debt (Spence \& Hlatshwayo, 2012).

The story is different when it comes to the tradable sector - that part of the workforce producing goods and services that can be traded internationally-e.g., manufacturing, information processing, mining, etc. In the US, the tradable sector has actually seen net contraction. The only real growth has been in high-income occupations such as consulting, computer systems design, finance, and insurance. These occupations face competition from individuals performing the same occupations in other countries (Spence \& Hlatshwayo, 2012). In an 
effort to address the expected slowed growth in the non-tradable employment sector and contraction/ income inequality in the tradable sector, a dynamic response is required that emphasizes growth of human capital.

Following Spence and Hlatshwayo's (2012) recommendation of increasing human capital, it is important not to overlook social issues. One of which is the lack of access to the essential knowledge and educational tools that are necessary not only to survive in the $21^{\text {st }}$ century economy but to improve learners' lives and develop to their full capacities (World Economic Forum, 1990). Large segments of the current and future global workforce are either excluded or left behind. For example, $70 \%$ of the world's poor reside in Sub-Saharan Africa (World Data Lab, 2019), and the majority of this population is under the age of 25 (Coulibaly, 2019). The learners of this region need both access to knowledge as well as greater economic opportunities for employment. Everyone, regardless of their sex, gender, religion, or geographic background, has the right to learn (UNESCO, 2000, 2019).

In practice, this requires universal access to the knowledge economy as well as a basic recognition and valuing of all ways of knowing. Developing an inclusive definition of knowledge and

Institutions of trust will need

to reconceptualize training to encompass a more holistic competence model enabling a learner to thrive over a lifetime of constant disruptions and uncertainty.

\section{Expected slowed growth in} the non-tradable employment sector and contraction in the tradable sector of the economy requires a dynamic response in growing the human capital.

the knowledge economy means rethinking current practices that exclude a vast amount of existing human capital. Fundamentally, thought leaders and institutions of trust must develop ways to connect the economy to this human capital, instead of connecting human capital to the economy. Focusing on the needs, diverse interests, abilities, and capacities of lifelong learners may be the first step toward influencing such a shift.

Furthermore, any effort to connect the economy to human capital must be progressive rather than reactionary. Currently, smart factories, artificial intelligence (AI), and automation disrupt the status quo (Muro et al., 2019). The needs of learners change as a result of these disruptions, which in turn requires that knowledge dissemination practices change. In fact, those responsible for providing additional knowledge and greater access must continuously adapt their methods of dissemination on behalf of learners that face challenges to successfully navigate these economic and technological shifts. For learners to thrive in an environment facing constant disruptions by machine learning, artificial intelligence, and future unknowns, institutions of trust will need to re-conceptualize training by focusing on the development of all types of human skills over a lifetime rather than idealizing preparation to be centered on a single career and limited to performing specialized tasks within one discipline. 
Table 1.1

\section{Comparison of Machine and Human Expertise}

\begin{tabular}{|cl}
\multicolumn{1}{c}{ Machine } & \multicolumn{1}{c}{ Repeating predictive tasks } \\
Performing tasks that hinge on computaional power & $\begin{array}{l}\text { Making decisions according to abstract values } \\
\text { Making products and results us able for humans and } \\
\text { communic ation about them }\end{array}$ \\
Maksifying huge amounts of data and inputs & $\begin{array}{l}\text { Deciding how to use limited resources across } \\
\text { dimensions strategic ally (including which tasks } \\
\text { machines should be doing and what data to give } \\
\text { them) }\end{array}$ \\
$\begin{array}{l}\text { Formulating questions and explanations across scales } \\
\text { and sources }\end{array}$ \\
$\begin{array}{l}\text { Experiencing authentic emotions and building } \\
\text { relationships }\end{array}$
\end{tabular}

Adapted from Holmes, W., Bialik, M., \& Fadel, C. (2019). Artificial intelligence in education: Promises and implications for teaching and learning. pp. 24-25.

According to economist David Autor (2015), programmers attempting to replace the tasks performed by humans with machines face immense challenges when it comes to more abstract and nonroutine categories. Similarly, economists at MIT in quantifying the effects of automation and AI on employment and wages, conclude that learners who possess nonroutine cognitive skills such as flexibility, problem solving, and complex communication face less threat from automation than those who perform routine cognitive tasks, routine manual tasks, and nonroutine manual tasks (Autor et al., 2003; Autor \& Price, 2013).

In the United Kingdom and European Union, officials have a long history of investing in lifelong learning programs as a response to economic issues (Popović, 2014; Rees \& Bartlett, 1999b).
These governing bodies view such programs as adequate responses to economic downturns and hope to address emerging gaps between industry's needs and the populations' skill set. Such an approach is not without criticism (Coffield, 2000; Popović, 2014; Rees \& Bartlett, 1999b). One criticism is that it places the impetus on the learners to acquire an adequate skill set rather than recommending the formation of partnerships to assist in upskilling (Rees \& Bartlett, 1999b). Another argument is with the naïve belief that improving the basic skills of a population will resolve a nation's macroeconomic issues (Brown \& Keep, 2000). More education or training will not help someone residing in a geographic region that lacks employment opportunities (Popović, 2014).

A philosophy of lifelong learning may be an 
important first step on the path toward universal access and equity if it engages comprehensively all the types of knowledge embodied by learner and especially the less extractable, more-difficult-to-assess categories of tacit and implicit knowledge (UNESCO, 2000). By focusing on one's knowledge in action (Polanyi, 1958; Schön, 1987), individuals become more valued (Rees \& Bartlett, 1999) and self-actualized (Maslow, 1968). Furthermore, lifelong learning needs to also address alignment to opportunities specific to one's relational contexts (i.e., geographic region).

Institutions of trust also have an important role to play in supporting individual learners in the pursuit of lifelong learning programs (Popović, 2014; Rees \& Bartlett, 1999b). The report Robot-Ready: Human+Skills for the Future of Work stresses the importance of educators, state governments, and employers collaborating in an effort to find a common language to describe (a) the totality of skills employers seek in composing job descriptions and (b) how the learner knows and applies the in-demand competencies of critical thinking and communication during their careers (Weise et al., 2018). Traditional training and learning assessment mechanisms often disregard learners' tacit knowledge gained through experiences across every aspect of daily life. Instead, they focus on explicit knowledge within the classroom and prepare graduates to practice within the domain-specific area of their chosen fields, with little regard for acquiring the "know-how" to perform within the context of a complex job (Eraut, 1985 ) or a fast-evolving global society. This focus on explicit, domain-specific knowledge is a remnant from the second industrial revolution that viewed learners' socioeconomic needs being fulfilled by a single career focused on performing a set of specialized tasks that evolved gradually. In this often-disrupted economy, these traditional

\section{Lifelong learning will not solve a} nation's macroeconomic issues.

systems of education do not fully meet the needs of the learners, their current and future employers or society as a whole (Banerji, 2007; National Academy of Engineering, 2005; Flowers, 2009). The resulting knowledge shortfall can be especially pronounced when learners lack the high-demand, transferable skills, such as communication, collaboration, and problem solving that are critical to the economy of the $21^{\text {st }}$ century (Rhodes, 2019; Snell et al., 2016).

An early foundational framework for understanding inclusive knowledge is Benjamin Bloom's taxonomy, which emphasizes three domains of learning: cognitive, affective, and psychomotor. The goal of this taxonomy is to create learning opportunities to help promote change in individual behaviors (Bloom, 1956). Cognitive learning focuses on the "amount and kind of knowledge" that the student possesses (Bloom, 1956, p. 28). The affective domain focuses on "a feeling tone, an emotion, or a degree of acceptance or rejection," by which an individual learns and then incorporates situational values (Krathwohl et al., 1956, p. 7). Finally, the psychomotor domain "emphasize[s] some muscular or motor skill, some manipulation of material and objectives, or some act which requires a neuromuscular coordination" (Krathwohl et al., 1956, p. 7). As learners have experiences that engage these domains, they become better equipped with skills to take on more complex challenges. The taxonomy shows this potential for growth by organizing each domain in rising levels of competency. Many curricular programs use Bloom's taxonomy as a guide to developing 
learning outcomes, with first- and second-year courses using lower levels of the taxonomy while third- and fourth-year courses focus on the higher levels. However, most traditional curricula develop learning outcomes that focus solely on the cognitive domain (Senge, 1990). This approach is counter to the well-established understanding that knowledge in complexity is embodied, experiential and integrative (Dewey, 1938, 1966; Dourish, 2001; Hutchins, 1995).

\subsection{Higher Education Evolves}

The need to update educational structures to address all types of human skills and their relation to contemporary workforce needs has been predicted for over 30 years (Jantsch, 1972; d'Hainaut, 1986). In 1991, Guest introduced the concept of the T-shaped individual as a variation of the Renaissance man: someone who develops generalizable skills by practicing across disparate specialization areas such as computing and music. Guest's (1991) definition of T-shaped individuals aligns with what Fadel, Bialik, and Trilling (2015) refer to as versatilists-learners who exhibit deep knowledge in a range of subjects as well as the generalizable skills to transfer knowledge across these domains. These learners "apply a depth of

Versatilists "apply a depth of skill to a widening scope of situations and experiences, gaining new competencies, building new relationships, and assuming new roles," which makes them adaptable learners, not generalists. skill to a widening scope of situations and experiences, gaining new competencies, building new relationships, and assuming new roles," which makes them adaptable learners, not generalists ( $p$. 12).

Unfortunately, The T-shaped individual concept gradually evolved away from the original concept of versatility. By 2006, Spohrer was calling for T-shaped individuals who acquire a greater breadth of knowledge in addition to a deep knowledge in one discipline. Interdisciplinary programs aimed at T-shaped learning, where the depth is associated with the segregated discipline, are now embedded in the majority of US Universities (Knight, 2013). Foundational education programs that continue to associate depth of knowledge with a few specific subsets of personal knowledge fail to acknowledge and leverage the relation of domain-specific and domain-general skills and the overall dimensionality and differentiation of personal knowledge. It is our contention that the simplification of learning into an outcome-focused, discipline-specific specialization, combined with a loosely-related body of general knowledge, contributes to the mismatch between learning outcomes produced by higher education and the skills demanded by employers and required by our complex societal needs (Hart, 2015; Madrigal, 2017). Furthermore, as societal problems become increasingly more complex and dynamic, demand for the full scope of personal and relational knowledge will continue to grow.

Several organizations are acting as thought leaders by taking action to aid learners in their discovery, application, and continuous adaptation of their full personal and relational knowledge within today's knowledge economy. The following paragraphs illustrate a few examples of efforts underway: 
The Coalition of Urban Serving Universities (USU) and the Association of Public and Land Grant Universities (APLU) state in their 2019 report Delivering $21^{\text {st }}$ Century Skills, that universities need to partner with industry leaders in order to develop and continuously improve the curriculum. Both organizations call for innovation in meeting the needs of individuals and society when it comes to the evolving workforce. This means focusing on technical, human, and social competencies in addition to the cognitive. The USU and APLU also recommend changes in affordability and more mobile credentials.

The National Association of Colleges and Employers (NACE) annually surveys employers to ask what skills they value most when hiring recent graduates. In 2019, they rated the following skills in order of importance: critical thinking/problem solving; oral/written communications; teamwork/ collaboration; information technology application; leadership; professionalism/work ethic; and career management. Researchers at NACE also state that the way for undergraduates to differentiate themselves amongst their peers is to exhibit "outstanding credentials in a number of non-industry specific desired skill areas" (DuPre \& Williams, 2011, p. 8).

The Association of American Colleges and Universities (AACU) maintains a list of value rubrics that includes such skills as "inquiry and analysis, critical thinking, creative thinking, written communication, oral communication, quantitative literacy, information literacy, reading, teamwork, problem-solving, civic knowledge and engagement-local and global, intercultural knowledge and competence, ethical reasoning and action, global learning, foundations and skills for lifelong learning, and integrative learning" (Association of American Colleges \& Universities, 2020, para.
2). AACU's Liberal Education and America's Promise initiative (LEAP) is responsible for the development of rubrics as part of leaders' efforts to connect the economy's needs to a liberal education (Association of American Colleges \& Universities, 2011).

Similar calls for changes in education appear in current literature. For example, Joseph Aoun, president of Northeastern University, proposes a new model called humanics, which he defines as "mastery of content as well as the development of particular skills" (Aoun, 2017, p.53). The purpose of this new model is twofold: (1) to enable learners' comprehension of the continuously advancing technological world that surrounds them, and (2) to enhance their ability to transcend that world through acquiring robot-proof skills, such as creativity and mental flexibility. The author recommends greater skill sets under the headings of data, technological, and human literacies (Aoun, 2017).

The Lumina Foundation's Degree Qualifications Profile (DQP) is a highly developed model of bridging academia with the needs of the $21^{\text {st }}$ century workforce. At the time of its second iteration, over 400 colleges and universities have adapted it. It aims to calibrate learners' knowledge and abilities per degree level by offering mechanisms for proving the learners' ability to apply what they have learned over the course of their college careers. While it does not standardize degrees, it does clarify the general proficiencies that graduates need to achieve regardless of their field of study within the specific degree level, currently covering associate's through master's. The DQP also "assumes that general education and the major must work together" (Adelman et al., 2014, p. 10). The DQP serves different higher education institutions as a tool to help shift from grades as a marker of performance to learners' levels of pro- 
ficiencies. These proficiencies are organized into five broad categories outlined below.

Specialized Knowledge: This area of proficiency concerns the learners' subject field. While the institution may have certain proficiencies regarding the subject, there are also accrediting professional and licensing bodies that develop standards. All fields usually require that this specialized knowledge be recognized in the learner's ability to comprehend and apply terminology, theory, methodologies, literature, and solve complex problems relating to the subject.

Broad and Integrative Knowledge: This area of proficiency may include the learner's area of specialization but, primarily, it incorporates learning across different fields. Rather than typical general education courses that are prescribed as part of the curricula at most universities, the DQP guides learners to explore, connect, and apply broad learning concepts and methods across contexts and throughout their careers (Adelman et al., 2014, p. 14).

Intellectual Skills: This group of skills crosses over many fields and domains. The skills of analytic inquiry, use of information sources, engaging diverse perspectives, ethical reasoning, quantitative fluency, and communicative fluency interact with the other areas of learning outlined in the DQP.

Applied and Collaborative Learning: Students exhibiting proficiency in this category use what they have learned either individually or via group effort. They demonstrate their problem-solving abilities across sectors such as the classroom, community, and work. Evidence of this proficiency might also be demonstrated by incorporating the skills used in expertise within their field(s) of major.
Civic and Global Learning: As the name suggests, this proficiency is all about students integrating and applying their knowledge to create a greater impact across civic, social, environmental, and economic challenges.

Inclusivity plays an important role for institutions of trust as they implement an integrative, lifelong learning philosophy. To be of service requires that institutions of higher education broaden their scope to serve all learners regardless of their life stage. Learners facing unemployment or underemployment will not have the time or the resources (Dede, 2019) to dedicate to those traditional, explicit representations of knowledge acquisition such as degrees or certificates. Associations, non-profits, and educational institutions that truly recognize this area of need will provide practical frameworks for implementing change that closes the gap between the competencies needed for mobility in this new economy and the existing knowledge repertoires of those learners already situated in the workplace.

\subsection{Meeting the Talent Demand Through On- ramps}

Strada Institute (Weise et al., 2019) finds that 32 million adults in the US are either underemployed or unemployed. This situation has grown even more dire due to the COVID-19 pandemic's influence on the economy. At the time of this report, an additional 29 million people had made first-time benefit claims for unemployment insurance during the Spring of 2020 (US Bureau of Labor, 2020). Many adults have less than two years of education and/or come from low-income environments. This means that they risk being left behind as technologies advance. The Strada Institute draws attention to this problem with its On-ramps to Good Jobs Report (2019). According to Strada, on-ramps are "the leading edge of a new market of 
intermediaries connecting working-class adults to better economic opportunity" (Weise et al., 2019, p. 3). On-ramps focus on serving adults who are unable to seek a degree due to possible barriers like finances, time, and childcare constraints while matching them to employers wanting to use a more diverse talent pipeline.

On-ramps differ from other established programs that currently exist to educate and train adults, namely those offered by community colleges, federal workforce programs, apprenticeships, and so-called last-mile providers such as code academies (Weise et al., 2019, p. 12). Onramps align learners without traditional, four-year degrees to high demand opportunities that require basic, technical, and human skill development. Lasting anywhere from a few weeks to several months, and occasionally as long as two years, these programs not only offer intensive services and training in areas such as reading and math but also, broaden learners' human skills, including critical thinking, creative thinking, problem solving, communication, teamwork, persistence, self-efficacy, and professionalism. These programs also "hone high-demand, technical skills in computer programming, information technology, business and financial services, and cybersecurity" (Weise et al., 2019, p. 8). In 2019, Strada identified 65 on-ramps in the US. The report goes on to highlight nine successful on-ramps from non-profit organizations, for-profit providers, and workforce boards. Some of these organizations even provide post-placement support to aid the new employee in confronting challenges and understanding how not only to succeed but to advance in the new environment.

Kevin Cooper, Assistant Dean of Applied Technology at Indian River State College in Fort Pierce, Florida, provides on-ramps for highly-skilled tech- nical workers in nuclear energy by partnering with industry. By listening to the needs of employers, he removed the college algebra barrier by creating courses for students to learn only the precise algebra, trigonometry, and statistics skills necessary to work within the field of nuclear energy. Members of industry provide guest instruction in these math classes to provide the learners with real-world, workforce application. The result has been a $90 \%$ success rate in these courses that center on matching learners' needs with specific industry needs (National Science Board, 2019).

The World Economic Forum (WEF) makes similar suggestions for action in the white paper Accelerating Workforce Reskilling for the Fourth Industrial Revolution (World Economic Forum, 2017), which comes out of its "Shaping the Future of Education, Gender, and Work" system initiative. This initiative aims to bring together governments, businesses, and other stakeholders so that they are better prepared to anticipate and manage economic and industry transitions. One important part of this is workforce training. The first step is to take stock of individuals' current skills repertoire. Only after this step is completed, training is recommended based on each learner's particular skill set and the needs of the specific workplace. The initiative recommends a consistent feedback loop between industry and educational institutions for

\section{On-ramps offer intensive} services, hone high-demand technical skills, and broaden learners' human skills for learners without traditional, four-year degrees. 
the purpose of understanding future skill demand. Furthermore, the WEF believes that co-funding models between government and employers could increase access to lifelong learning programs previously unattainable to those with less formal education or technical skills. Other recommendations from the initiative include affecting adult learners' motivation via policy creation and increased accessibility, creating shorter modules, and promoting and maximizing on-the-job training opportunities. The initiative recommends targeting those learners who need it most: the ones employed in small and medium-sized enterprises, lower-skilled workers, and older workers. Lastly, the initiative recognizes techniques such as gamification in learning as well as tools such as blended online learning for motivating adult learners and expanding access.

The Fraunhofer Institute for Production Systems and Design Technology in Berlin proposes a "holistic competence model" (Hecklau et al., 2016) for sustainable workforce development for the fourth industrial revolution. The model is based on a close examination of the critical issues facing today's companies-economic, social, technical, environmental, political, and legal. It aims to allow companies to meet the talent demand created by the technological shift, even as they qualify and

\section{Training is recommended based} on each learner's particular skill set and the needs of the specific workplace. Co-funding models between government and employers increase access to lifelong learning. retain their older employees. The model identifies four categories of competency:

1. Technical: The knowledge and skills related directly to doing one's job, including such domain-specific knowledge as state-of-the-art knowledge, media skills, and process understanding.

2. Methodological: The skills and abilities related to problem solving, decision making, conflict resolving, and research and analysis; also, efficiency oriented towards the domain-general knowledge category.

3. Social: The skills and abilities, as well as the overall attitude, to cooperate and communicate with others (p. 2). This includes intercultural, language, communication, and networking skills, as well as the ability to work in a team, transfer knowledge, and demonstrate leadership skills (p. 4).

4. Personal: Hecklau et al. refer to this set of skills as "social values, motivations, and attitudes" (p. 2). This ultimately comes down to being "flexible" with one's job responsibilities, which is operationalized into specific skills such as accepting change (such as working virtually), the ability to work under pressure, having a "sustainable mindset," and "compliance" (in response to stricter rules for IT security, working with machines, or working hours) (p. 4).

Systems approaches to the fourth industrial revolution, that aim to address sociotechnical and socioeconomic issues in an integrative manner, are collectively referred to as Industry 4.0. Industry 4.0 is defined by five core technologies that have evolved to define 13 enabling technologies (Habib et al., 2019) that are supporting five Sustainable Development Goals (SDG) for the year 2030 
(United Nations General Assembly, 2015; World Economic Forum, 2016b). The original five core technologies were developed from the integration of traditional Operation Technologies (OT) and Information Technologies (IT). The SDG outcomes require that technical development of the enabling technologies be placed in a systems context of People, Peace, Planet, Prosperity and Partnership. Implementation of such systems approaches to a technology-enabled sustainable society requires the valuing of all the skills of the Fraunhofer report and the preparation of a workforce that can easily connect domain-general skills as well as personal and social competencies to domain-specific proficiency (De Weck et al., 2011). It furthermore requires an inclusive and lifelong learning paradigm for all participants (UNESCO, 2019).

\subsection{Integrative Professional and Personal Development Model}

To achieve the level of sustainable workforce participation that the new knowledge economy requires, current modes of learning and training must be rethought. This is achievable by embracing the notion of knowledge in action (as detailed in the introduction of this report). This report proposes an Integrative Professional and Personal Development (IPPD) model (see Figure 1.1) that aims to recognize and co-develop all skills and competencies encompassed within a knowledge in action framework. This IPPD model is a combination and adaptation of the Rees and Bartlett (1999b) model for creating learning societies, the John B. Carroll model of three stratum theory (1993), and the Polanyi, Argyris, and Schön writings of knowledge in action $(1958,1978,1983)$. The IPPD model is also informed by the initiatives and literature discussed in previous sections of this chapter.

The IPPD model recognizes that knowledge in action has two highly interrelated compo- nents: personal and relational. Furthermore, the IPPD model represents personal knowledge as a three-layer hierarchy of skills that can be dynamically organized into competencies. The three layers (from top to bottom of the hierarchy) are:

- Life skills and personal fulfillment

- Domain-general skills (highly transferable skills and abstract concepts)

- Domain-specific skills (specialized knowledge and related task performance)

The three layers of skills are integrated. The learner achieves competencies as well as depth and sustainability of personal knowledge through concurrent growth across all layers rather than through compartmental training in one skill, a subset of skills, or one layer of skills. In terms of the IPPD model, competency is defined as a combination of strong skills across all three layers that enables the learner to do a job well. Skills develop across professional and personal experiences that span the process-outcome continuum. Higher-layer skills are aggregates of diverse knowledge experiences that can generalize to many lower-layer skills; higher-layer skills inform and are informed by many lower-layer skills. In the following section, each skill layer of the IPPD model is defined and its relation to existing theories of knowledge is discussed. Following the definitions, recommendations are made for implementing learning strategies that can assist learners with IPPD. In Chapter $I I$, the authors discuss detailed recommendations for adaptive instructional design that supports and promotes lifelong IPPD.

\subsubsection{Social Learning}

The global component of the IPPD mode represents socially constructed and contextually situated learning while acknowledging that a 
CHAPTER I

Figure 1.1

Skills and Skill Relations in Integrative and Adaptive IPPD

Social Learning

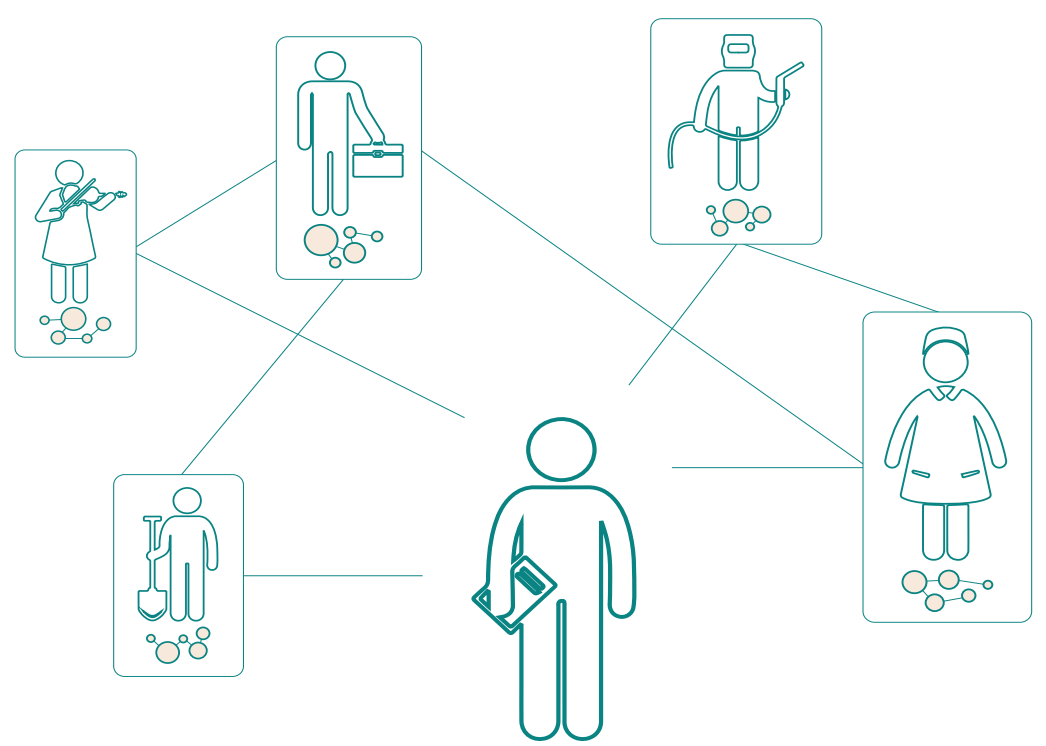

Life Skills

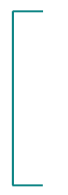

Domain General Skills

Domain Specific Skills

Specialized Task

Performance

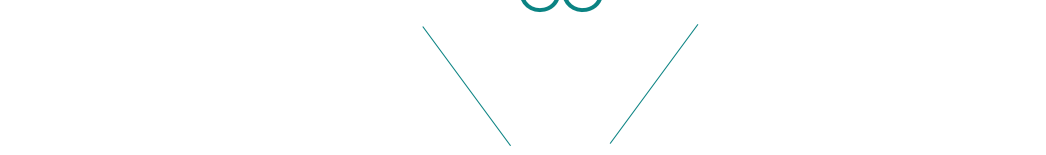


This report proposes an

Integrative Professional and

Personal Development (IPPD)

model that incorporates

the personal and relational

components of knowledge in

action. The model represents

personal knowledge as a three-

layer hierarchy of skills: domain-

specific, domain-general, and

life skills.

paradigm shift is necessary to ready all learners, regardless of education level or age, for the $21^{\text {st }}$ century knowledge economy. This in turn depends on strategic cross-sector partnerships that leverage a broad scope of social learning.

The IPPD social learning component takes inspiration from Rees \& Bartlett's (1999b) social learning model, which identifies the role of "social connectivity and the institutions of trust and cooperation in providing the economic foundation on which market-based economies can flourish and prosper" (Bartlett \& Rees, 2000, p. 161). The IPPD model expands on the social learning model to include theories of situated cognition (Brown, Collins, \& Duguid, 1989), collective intelligence (Hutchins, 1995; Schuler, De Cindio, \& De Liddo, 2015), and constructivism (Bruner, 1990; Piaget, 1963; Vygotsky, 1978) as well as additional theories of social learning (Bandura, 1986, 1997, 2001). The IPPD model emphasizes the importance of - and interactions betweensocial, technical, cultural, and economic contexts and the history or legacies within which knowl- edge is situated (Coghlan \& Brydon-Miller, 2014). Knowledge, in this context, is not a set of rational, discoverable facts that can be neutrally applied to test an idea, perform a task, or solve a problem. Rather, this knowledge is indistinguishable from how one acquires it (Polanyi, 1958) and the multiple interactions that give meaning to information.

As mentioned in the introduction, learners accumulate knowledge across many different relational contexts (school, work, home, society) and carry their accumulated knowledge to every learning context. Domain-general and life skills are more abstract and can thus transfer across different relational contexts and support integrative development across different personal and professional situations. It is a key reason why these skills are gaining in importance in the $21^{\text {st }}$ century economy. Leveraging domain-general and life skills can provide inclusive and efficient entry points and pathways to the domain-specific components of different relational contexts for all learners. These entry pathways, however, need to be adaptive. Fixed relational contexts (i.e., standardized tests in mathematics using symbolic methods) may not strongly relate to the intelligences of some learners, thus portraying these learners as lacking in ability. Adapting relational contexts (i.e., using symbolic and statistical methods in teaching basic mathematical principles) can provide connections for differentiated learners (Costa et al., 2018; Van Herwegen et al., 2018).

The relational component of the IPPD model emphasizes the technical, cultural, and economic contexts within which knowledge is situated. 


\subsubsection{Life Skills and Personal Fulfillment}

Personal growth strategies tend to focus on developing an individual's resilience in response to threats to the economy. We need strategies that go beyond this to consider an individual's satisfaction and fulfillment, which in turn will benefit society as a whole (Popović, 2014). Rees and Bartlett's (1999b) personal development model, which calls for an increase in each individual's "capacities to achieve self-fulfillment in other spheres of life, not just economic activities," inspires this layer of skills within the IPPD model (p. 21). Life skills span the cognitive, psychomotor, and affective domains (Anderson \& Krathwohl, 2001) and thus cannot be treated only as high-level cognition (Carroll, 1993). Often tested as personality traits (National Research Council, 2013), such integrative skills are key components of complex professional competencies (NACE, 2017) as well as indicators of success in other areas of one's life (Kelly, 2016). More and more, researchers (Holmes et al., 2019) and industry representatives (NACE, 2017) are coming to terms with the evolving needs of the $21^{\text {st }}$ century economy, and a key part of this is valuing each individual's ability to exercise life skills in multiple contexts. Life skills are critical to leverage social learning for professional and personal development and to inform the reorganization of lower-layer skills to deal with a fast-changing world. The overarching goal is for learners to acquire appropriate generalizable life skills as they realize their own principles and values within a rich and inclusive social learning context.

The most salient life skills and personal fulfillment skills are communication (Adelman et al., 2014; APLU \& USU, 2019; NACE, 2017); collaboration (Rhodes, 2019; Weise et al., 2019); reflection (Schön, 1987); cultural agility (Adelman et al., 2014; Aoun, 2017); self-direction (Aoun, 2017); empathy (Aoun, 2017); creativity (APLU
\& USU, 2019; Rhodes, 2019); productivity (Trilling \& Fadel, 2009); efficiency (Hecklau et al., 2016); as well as exhibiting values and principles that indicate a learner can coexist with others $(\mathrm{Na}-$ gel, 1986).

Georgia Tech's (2018b) whole-person education initiative (Initiative 1) is one example of a university taking action to answer employers' calls to develop these skills in future employees (Georgia Tech, 2018b; 2018c). Initiative 1 acknowledges the need for learners to develop not simply discipline-specific knowledge (e.g., engineering fields) but higher-level skills that span beyond the cognitive domain such as the interpersonal and intrapersonal. The interpersonal skills include communication, teamwork, and leadership. The intrapersonal skills cover adaptability, initiative, discipline, ethics, and persistence. These are recognized as traits that lead to long-term success (Georgia Tech, 2018c).

Higher education's commitment to life skills and whole person development needs to be reinforced by explicit engagement and valuing of these skills by industry. The Boeing Values-Based Leadership Model establishes eight different life skills/character traits that are explicitly connected to success and career development within and across the domain-specific areas of the company (Boeing, 2020).

The overarching goal is for learners to acquire generalizable life skills that are critical to leveraging social learning for professional and personal development. 


\subsubsection{Domain-General Knowledge}

This layer of skills of the IPPD model is key for learners wanting to adopt a lifelong learning mentality because it assists them in achieving knowledge transfer and connecting life experiences to domain-specific skills. Domain-general skills are also referred to as transferable skills and/ or abstract concepts in the knowledge frameworks covered in section 1.2 and section 1.3. The most common general skills covered in these frameworks are logic and deduction, quantitative and computational thinking, analytical thinking and problem-solving, written and oral communication, data and information literacy, sensorimotor skills (i.e., visual perception, auditory perception), general memory, and systems thinking.

It is important to realize that domain-general and domain-specific are areas of teaching and learning, which are not exclusive of one another (Perkins \& Salomon, 1989). Learners who have domain-general knowledge may use techniques that exhibit metacognition, such as self-monitoring and self-directing their own learning through the use of self-questioning. Such skills need to be taught in conjunction with those that are domain-specific (Perkins \& Salomon, 1989). Development of domain-general skills in tandem with domain-specific skills can gradually accelerate learning of domain-specific skills through knowledge transfer. An example of this is the use of proof in mathematics, which a student may learn in a specific domain but, through guidance by an instructor, see the concept's ready application in both philosophy and English. Once the concept is learned and carried across sectors, it can be highly transferable to real life such as dissecting a politician's argument or deconstructing a pundit's editorial (Fadel et al., 2015). Another example is that of an undergraduate student who practices analyzing poetry in a British survey course and is then able to count that as a skill to be applied when it comes time to enter the workforce as a financial analyst (Aoun, 2017).

An example of domain-specific and domain-general learning from military training is the Department of Defense Language Institute's use of Mordecai Meirowitz's board game, Mastermind, to test the aptitude of potential cryptographers (J. Avery, personal communication, August 2019). If a learner could demonstrate the logical reasoning necessary to detect the encoder's hidden pattern in the game's colored pegs, then the examiners viewed this as a skill transferable to the language school training administered in Monterey, California. The evidence of pattern recognition skills indicated the presence of cryptographic skills required to break encoded communications. Additionally, a person with such transferable skills might easily transition into the fields of machine learning or robotic computing ( $\mathrm{Lu}$, Yang, \& Chu, 2017).

Greater research is needed in order to make evidence-based recommendations on how to best teach domain-general knowledge in tandem with domain-specific knowledge (National Research Council, 2013). Throughout this report, we explore the role of collaborative learning as a strategy where the learners' roles and responsibilities in a domain-general context are explicitly stated and easily coupled with more domain-specific projects.

Domain-general skills assist learners in achieving knowledge transfer and connecting life experiences to domain-specific skills. 
Another generalizable strategy is the combination of instruction and construction through guided experiential learning (Mooney, 2013). For example, assigning a research paper that is conceptualized and written over the course of a semester would allow an instructor to guide the students in deadlines that work backwards from the due date while scaffolding the learner with suggested benchmarks to teach them project and time management in addition to the domain of the research. Offering techniques for memory recall in tandem with content development aids the learner in priming their own memory or explicitly stating what should be in their own schema before presenting content. Such techniques may assist with long-term memory and logical deduction.

\subsubsection{Domain-Specific Knowledge, Task Performance, and Competencies}

Woolfolk and Margetts (2013) define domain-specific knowledge as pertaining to "a particular task or subject" (p. 251) and the Lumina Foundation in its Degree Qualifications Profile refers to this category of knowledge as the learner's field of study. Within the IPPD model, a domain-specific field of study is approached as a set of closely related domain-specific skills (see $A p$ pendix $A$ ). For learners to reach high proficiency in a specific skill or task, they need only master a specific domain or sub-domain (Hoffman et al., 2014). However, to reach expert status in a field of study, they must be able to integrate high proficiency in relevant domain-specific skills within a complex competency envelope that spans domain-specific, domain-general, and life skills (Hoffman et al., 2014, p. 64). The ability of highly competent medical doctors to relate to their patients (through strong personal and relational life skills) and connect that process to abstract knowledge of human behavior and specialized knowledge of their sub- field is a knowledge-in-action paradigm that spans all three layers of skills and integrates professional and personal development across the full span of the process-to-outcome continuum (Osterberg et al., 2016; Thornton, 2013). For this reason, the IPPD model approaches competencies as multilayer networks of skills.

To understand the development of skill proficiency it is important to understand the differences between tasks and skills. David Autor (2013)

To reach expert status in a field of study, learners must be able to integrate high proficiency in relevant domain-specific skills within a complex competency envelope that spans domainspecific, domain-general, and life skills.

in "The 'Task Approach' to Labor Markets" defines the word task as a "unit of work activity that produces output" and defines skill as "a worker's stock of capabilities for performing various tasks" (p. 4). He advances this further by claiming that skills must be applied to a task for output to occur. To move this into the realm of education, if an instructor wants the learner to acquire a skill, the process may begin with readings and lectures, but practice is what ultimately moves the newly acquired knowledge into an application. Outside of education, the sport of baseball may serve as a similar example of tasks providing output. A person may have great knowledge about the sport of baseball through knowledge of the statistics and 
rules of the game and by observing players' performance on the field. This does not mean, however, that the individual has the skill of accurately throwing the ball, running to the base with enough speed to avoid being tagged out, or judging the player's pitch with enough accuracy to hit the ball into an open area of the field.

Furthermore, a task is a building block that links theory to practice. Learners perform many tasks over the course of their academic careers: studying, answering questions, listening, and taking exams. However, it does not necessarily follow that they have developed these tasks into a skill (Boulet, 2015). Performing tasks may be indicative of knowledge gained from the content. However, a skill has not been achieved until the learner is able to provide an output (Autor, 2013) that has developed from applying classroom learning to task performance. To use the sport of baseball as an example again, someone new to intramural sports might be able to hit a baseball (task) when receiving pitches off of their own team's pitcher but still not have the skill to avoid striking out when facing different pitchers due to their misjudgment of the ball's speed and location with respect to the strike zone.

Following the paradigms of previous multilayered human intelligence models (Carroll 1993; Johnson \& Bouchard, 2005), the IPPD model representation (Fig 1.1) places measurable performance of tasks under domain-specific skills. The placement highlights that specialized tasks cannot be performed well without proficiency in pertinent domain-specific skills. However, as tasks get more complex, dynamic or ambiguous they require the concurrent application of domain-specific and higher layer skills for masterful performance. Holmes, Bialik, and Fadel (2019) as well as Hoffman, Ward, Feltovich, et al., (2014) advise educators to become better at assisting learners in efficiently achieving the high proficiency of skills necessary for masterful performance in the face of an economy that is ever-changing and increasingly complex. Based on their research into the possible threat of artificial intelligence on human workers, Dreyfus and Dreyfus (1986) developed a fivestep guide to skill acquisition. This guide explains how someone passes through at least five levels of "qualitatively different perceptions of his task and/ or mode of decision making as his skill improves" (p. 19). The five levels of proficiency are: novice, advanced beginner, mastery, proficiency, and expert. As learners advance through each of these levels over their lifetimes, they become increasingly able to integrate domain-specific knowledge with domain-general knowledge and life experience. This integration across skill layers increases proficiency and facilitates speed of acquisition.

At the novice level of proficiency, elements are context-free, meaning learners have no experiential-based knowledge of the skill content. All behavior of learners at this stage is described as rule-driven, limited, and inflexible (Benner, 2004). Students judge their performances by how well they follow the rules because they "lack [a] coherent sense of the overall task" (Dreyfus \& Dreyfus, 1986, p. 22). Students move to the next level, advanced-beginner, when they have gained some experience through real situations. These situations are similar to examples that have been provided in class or read in textbooks. An example of this level would be a driver new to using a manual fivespeed transmission. The driver no longer looks at a range on the odometer to tell if they have shifted into the appropriate gear, but instead relies on the sound of the engine revving to indicate the need to shift up or down (Dreyfus \& Dreyfus, 1986). Both levels are still rule-based and objective, relying on what was previously learned. 
As learners advance over their lifetimes through proficiency levels they become increasingly able to integrate domainspecific knowledge with domain-general knowledge and life experiences. This integration increases proficiency and facilitates speed of acquisition.

The third level of skill acquisition is referred to as mastery. Learners reach this level when they exhibit hierarchical decision-making, which requires the domain-general skills of deduction and decision making. For example, a nurse-trainee is gradually able to decide, through experience, what is most important and which patient needs attention most urgently. The fourth level of skill acquisition, proficiency, is achieved when a learner is able to leave the rule-based supports of those early stages. At this stage the learner realizes the most salient features of a situation and forces other less relevant features into the background (Dreyfus \& Dreyfus, 1986). Moreover, the learner sees similarities with past professional and life experiences and is able to draw upon this domain-general knowledge to inform their decision-making in a mix that is both intuitive and analytical.

The final, fifth stage of skill acquisition, expert, describes an individual who has "an immense library of distinguishable situations...built up on the basis of [their] experience" (p. 32). In thinking of these stages and the journey one takes involving deliberate practice over years in order to reach their goal of achieving expertise (Ericsson et al., 1993), the domain-specific knowledge accrued through explicit forms early in one's education serves as a foundation as the learner navigates from novice to expert in their practice. The accrued experience of placing domain-specific knowledge into complex life situations integrally informs all layers of skills and the adaptation of the skills to deal with different relational contexts.

\subsection{Characteristics of Integrative Development}

An irregular hierarchy representation of the IPPD (Figure 1.1 above) is chosen to highlight several key characteristics of the model.

1. Skill interconnectivity can be represented as an irregular hierarchical network. The circular nodes in the IPPD figure represent skills and the lines (edges) represent their connectivity. There are multidirectional connections across skill layers (domain-specific sport and music practice both improve domain-general sensorimotor skills and improved sensorimotor skills improve sports and music performance) but also within layers (understanding of derivatives in calculus can be supported by practicing problem sets across physics, math, business, and design). The hierarchical network approach of the IPPD model symbolizes the purpose of training and education, which is to increase proficiency in domain-specific skills and increase the learners' ability to transfer skills and capabilities to higher levels (Goldstein \& Ford, 2002) and across domains and sectors when applying them in the workforce. The desire for more transferable skills is based on the proposed instability of skills - a $42 \%$ predicted shift between the years of 2018-2022 of the core skills needed to do a job (World Economic Forum \& Boston Consulting Group, 2018). Strong and customized connectivity among the three layers of personal knowledge allows adaptability to changing relational contexts. The IPPD approaches skills 
growth as the result of complex interdependencies between the skills of an individual and the knowledge economy institutions, and society overall. According to Schön (1987), there is a difference between knowing something and taking action on that knowledge. Similarly, in the Lumina DQP (Adelman et al., 2014), learners achieve high proficiency only when they exhibit the ability to apply knowledge in complex and changing situations. It is not a matter of "seat time" or grades.

Within an IPPD model, the three domains of Bloom's (1956) taxonomy (affective, psychomotor, and cognitive skills) grow in a parallel and interconnected manner. Their interconnected growth characterizes the domain-general and domain-specific abilities of a person and supports the growth of interrelated life skills such as communication, reflection, relatedness, adaptability, creativity, and empathy. As one moves up the IPPD hierarchy, skills become more general and more integrative. A significant portion of domain-general and life skills may be tacit and transferable. For example, as a waitress gains expertise in her job, she is also building tacit abilities in everything from multi-faceted communication and quantitative intelligence to multi-tasking and responding to unforeseen events.

A simple example of interconnected, hierarchical skill development is that of a student evolving into a professional pianist. Societal discourse and shared creative practice shape the student's musical aspirations and communication needs (Dewey, 1934). These aspirations advance life skills such as understanding and directing complex feelings, leveraging critique to drive reflection, and commitment to rigor. To achieve good piano performance technique (specialized task performance), the student must demonstrate a combination of skills including (a) specialized sensorimotor skills
The purpose of training and education is to increase proficiency in domain-specific skills and increase the learner's ability to transfer skills and capabilities to higher levels and across domains and sectors. The learner's ability will vary and necessitates adaptive instructional approaches.

(using the fingers to concurrently control multiple piano notes), (b) general sensorimotor skills (the ability to read the notes and use multisensory feedback in order to apply the prescribed pressure for the appropriate duration given by the score), (c) specialized understanding of a musical form (e.g., Chopin's Nocturne), and (d) abstract abilities to understand formal relations, memorize structures, and map them over time. Sensorimotor skills and formal understanding that are trained through music performance are highly transferable to mathematical, spatial, and verbal performances (Wan \& Schlaug, 2010). Mathematical reasoning improves formal understanding, which collectively improves the performance of specific musical pieces. Sensorimotor, affective, and cognitive skills support and improve life skills such as communication, reasoning, and reflection. The sharing of a moving performance that promotes societal reflection constitutes an example of integrating personal development into societal development (Carayannis, 2014) and denotes that the piano player has reached the level of expert. High competency in piano performance can therefore be seen as a network of multilayer skills spanning life and profes- 
sional experience. When supported by relational knowledge contexts that favor knowledge transfer, these integrated skills can inform and be informed by research and education in many fields of human performance (from neuroscience to social science to sports science).

2. Every learner's personal knowledge is different. Individuals accumulate knowledge based on their own mode(s) of participation, preferences, situational contexts, and goals (Anderson, Reder, \& Simon, 1996; Brown, Collins, \& Duguid, 1989). There is evidence of this type of layering in Michael Eraut's (2004) research on professional development when he claims that "there will also be aspects of a person's knowledge that have been constructed through lifelong learning and have become unique to them, i.e., outside the circle of shared cultural knowledge, because of the unique set of situations in which they have participated" (p. 202). Even though people can have similar collections of skills (nodes), each person will have different skill strengths (depicted by size of nodes in Figure 1.1) and will have developed these skills through different connectivity. Domain-specific skills and training will transfer more readily for some learners and less so for others, depending on each learner's general ability and strategies as well as their "crystalized ability to transfer the skill from past experience to similar tasks" or "fluid ability, flexible adaptation of skills to novel learning tasks" (Clark \& Voogel, 1985, p. 121). Because of this, the degree to which specific lower-level skills are connected to higher-level skills will vary from person to person, which in turn will necessitate adaptive instructional approaches. The links in the network representation of personal knowledge (Figure 1.1) have different strengths, however, both strong and weak links need to be considered for professional and personal development. A performance of a specialized task (a key characteristic of assessing professional development) may have a strong link to domain-specific knowledge (Carroll, 1993) but it is critically connected to many other things (Rees and Bartlett, 1999b).

3. Skill development is process focused and outcome focused. A significant amount of personal knowledge is built through activities that focus on process. For example, participation in team sports and cultural activities can help individuals develop complex networks of skills across layers while also connecting personal and relational development (e.g., developing into a good team member across varied situations). For many learners, these process-based activities may not produce a strong measurable outcome such as high-end performance in sports or arts. However, the ability of these participatory processes to develop skills across all layers of personal knowledge (including some of the more complex abstract skills near the top of the hierarchy such as teamwork, communication, reflection, and recovery from failure) can help performance in other measurable outcomes that are strongly connected to professional development.

For example, there is a strong correlation between women who become student athletes and their success in achieving leadership positions in Fortune 500 companies (Zarya, 2017). There is

A significant amount of personal knowledge is built through process-based activities (e.g., sports and arts) that help professional development in a tacit manner. 
significant research and theory (Carayannis, 2014; Dewey, 1938; Florida, 2002) indicating that societies that support participatory cultural activity build a reservoir of tacit complex knowledge amongst their citizens, which then enables these societies to be more resilient to change and disruptions. This is not knowledge that is measurable at the level of individual performance in specialized outcomes but knowledge that is evident in the higher layers of personal knowledge and in the collective. The irregular hierarchy representation of skills of the IPPD model aims to highlight the complex and idiosyncratic connectivity and transferability of knowledge across different experiences that is facilitated by aggregated development of higher layer skills. One of the working groups to follow this report (see Working Groups section) will explore how an IPPD approach to knowledge can lead to revaluing of arts and humanism as mechanisms for supporting collective experience that advances everyone's domain-general and life skills.

A society that defines knowledge inclusively (across the full spectrum of the four dimensions outlined in our introduction) is better able to recognize and benefit from the full diversity of personal knowledge of its members as well as the full range of skills of each person in their many different manifestations and combinations. Adaptive learning is critical to identifying and advancing different types of personal knowledge. Valuing of diverse knowledge within society encourages each individual to embody and relate to difference. It also generates complex pluralistic discourse among individuals. Such discourse can provide sustainable solutions to complex problems.

\subsection{Collective Responsibility for Integrative Professional and Personal Development}

A number of times in this report, the authors note that institutions of trust play an important role in developing learners. The authors also provide examples that demonstrate the need for institutional partnering. Creating and mapping pathways for the skills and competencies that already exist in the learner and those that need to be acquired for future careers and promotions are crucial for the learner's success.

\subsubsection{Knowledge Transfer}

Developing a robust skill repertoire depends on each learner's ability to transfer existing and newly developed knowledge to areas beyond the context in which the knowledge was developed (i.e., beyond the classroom). Enabling learners to transfer their knowledge as they apply their skills across different contexts and in unknown settings still to come will enhance their performance and increase their mobility over their careers. While such knowledge transfer is difficult to achieve (Baldwin \& Ford, 1988), instructors, trainers, learners, and employers all must share in the responsibility for success. When instructors are able to take specific concepts, constructs, and tools of one domain and explicitly connect them to other domains and/or applications, they help to make the content more meaningful to the learner and enable knowledge transfer via practice and across different contexts (Fadel et al., 2015).

It is well known that learners often naturally acquire domain-specific and domain-general knowledge in tandem (Perkins \& Salomon, 1989). When designing for instruction it is important to ask, "What concepts will remain in the learner after they graduate?" (Fadel et al., 2015). In other words, "How can this content be taught in a way that enables the learners to transfer it to other domains and possibly real-world applications while also providing them with the essentials to the discipline?" (Fadel et al., 2015). Instructors wanting to operationalize integrated domain-specific and 
domain-general acquisition of skills may find it useful to set up a matrix as described by (Fadel et al., 2015). If doing so, instructors need to realize that it is not unusual for the matrix to be unevenly or incompletely populated across the layers of the IPPD model. The idea of mapping connections between the domain-specific and the domain-general works well with what Fadel, Bialik, and Trilling (2015) refer to as concepts and metaconcepts. Take, for example, the idea of rate of change, which students frequently learn in mathematics classes by memorizing "rise over run" when determining the facts about a line (Fadel et al., 2015, p. 77). In physics, the concept is used to figure relationships between velocity, position, and ac-

\section{Knowledge transfer is difficult}

to achieve. Instructors, trainers, learners, and employers all must share in the responsibility for its realization.

celeration. While learned in a specific domain, the abstract of it helps with understanding change in one's everyday life. A general member of the public may use it to understand how pandemics spread (Fadel et al., 2015).

This approach of teaching math inside and outside the first principles method can apply to the overall teaching of derivatives. Many disciplines have calculus as an element and many of those disciplines teach the fundamentals of calculus as building blocks to the final outcomes. A derivative represents a change over time of some fixed parameter that has an implied direction of movement represented by a function or vector. A second de- rivative will reveal a higher-level rate of change or a maximum or minimum value. Unless you are a mathematician, the real knowledge for a discipline is understanding the purpose of each derivative and how to use it, not the process by which it is obtained. The Wikipedia article on time derivatives ("Time Derivative," n.d.) gives the following examples from physics: (1) force is time derivative of momentum, (2) current is time derivative of charge, and (3) power is time derivative of energy. It also discusses the following examples from economics: (1) the flow of net fixed investment is the time derivative of the capital stock, (2) the flow of inventory investment is the time derivative of the stock of inventories, (3) the growth rate of the money supply is the time derivative of the money supply divided by the money supply itself, and (4) the growth rate of the labor force is the time derivative of the labor force divided by the labor force itself.

All of these examples use the same fundamental processes that can be laborious and confusing to develop from first mathematical principles. However, effective integrative thinkers will be able to grasp the relationships being expressed by the examples, even when they are not part of their core discipline training, because the relationships are contextually understandable. They can calculate an outcome through the understanding of the contextual relation and the use of computational tools that do not require deep first principle mathematics understanding. Teaching computational tools and how to use the results in context would provide the real knowledge to integrative thinkers. Adaptively, students could dive deeper into the results in different domains or into the fundamentals of mathematics if so desired. The entry point to understanding and using derivatives can even be experiential. For example, a pianist has tacit knowledge of velocity being a derivative of 
rate of displacement of a piano key from rest position to the hammer hitting the string; the faster that displacement the louder the note. The pianist uses this tacit knowledge expertly to control dynamics and with the appropriate instructional support could translate that knowledge into other domains that use derivatives. Earlier in this section we discussed the relevant real-life example of the Indian River State College in Fort Pierce, Florida that removed college algebra barriers by creating courses for students to learn only the precise algebra, trigonometry, and statistics skills necessary to work within the field of nuclear energy (National Science Board, 2019).

This section focused on knowledge transfer processes between domain-specific and domain-general skills in order to highlight that these skills can develop in tandem and that they are synergistic. The authors discuss in more detail in Chapter II, how connections between domain-general skills and life skills may be achieved through informal approaches such as mentoring, advising, solving research problems, or participating in collaborative problem-solving projects.

\subsubsection{Learner Autonomy}

While the beginning awareness of transfer may originate with an instructor, trainer, or peer in a learner's educational institution or place of employment, the ability to continue moving and enhancing a skill set belongs to and resides within each learner. As such, instructors, mentors, managers, counselors, and advisors can assist learners in realizing their prior knowledge and skills through a learners analysis, which can be viewed as an inventory for the purpose of connecting that knowledge to new concepts and realizing its relevance through application outside of the original acquisition context (Anderson, Reder, \& Simon, 1996).
In a similar way, simultaneously acting as a guide on the side, an instructor or a mentor may empower the learner to develop and implement their own metacognitive strategies and self-regulation (Ford et al., 1998); practices that will remain with the learners and assist their professional and personal development throughout their lifetimes. Doing so aids learners in realizing how their own inventory of knowledge and skills connects to possible goals within the range of their zones of proximal development (Vygotsky, 1978). It might also help them gain the self-efficacy and wherewithal to pursue and develop whatever skills they might need to fill the gap between their current professional states and their goal states. Resources provided by institutions of trust can assist them throughout this co-creation.

A well-structured co-creation paradigm can empower the learner without losing quality or rigor. For example, the highly ranked Computer Science (CS) program at Carnegie Mellon University identifies only eight computer science courses and four mathematics courses as fixed requirements of the BS degree. Proficiency in other areas of the degree is achieved by the student choosing from a list of electives per area. Many of the electives bridge CS with another field of knowledge. Students are also required to complete a minor outside of CS. Finally, students can receive significant hours of credit for research and work with industry (i.e., internships) (Carnegie Mellon University, n.d. -b).

Beyond the classroom or training context, higher education bears the responsibility to assist learners as they discover and align their career goals via pathways. Part of this responsibility can be achieved by fostering learners' relationships with representatives from industry for the purpose of later exploring opportunities through internships or cooperatives (Coffield, 1999; Matusovich 
et al., 2016) that serve the dual purpose of (a) "trying on" various job roles prior to committing to a specific career, and (b) aiding learners in moving or generalizing their knowledge from the classroom to the job and vice versa as they see the skills being applied in the workplace. Once learners decide on a career goal, they need the flexibility to customize their personal curricula to match that goal (Georgia Tech, 2018a). This may be achieved through the traditional format of coursework, through experiential learning opportunities with industry, or via shorter, just-in-time mediums offered via services like Coursera, LinkedIn Learning, or boot-camps.

Lifelong adaptive and integrative professional and personal development also requires a co-creation paradigm that engages both the employer and employee. At a time when automation and socioeconomic innovations make job tasks fleeting (Manyika et al., 2017), learners can perform certain tasks within the context of their jobs while simultaneously developing more inherent capabilities that, with the right support structures, can be portable (Muro et al., 2019). Because individuals add value to their place of employment (and the economy more broadly), the workplace system must also give value to the individual in the form of remuneration, as well as opportunities for personal and professional development (Wolff \& Resnick, 2012). In return, employees should be encouraged to grow their capabilities - including but not limited to specific job task knowledge-in such a way that they are building a foundation for mobility within the organization and/or the economy more broadly.

Evidence of this thinking is being put into action by companies such as Amazon, AT\&T, and General Electric (GE), all of whom explicitly map pathways that enable their employees to clearly see routes to advancement or career changes. Chapter III of the report includes a summary of the adaptive lifelong learning programs instituted by GE Appliances for facilitating worker mobility and advancement. Details on these programs and their outcomes are provided In the Resources section.

It is important to note in closing that integrative development of skills allows all learners to connect their diverse life experiences to multiple professional pathways. It also makes each learner's complex stock of skills highly adjustable to changing workforce needs and provides employers with a large diversity of intelligences for dealing with $21^{\text {st }}$ century complexity. In the remaining chapters, the authors discuss how developing such a non-linear model can only happen through ongoing trial, innovation, and collaboration between and among different sectors. 


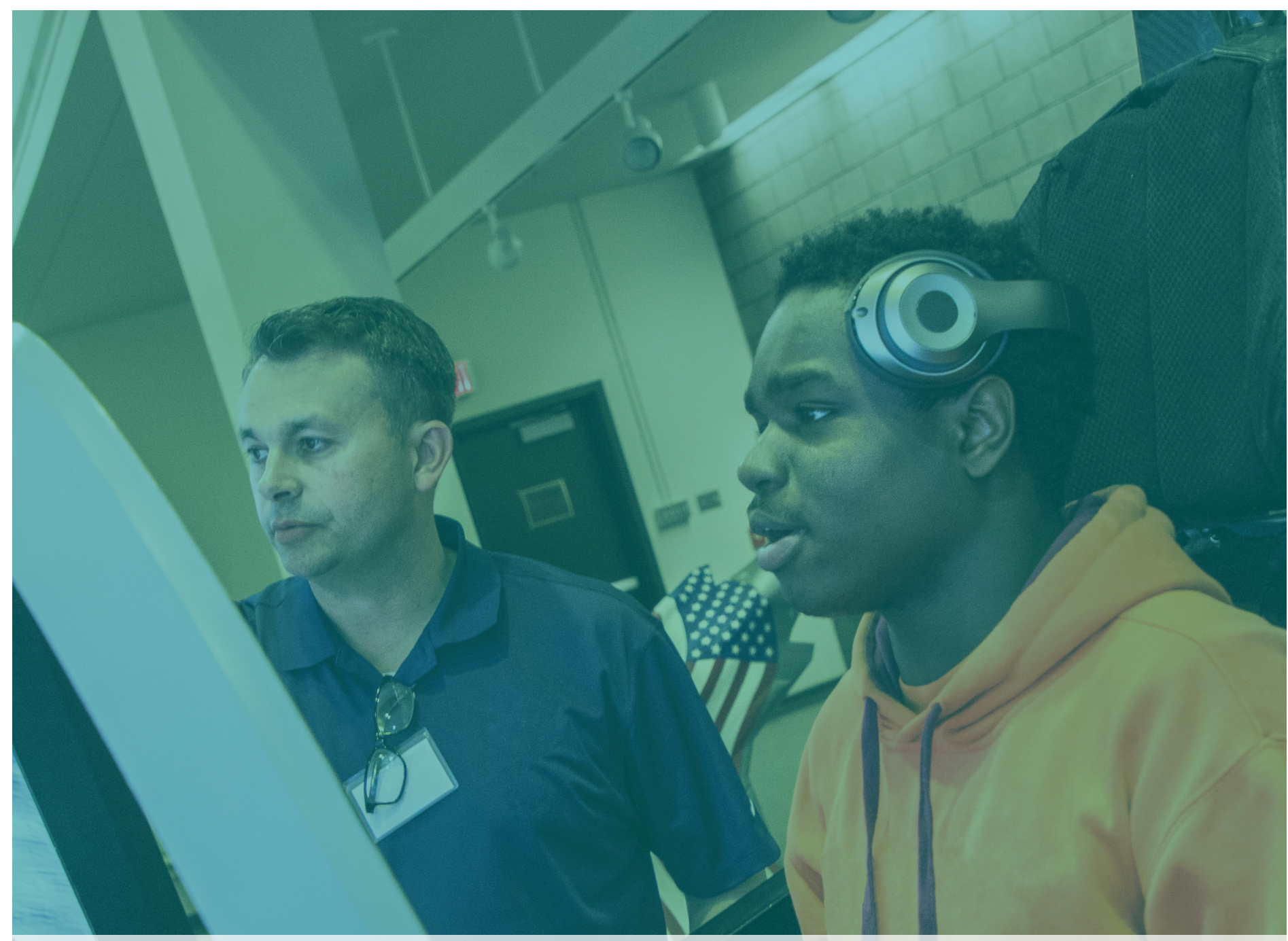

Chapter II:

Adaptive Approaches to Integrative Professional and Personal Development 


\title{
CHAPTER II
}

\section{Adaptive Approaches to Integrative Professional and Personal Development}

\author{
Authors: Thanassis Rikakis, Kimberly Carlson, Jared Keyel, Owen Cardwell \\ Co-authors: David Tegarden, Randy Swearer, Barbara Lockee, Feng Hou, Glen Holmes, \\ Sylvester Johnson \\ Contributors: Taran Cardone, Mark Kamlet, Dale Whittaker, Colin Potts, Amy Arnold, John \\ Boyer, Tazio Grivetti, Chip Blankenship, Michael Richey
}

$\mathrm{n}$ this chapter, we explore adaptive learning
methods designed to achieve integrative
professional and personal development. We argue that the mapping of personal experience and aspirations to adaptive career paths requires us to rethink the notion of curriculum. The primary focus must be on the skills and competencies that individual learners accumulate rather than on the courses they take. We then propose an approach to learning in which the curriculum is conceived as a network of modular learning experiences connected through multiple pathways that allow individual learners to develop skill proficiency and connectivity in their own unique ways. Finally, we discuss a number of existing technological tools and technology-assisted processes that facilitate adaptation in the learning experience.

\subsection{Adaptation and Integrative Development}

Integrative Professional and Personal Development (IPPD) is "lifelong," occurring throughout the stages of one's life; "life-wide," taking place across a range of activities and social settings; and "life-deep," referring both to the multilayer complexities of $21^{\text {st }}$ century competencies (as outlined in the previous chapter) and to the cultural and social values that influence learning (Banks et

\section{Integrative Professional and}

Personal Development is "lifelong," "life-wide," and "lifedeep." This notion of learning is varied and requires a high level of adaptation.

al., 2007). Such learning takes place in everyday settings and family activities; the workplace and professional settings; designed spaces (such as studios, classrooms, museums, and libraries) and programs; and increasingly, online and via mobile technology. Within this context, the notion of "learning" is varied and therefore requires a high level of adaptation.

What this adaptation looks like is determined by asking the following questions:

- Who is the learner? How do we facilitate the emergence of each person's knowledge, strengths, and aspirations so that we can customize learning to these strengths and aspirations? How do we integrate continuous and 
active learner participation into an individualized program of professional and personal development?

- What is the learner's need(s)? Needs can range from a minor upgrading of skills to reshaping of an entire career.

- When, where, and how can the most effective learning take place? In answering these questions, it is important to anticipate that timing, delivery mode, and place of learning might have to change along the way.

- How do we track, record, and reward lifelong, life-wide, and life-deep learning? How do we make pathways flexible so as to respond to learner development and discovery and to the changing needs of the world?

- How do we facilitate the merging of human expertise with technological tools and the continuous development of cyber-human intelligence to help address the complexity and dynamicity of high-dimensional adaptive and integrative learning?

Prior to the emergence of the current knowledge economy, opportunities for adaptive lifelong learning tended to focus on the needs of non-traditional learners, especially working professionals with a need for enhanced on-the-job knowledge or a desire for career mobility through the attainment of a certificate or an advanced degree. For the most part, the programs (or products) created to address these needs have usually been delivered through correspondence courses, video programs, and more recently, asynchronous online instructionmodes that allow for flexible access and self-paced engagement. Higher education institutions have recognized the need for adaptive learning at least since the emergence of the new economy, but formal implementation has been sporadic (Crow \&
Dabars, 2020). The need for more inclusive approaches to learning that also address rising costs and restrictive access to educational programs is driving higher education institutions to rapidly consider alternative approaches to curriculum development and course delivery (e.g., EdX, Coursera, Edplus).

While these programs are invaluable, it might help us to also look outside of higher education to identify emerging trends in learning and development organizations, especially within industry where flexible and customizable learning approaches are being implemented. Looking for emerging solutions to adaptive learning across sectors is also consistent with the spirit of integrative personal and professional development. After all, school typically occupies only $18.5 \%$ of a person's lifetime waking hours (Stevens, 2005), which means that most people attain the majority of their knowledge through adaptive "free-choice" learning outside of the classroom setting. This kind of learning can be characterized as "learner-motivated, guided by learner interests, voluntary, personal, ongoing, contextually relevant, collaborative, nonlinear, and open ended" (National Research Council, 2009, p. 11). The current time window is opportune for cross-sector sharing of practices for scaling of adaptive learning across higher education and professional training.

\subsection{Co-Creation Approaches to Learning}

A growing number of studies are discovering both social and economic reasons for rethinking traditional approaches to curriculum development. For instance, Robert J. Sternberg (2006) has found that students perform significantly better when teachers forgo a textbook-based curriculum in favor of a curriculum constructed around students' everyday cultural experiences or adaptive skills they learned outside of the classroom. This 
is experiential learning at its best. In another study, Sternberg and colleagues (2006) found that "when we teach students in a way that fits how they think, they do better in school" (p. 33).

In their book Unlocking Student Potential: How Do I Identify and Activate Student Strengths, Yvette Jackson and Veronica McDermott (2015) argue that learners demonstrate in everyday, non-academic settings many of the skills that educators think students need to be college ready. These skills include exercising independence, responding to the demands of a situation, comprehending and critiquing, and using technology and digital media (p. 6). The key, they maintain, is to tap into these skills, make learners aware of them, and help learners to employ them in other settings. When this happens, learners are (a) better prepared to learn and (b) more likely to view themselves as capable, valued, and respected. This, in turn, promotes greater engagement, performance, and enjoyment in learning in an academic setting (Jackson \& McDermott, 2015, p. 8).

The challenge, unfortunately, is that social norms tend to push learners to focus on their deficits rather than their achievements. Most of the time, these deficits are defined by standards and models that originated during the second industrial revolution - standardized testing of domain-specific skills and task performance (i.e., grades in standardized tests). Not surprisingly, students judge themselves based on these standards and models, even though in some cases they may be outmoded. It is essential, therefore, to counter this tendency by empowering students to recognize their strengths and then build upon them. Jackson and McDermott (2015) cite numerous studies showing the benefits of this positive reinforcement. For instance:

- Confidence increases when teachers empha- size a student's strengths. This produces neurological stimulation that, in turn, builds more confidence (Jensen, 1998).

- When students reveal their interests, and when they are allowed to practice skills based on those interests, they exercise personal strengths more frequently, which causes the brain to create more neurons, thereby helping them to be more efficient and perform better (Anderson, 2005).

- Focusing on students' positive talents improves their emotional health, which is directly tied to better learning and performance (Costa \& Kallick, 2014).

- When teachers intentionally bridge learning with students' cultural backgrounds and interests, students are better able to tap into innate strengths, which enables them to learn better (Duncan-Andrade \& Morrell, 2008; Mahiri, 1998).

\subsubsection{Redefining Strength}

When many of us hear the word "strength" in a professional or educational context we think of the Clifton StrengthsFinder (Clifton, Anderson, \& Schreiner, 2002), which identifies a strength as a natural talent embedded in a person's identity. If cultivated over time, this talent can become a strength and, for the most part, it remains relatively stable across situations and experiences. This notion has been enormously influential in the business world. The Gallup Clifton StrengthsFinder assessment is used by $90 \%$ of Fortune 500 companies in their organizations (Clifton StrengthsFinder, 2019). And yet, there is a danger in viewing a person's dynamic skill set through such a restrictive lens: We risk identifying a person's strength tags prematurely and then locking them into an unnecessarily circumscribed learning path. Once this 
happens, strength tags have a tendency to become fixed, which can then limit adaptive development.

For this reason, our IPPD model approaches strengths as a dynamic amalgam of tacit, implicit, and explicit skills. By empowering social learning across different contexts, this amalgam of skills acts as an anchor for varied personal and professional development pathways-i.e., for forming many different types of explicit competencies. Changes in relational context and personal development will enable a person's unique array of skills to emerge, develop, and evolve, which might in turn force us to rethink that person's perceived strengths. For example, strong hand-eye coordination may manifest in sports or crafts. Within an inclusive and adaptive learning context, this ability can become a strength that contributes a great deal to a career as a neurosurgeon, architect, sports coach, or airplane pilot. A learner may have strengths that are not emerging because of the teaching methodology. Research at Kingston University London has shown that learners who may struggle with symbolic methods of teaching fundamental math skills can achieve high levels of mastery of these skills through statistical methods of teaching (Costa et al., 2018; Van Herwegen et al., 2018). Even a simple change to testing methodologies can result in a different ranking of a person's skills because that person's tacit and personal skills may not be captured by institutionalized and standardized testing (Bhattacharyya et al., 2013).

\subsubsection{Integrative Lifelong Development through Collective Co-Creation}

The IPPD model links integrative development to adaptive learning by emphasizing that a person's accumulated life, domain-general, and domain-specific skills do not have to be narrow, fixed, or immovable. They can be reorganized, expanded, and remixed in response to different con- texts and evolving learner needs and aspirations. Continuous personal discovery is most likely to happen when learners are active participants in dynamic learning processes. There is significant research showing that learning is most effective when it combines (a) instruction with construction and (b) knowledge assimilation with knowledge accommodation (Mooney, 2013; Niemiec \& Ryan, 2009). An integrative co-creation approach to learning brings together instances across the full spectrum of the four-dimensional inclusive knowledge representation discussed in the Introduction of this report. For example, participatory design exercises tend to be more successful when they encourage self-authorship and team formation; this is more likely to happen when the exercises move constantly between process-focused and outcome-focused instances and between segregated and integrative work (Senge et al., 2012). When the learner explores different pathways, they find new strengths and discover new interests. This opens new opportunities for professional careers and personal development. Institutions must, in turn, adapt their learning and career pathways to accommodate the learners. In other words, learning is most successful when it happens via continuous co-creation.

One example of an integrative co-creation approach to learning is Maria Montessori's well-es-

Active participation in dynamic learning processes creates continuous professional and personal development. Skills are reorganized and expanded in response to different contexts. 
tablished method for early childhood education (Mooney, 2013). The Montessori method values self-directed, hands-on learning, with the goal being for children to become self-motivated in all areas of their development: cognitive, emotional, social, and physical (American Montessori Society, 2020). Recent research shows that children who attend such preschools perform better in academics and social cognition, are more mastery-oriented, and tend to enjoy academic tasks over recreational ones (Lillard, et al., 2017). There is, however, some debate over the effectiveness of the Montessori method. Advocates believe it prepares students for success as they age, but some studies have found no difference in Montessori versus traditional education for middle and high schoolers (Lopata, Wallace, \& Finn, 2005; Ruijs, 2017). Some speculate that teachers in these higher grades have not been adequately trained to deliver a continuation of the Montessori curriculum, that there are more options available for other specializations in high school, or that this curricular framework which was developed based on early childhood development works well for young children but that students in traditional schools eventually catch up. Another possible explanation is that the focus on standardized, domain-specific outcomes in traditional middle and high school education disincentivizes the continuous growth of domain-general and life skills a child begins to build in early Montessori education. Nevertheless, the Montessori method is a helpful example of the types of co-creation in learning for which the IPPD strives.

In the realm of higher education, co-creation approaches to learning are opening new opportunities for college students to customize their learning experiences - or "journeys"-in ways that go against the traditional educational paradigm, which expects students to excel in tasks and spe- cific knowledge before they have had a chance to reflect and develop as individuals. For instance, Taran Cardone (2018) describes how we might use design thinking to customize learning through a model called personal learning design. Educators can engage students in personal learning design by asking them to "map out experiences as big as their overall college journey and as small as specific experiences along that path" (p. 15). For their part, students are encouraged to ask themselves, "What unique combination of involvement, coursework, and everyday interactions would amount to a journey that mattered?" (p. 11). In a similar vein, Journeysmap.com is an online tool that enables individuals to chart their life journey from pre-kindergarten through secondary and college education, to their career, and beyond. If a learner has a dream career, they can search through the database and discover multiple paths to achieve that dream. Self-discovery exercises like journey mapping can be effective because they exploit the strong relationship between personal and relational knowledge, enabling people not only to discover their abilities and interests but to also gain confidence by seeing how different abilities can be combined to solve complex problems.

Co-creation approaches to learning can leverage inclusive relational contexts to promote self-discovery for all kinds of learners while diversifying their interpersonal relations and consequently expanding their aspirations. This contributes to the development of much-needed social capital, which Avis (2002) and Szreter (1998) argue is crucial to boosting the economy while also increasing social inclusion and cohesion. Collective intelligence scholars propose defining Collective Intelligence for the Common Good as a method for harnessing the power of a diverse group to promote societal good, improve civic engagement, and produce transformative solutions to complex 
problems through democratic decision making (Schuler, De Cindio, \& De Liddo, 2015). In other words, bring people with a variety of skills together to leverage those skills for the broader, social good. In turn, those same people discover and gain confidence in their abilities, grow and develop personally, and create wide societal aspirations. Appreciative inquiry may be one method of promoting self-discovery and collective intelligence. Appreciative inquiry is a process that "encourages organizations to identify strengths and imagine possibilities to outgrow problems and realize visions" (Tschannen-Moran \& Tschannen-Moran, 2011, p. 422). Instead of focusing on problems that can spiral down to a blame game, appreciative inquiry, which is founded on positive psychology, focuses on identifying positive aspects of people and the situation and therefore shifts the team's mindset in new, positive directions (Tschannen-Moran \& Tschannen-Moran, 2011). From there, the team can explore tasks to solve complex problems or may begin to understand how their own skills can be used in other areas of their lives (personal development). We discuss in more detail the issue of participation as knowledge creation in Chapter IV.

\subsection{Understanding Learners' Personal and Relational Knowledge}

Our current learning institutions and systems are very good at measuring domain-specific skills through standardized approaches. But this only takes us so far. IPPD-based learning strategies supported by relevant high-dimensional analytics (see section 2.5) can help us understand and possibly begin to quantify integrative development across domain-specific, domain-general, and life skills. However, in order to track and understand the totality of a learner's personal knowledge, we also need a qualitative framework, one that focuses on the experience of personal development. Combined with quantitative approaches to multi-layered skills, this qualitative framework can inform the comprehensive implementation of lifelong adaptive and integrative learning.

One possible starting point for developing a qualitative framework is Ken Wilber's model for integral theory, commonly referred to as AQAL, which is shorthand for "all quadrants, all levels, all lines, all states, all types." Wilber et al. (2012) contend that "this is the simplest set of distinctions that account for the complexity of our evolving world and the depth and breadth of consciousness for which authentic practice strives" (p. 1628). While it is often said that AQAL "makes sense of everything," the framework is not totalizing. In fact, Wilber (2012) would argue that it leaves out most of the details, to be filled in by new discoveries and individual experiences. We provide here a brief overview of the AQAL elements, and Owen Cardwell explores the AQAL model in more detail in the Resources section.

- Quadrants refer to the four dimensions of being-in-the-world: interior/exterior and individual/collective, which translate into thinking (I), behavior (It), culture (We), and social systems (Its). The first two quadrants - I and It - focus on individuals and their strengths, abilities, frame of mind, and how they relate to the physical environment. The We and Its quadrants help the individual see how they fit within the broader social world. Using Wilber's AQAL model, an integrally developed person is one who can draw upon all four quadrants. According to Wilber et al. (2011), "phenomena arise in all four dimensions simultaneously. The four quadrants co-arise (or, more precisely, 'tetra-arise') in the experience of every now" (p. 1704). In order to be both aware of the narrative being performed and able to reframe that narrative, it is important to 
recognize all four dimensions in any situation.

- Levels of Consciousness are higher-order structures that emerge as evolution breaks into new territory. These structures reflect attitudes of consciousness (such as egocentric, ethnocentric, world-centric). According to Wilber et al. (2011), there are higher and lower structures of consciousness, and it is possible to grow to higher levels in progressive stages or waves of development. For example, as human beings we move from childhood to adolescence to adulthood; as a society America moved from slavery to segregation to civil rights. Our level of consciousness defines our worldview.

- Lines of Development are specific areas in which growth and development occur (e.g., interpersonal, moral, musical, needs, cognitive). They are also sometimes called "multiple intelligences" or "streams" of development.

According to the AQAL model, consciousness does not develop monolithically in all areas at the same time. The pace of growth may differ in different areas, and growth in some areas may be necessary for growth in others, yet multiple developmental lines can be distinguished through which growth occurs in a relatively independent fashion (Wilber et al., 2011). Psychologists have identified multiple dimensions of development (Abes, Jones, \& McEwen, 2007; Kohlberg, 1971, 1981). In this report, our focus is on lines of development that address existential questions and have potential connections to the IPPD life skills such as reflection, self-discovery, values, and principles. The idea behind these self-evaluative questions is to bring forward a person's tacit life skills that can facilitate adaptive and lifelong learning.

- Self: Who am I?

- Interpersonal: Who are the people with whom I coexist?
- Cognitive: What am I aware of internally and externally?

- Values: What is important to me and what is important to others?

- Emotional: How do I feel?

- Empathy: How do others feel?

\subsection{Moving From Fixed Courses and Curricula to IPPD-based Adaptive Learning Platforms}

If a traditional learning model focuses on the courses someone took, a learning model focused on IPPD shifts the focus to the skills that accumulate in the learner and on how these skills can quickly transform to meet fast-changing workforce needs. Lifelong application of an IPPD model requires highly adaptive learning platforms that (a) can recognize the full stock of the learner's existing skills across the IPPD layers, and (b) allow learners to pick up skills in many different ways and environments (ranging from practical experience in the job to a formal course) and to compile skills into competencies through customized pathways.

An adaptive learning platform that supports IPPD requires full flexibility of timing and content. A learner can access and exit structured learning fitted to their needs at any time. The learning experience can range from a short module focused on a single skill to a long pathway that produces multiple competencies. Learners can, and should, engage in these experiences throughout their lives and realize adaptive pathways on their own schedule. IPPD-based learning platforms recognize all types of knowledge (tacit, implicit, and explicit) and all layers of skills (domain-specific, domain-general, and life) thus allowing all types of experiences to contribute to learning. For instance, upskilling for an employee can include 


\section{Lifelong application of an IPPD} model requires highly adaptive learning platforms that recognize all of learners' existing skills and allow learners to pick up skills in many different ways.

everything from apprenticeships and mentoring to online content and flipped classrooms (Lohr, 2020). The timing flexibility of an IPPD-based platform refers to when a person chooses to engage an experience but also how long they will spend on that experience. Organizing content in smaller units (modules) and allowing each person to take different amounts of time to complete each unit can contribute to completion and retention rates (University of Detroit Mercy, n.d.). Modular content also allows testing for different ordering of concepts which helps with adaptation to learner needs and with the creation of overall analytics to inform ordering recommendations (Koedinger, McLaughlin, \& Stamper 2014). Modular content also contributes to just-in-time advising as learner analytics emerging from small learning units can be used to frequently update the learner pathways.

An IPPD-based adaptive learning platform can effectively be structured as a dynamic collection of networks of modules that connect through multiple pathways to allow learners to develop skill proficiencies in a customized manner. Different modules can approach the building of skill proficiency through different formats (experiential, theoretical, in-person, asynchronous, blended, etc.) so as to accommodate different ways of learning and different learners. We represent modular building of skill proficiency in Figure 2.1a: square nodes represent modules while links represent pathways between modules (or flexible prerequisites). Proficiency in the targeted skill progresses through the novice, capable, and skilled levels (see Chapter I). Each proficiency level has multiple modules available that are interconnected by multiple pathways. To further advance a co-creation paradigm, entry-level modules are short and focused on helping learners discover their preferences before committing to a longer pathway. In the Resources section, we discuss a current pilot program at Virginia Tech in geography where entry to more specialized geography courses is facilitated by short, asynchronous entry-level modules open to all university students.

Instructors developing content for an IPPD based platform should aim to connect domain-specific and domain-general knowledge in the learning experiences wherever possible. This may enable a learner to more easily transfer knowledge between domain-specific areas, scaffold faster across levels of proficiency, and begin to embody an integrative understanding of the relation of domain-specific skills to domain-general skills. For example, domain-general knowledge of the concept of derivatives can be mapped by instructors across domain-specific modules in engineering, business, and physics (see Chapter I). This would allow learners with experience in novice- and capable-level engineering modules to skip some novice-level modules when acquiring related business information technology skills. Approaching
An IPPD-based adaptive learning platform can be structured as dynamic, multi-pathway networks of diverse modules. 
complex concepts, such as derivatives, through different domain-specific lenses (i.e., engineering and business) also enhances the student's ability to connect seemingly disparate skill sets and builds the life skill of creativity (Page, 2008). Figure 2.1b illustrates this idea and highlights that tracking the accumulation of multilayered skill development in the learner, rather than progress through a fixed sequence of courses, can significantly shorten learning paths and reduce burden on the learner. In Figure 2.1 b, skills are represented as oval nodes.

An IPPD-based platform places structured learning experiences between domain-specific and domain-general skills and between domain-general and life skills. Learning experiences that focus on connecting life skills with domain-general skills can also be modular and may include self-discovery design exercises, collaborative problem-solving, and various forms of experiential learning that engage complex and inclusive "real world" contexts. The gradual integration of skill layers achieved through IPPD-based adaptive learning can facilitate collaborative engagement of real-world challenges and the emergence of diverse collective intelligence. For example, domain-specific skills in philosophy, design, social science, and computing can be mapped, through appropriately structured modules, to the domain-general concepts of logical deduction and derivation. The common space of the domain-general concepts can in turn facilitate a collaborative learning experience between these diverse disciplines on integrated security. This collaborative experience would build life skills and address societal purpose. It would promote multi-perspective discourse and reflection that can address the high dimensional complexity of safety and security in the $21^{\text {st }}$ century while also being fulfilling for all participants. The coordination of learning experiences across layers reduces the need for any one learning experience to map
An IPPD-based platform places

modular learning experiences

between domain-specific and

domain-general skills and

between domain-general and life skills.

to all three layers while shortening learning paths and still achieving an integrated development of skills across the three layers.

Figure 2.1a

\section{Adaptive Pathways Between Modules at Different Levels of Proficiency}

\section{Modules}

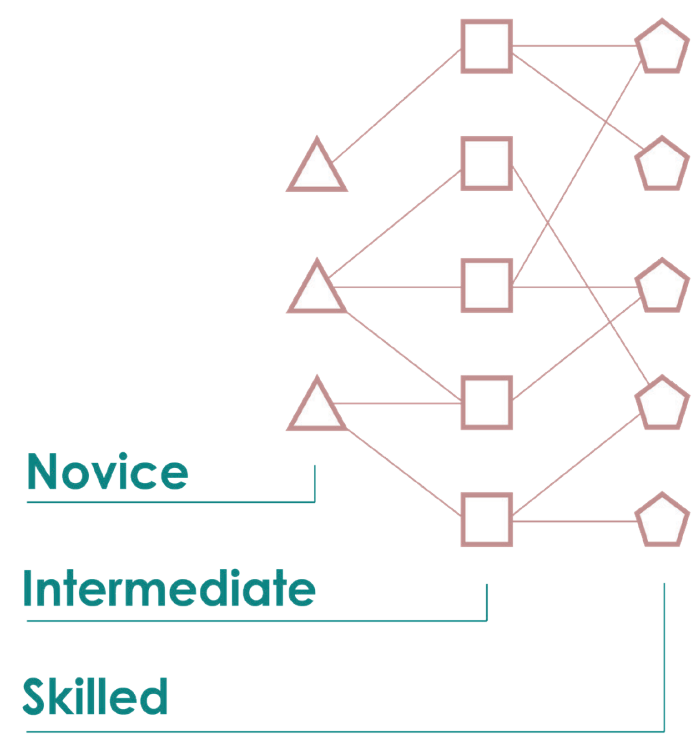


Figure 2.1b

\section{Shortening Domain-Specific Pathways Through Domain-General Skill}

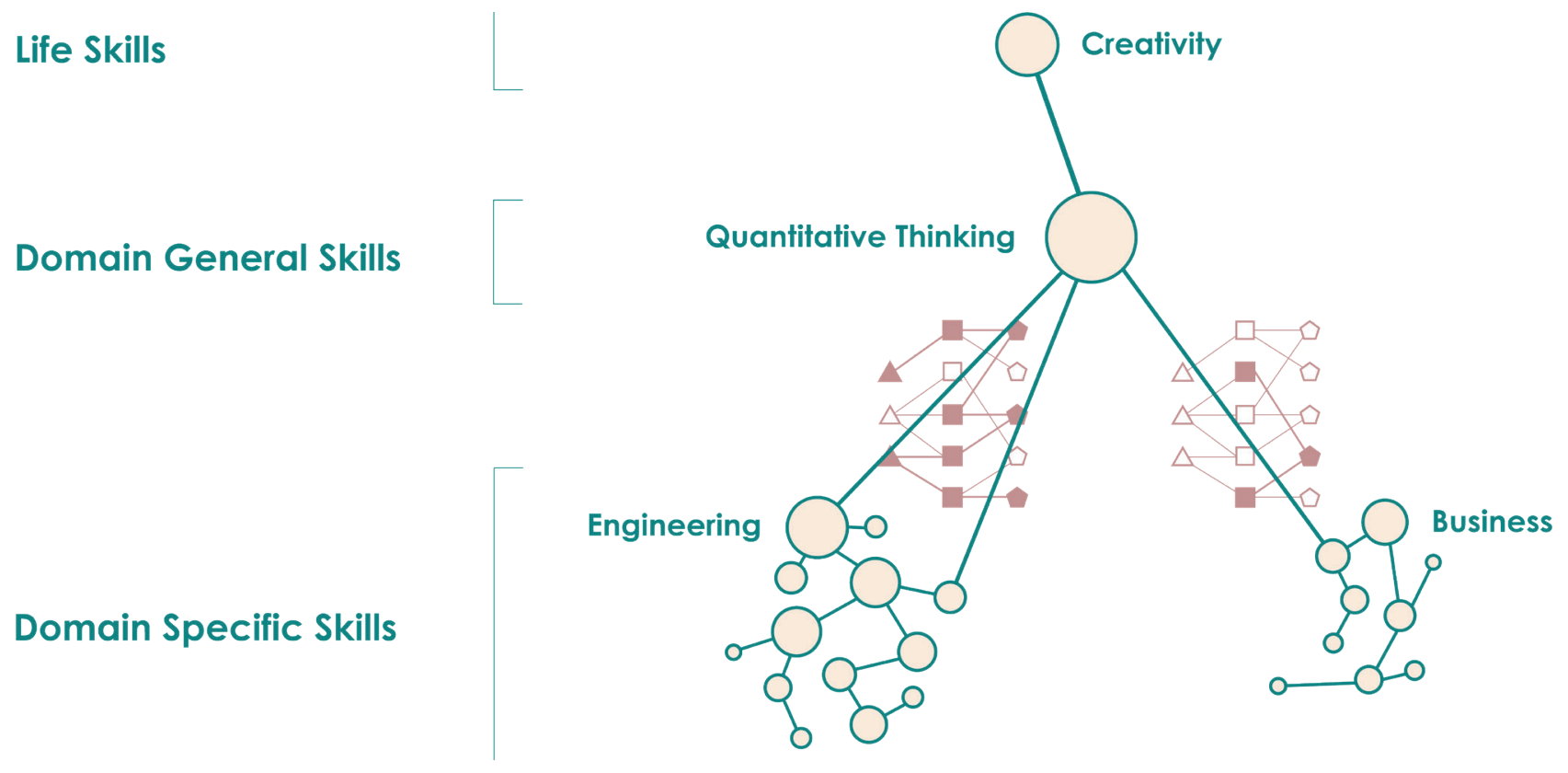

In Figure 2.2, we illustrate the layered nature of learning experiences recognized and facilitated by an IPPD-based platform. The size of the oval nodes denotes the strength of skills achieved by the learner while the proximity of nodes shows similarity of skills. The size of the links that connect skills shows the connectivity strength of skills embodied by an individual learner. Development of integrative knowledge is based partly on structured learning modules and partly on the learner's tacit knowledge from various life experiences.

Competencies within the IPPD-based platform can thus be seen as customized networks involving strong skills across the three layers that allow someone to perform a job well. Competencies are partly standardized and institutional (due to structured learning provided by various mediums) and partly personal and adaptive. For example, two people can become competent engineers by taking different sets of engineering

specific modules (as well as following different paths between modules) and by connecting the domain-specific skills arising from these modules to different combinations of domain-specific, domain-general, and life skills. Furthermore, personal competencies (i.e., being a good partner) are related to professional competencies (i.e., being a good engineer) - they both rely on and develop the life skills of collaboration, communication, and agility. We highlight these potential connections to emphasize the importance of integrated personal and professional development. 
Figure 2.2

\title{
Multilayer Skill Development Supported by Multilayer Modular Learning
}

\author{
Life Skills
}

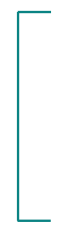

\section{Domain General Skills}

\section{Domain Specific Skills}

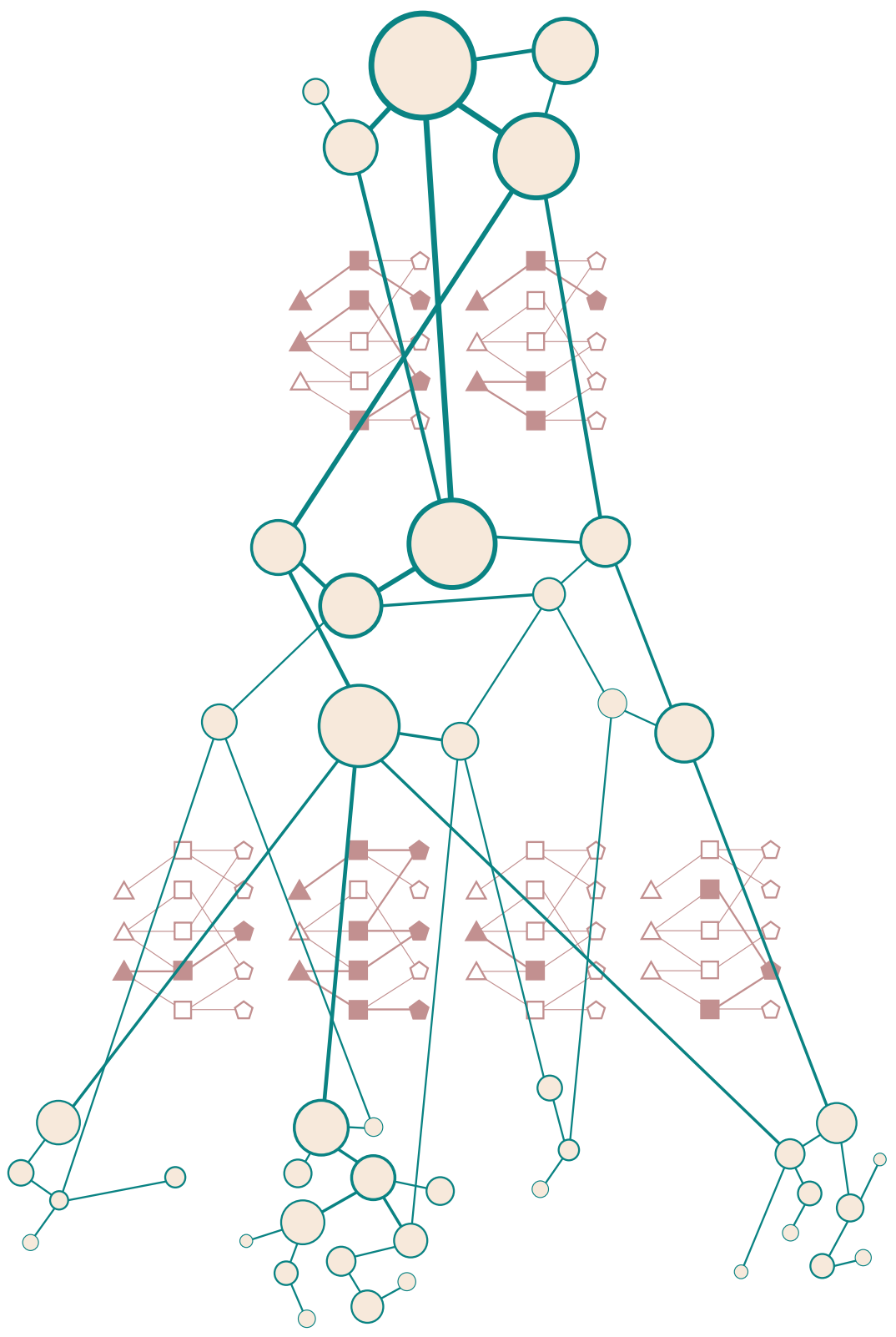

Mobility of the learner across learning experiences on the vertical (layer of skills) and horizontal (type of skills) facilitates integrative learning and promotes complex thinking and dynamic lifelong learning.

It is also worth noting that while the size and combinations of nodes and edges in Figure 2.2 are fixed, this is merely a limitation of the diagram. Indeed, we believe that adaptive lifelong learning is and should be flexible with respect to the formation of competencies. Network shaping is informed and continuously updated based on a combination of institutional knowledge, learner analytics, and workforce data. Our modular 


\section{Rather than traditional}

admissions, learners enter

IPPD-based platforms through

just-in-time identification of

tacit, implicit, and explicit skills.

Advising becomes individualized

pathway recommendations for

developing existing skills into

IPPD-based competencies.

approach to implementing adaptive learning for IPPD makes it easy to add or subtract modules and improve mappings of modules to skills and skills to competencies as societal knowledge evolves.

The notion of admissions to an IPPD-based adaptive learning platform becomes the just-intime quantitative and qualitative identification of a learner's tacit strengths and aspirations, explicit and implicit skills, and related zones of proximal development. The notion of advising becomes a set of individualized recommendations of pathways for developing existing skills into explicit competencies and for overall professional and personal development.

Of course, when advising learners on pathways it is easier to recommend immediate steps than it is faraway steps (Vygotsky, 1978). In this respect, a Hierarchical Bayesian Modeling (HBM) approach to learning in complexity (Tenenbaum et al., 2011) might be helpful to those advising learners utilizing an IPPD-based platform because it is statistical (rather than deterministic), allows for updating the prior knowledge model of the learner at every learning step, and accounts for multiple layers of skills work- ing together. For example, collecting large amounts of learner data across sectors could allow previous experiences of a learner as a waitress, trucker, or mechanic to be modeled as probabilities of existing skills across the three IPPD layers. This modeling could inform the recommendation of pathways for each of these learners to reskill for software engineering employment (Lohr, 2020) while allowing for the recommendations to be updated continuously as the different learners begin to tackle their learning pathways. An HBM approach also accommodates the combined modeling of the learning environment and the individual learner, which can significantly increase the efficacy and efficiency of learning (Koedinger et al., 2013). For example, the probability of the number and type of repetitions of a particular exercise necessary for a learner to grasp a concept can be modeled in tandem with a particular learner's prior skill stock and emerging learning preferences.

An HBM approach to adaptation is also compatible with both human and computational models of learning and can thus facilitate the development of cyber-human systems that support IPPD-based platforms (Rikakis et al., 2018). In section 2.5, we discuss a number of technological advances (i.e., the Internet of Things) that can be combined with human expertise to instrument a wide range of learner-observed characteristics across multiple learning contexts (i.e., performing specialized tasks at work and studying related skills through online learning). Considering the resulting data as a single unified ecosystem could eventually uncover the distributed nature of human learning that is embedded in a thick network of human behaviors. The ability to shed light onto the so-called "ghost in the machine" (Koestler, 1967), where knowledge making is embodied across a variety of learner actions, has a powerful appeal (Madhavan \& Richey, 2016). A holistic cyber-human un- 


\section{An integrative learning}

record should be an external

representation of an individual's

internal layers of development.

This requires a shift from

institution-based to portable

credentials owned by individuals.

derstanding of personal and relational "knowledge in action" (see the Introduction) would facilitate the development of IPPD-based platforms that can recognize and leverage the full range of skills of differentiated learners.

An IPPD-based platform that recognizes the sum of the knowledge gained by an individual would also require new structures for credentialing this knowledge. Such a change entails a shift from credentials emanating from institutions to portable credentials owned by individuals.

While badging (Zucker \& Hicks, 2019) and micro-credentials (Georgia Tech, 2018a) provide possible solutions, they are not without issue. In "Credential Inflation and the Future of Universities" Collins (2002) argues that the pressure for institution based micro-credentialing comes primarily from institutions of knowledge and is not based on employers' needs. Coffield (1999) also warns against emphasis on micro-credentialing, rather than integrative knowledge embodied by the learner. He warns that many learners will pursue badging or micro-credentials for the sake of employment acquisition or promotion without regard for mastery in their professional practice. The issue of how to create and store credentialing outside of a specific authority such as the original employer or educational provider remains a challenge. An integrative record should be an external representation of the internal layers of personal and professional development that an individual participating in the economy and society have sought and created. Certifying learning across many modalities is challenging, but can be done. We discuss approaches to this issue in more detail in Chapter III.

Appendix A contains a description of the Calhoun Discovery Program (CDP) that has been set up to support integrative learning across the layers of the IPPD model through modular and diverse learning experiences and customized pathways. The CDP is in its early stages and works within the constraints of traditional university curricula. Thus, the CDP cannot fully engage the open co-creation paradigm of an IPPD-based platform as discussed in this section. However, the CDP does provide an ongoing proof of concept experiment of many of the integrative and adaptive learning concepts explored in Chapters I and II.

\subsection{Technological Tools for Aiding Adaptation}

Person-to-person tutoring and mentoring is still one of the most effective ways to implement adaptive and integrative learning (Bloom, 1984) but it is not always an option, especially at a large scale. Fortunately, a number of tools, platforms, and technological solutions are being developed that combine human expertise and technological strengths to deliver integrative adaptive learning at scale.

\subsubsection{Intelligent Tutor Systems}

Intelligent tutor systems (ITS) show significant promise for implementing adaptive learning at scale. In essence, an intelligent tutor is a computer program designed around the concept of mastery learning. Performance feedback enables 
learners to adapt their approach to learning a skill until they reach a desired level of performance (Georgia Tech, 2018a). Likewise, intelligent tutors adapt over time. They are programmed with domain knowledge and gain both tutoring and learner knowledge through interactions. Cognitive tutors are an especially promising subcategory of intelligent tutors, although they are also complex and costly. Cognitive tutors aim to simulate human-student learning both in terms of domain knowledge and learner representation (Koedinger et al., 2015; Aleven et al., 2016). This approach allows learners to self-pace and find a learning path that works best for them. For example, the number and manner of training repetitions per skill component and the order the skill components are presented can vary while the intelligent tutor is also providing rewards and hints. The learner gets individualized support (tutoring), which has been shown to increase performance by two standard deviations and increase attainment for all students (Bloom, 1984; Ericsson, Krampe, \& Tesch-Römer, 1993) without requiring extensive interaction with a teacher.

Intelligent tutors (like many other artificial intelligence applications) are most effective when the goal of learning is clear and fixed (Kelly, 2016). Therefore, they are best at teaching standardized, domain-specific skills. For example, the Open Learning Initiative (OLI) at Carnegie Mellon University (CMU) and Georgia Tech's virtual teaching assistant (TA) program, Jill Watson, have had significant success in developing cognitive tutors for teaching programming to large numbers of students (Koedinger et al., 2015; Goel \& Polepeddi, 2016). The OLI has also had success in cognitive tutors for teaching basic math concepts to secondary education students as well as introduction to writing, communication, and psychology to CMU students (Joo \& Spies, 2019). Interactive learning through online education, like that provided by intelligent tutors, is much more effective than a passive massive open online course (MOOC) and provides significant promise for bringing adaptive learning to greater numbers of people (Koedinger et al., 2013).

Analytics from interactive large-scale learning is important for developing intelligent tutors that understand the engagement and progress of different learners and can use this information to customize learning paths, provide feedback, and even predict the level of mastery (or grade) a learner is likely to reach (Ginda et al., 2019). The data collected not only improves intelligent tutors but also provides information that can be used to update the structure of the domain knowledge. For example, work at CMU has shown that some exercises widely used for teaching math in secondary education are not as effective as others, and that the order of problem-solving skills traditionally used for teaching basic math skills in primary schools may not be optimal (Koedinger, McLaughlin, \& Stamper 2014). Interactive learning can be further enhanced by availability of human experts to deal with unexpected or complex situations. For example, both in the CMU and the Georgia Tech course, complex questions are passed to TAs (Goel \& Polepeddi, 2016).

Interactive adaptive teaching of some domain-specific skills at scale can increase efficiency without losing quality. The experiences of $\mathrm{CMU}$ and Georgia Tech show very little difference in learning outcomes between students who took the interactive learning versions of introduction to computer science courses compared with those who took the course in a traditional instructor format (Georgia Tech, 2018a). However, the students that took the online version reported spending less time on the course (Georgia Tech, 2018c). Similarly, Boeing reports that in its training courses, 
learner trajectories can be optimized equally well for online learning and in-person learning depending on the skills sought (Ginda et al., 2019). Moving some of the mastery of domain-specific skills to interactive learning would also free up time for faculty to focus on teaching more complex domain-specific or domain-general skills. A very promising future direction for interactive online learning is the development of hybrid computer-human courses where the intelligent tutors deal with the teaching of the more repetitive domain-specific skills, and educators (trainers, teachers, instructors, and professors) teach more complex domain-specific and domain-general components (Georgia Tech, 2018a). This could be extremely valuable at a time when the need for domain-general skills connected to domain-specific skills is increasing, the number of people that require this type of training is expanding, and where knowledge dissemination through technology enabled learning and social networks is driven by the understanding that decisions are based on rapidly altering foundations.

\subsubsection{Peer-to-Peer and Collaborative Learning}

Another human-to-human issue that needs to be addressed in interactive online learning is that

\section{Opportunities are emerging}

to instrument, analyze, and enhance individualized learning and collective cyber-human intelligence within all learning environments to better support integrative professional and personal development. of peer-to-peer and collaborative learning. This issue is beginning to be addressed by cloud-based tools for writing, editing, and collaboration such as Amazon Web Services (AWS), Google Suite, and Microsoft OneDrive used in combination with Skype, Zoom, or another teleconferencing application. Not surprisingly, these approaches have gained in popularity during the recent closing of schools during the global COVID-19 pandemic (Miller, 2020; Novet, 2020), and it seems likely that they will continue to be used in tandem with in-person teaching even after the pandemic.

\subsubsection{The Internet of Things}

A significant amount of technology-assisted adaptive learning focuses on cognitive skills. However, our report proposes that adaptive learning should address the totality of human skills and learning situations. One potential avenue for applying adaptive learning to the totality of human skills is the proliferation of wearable, household, workspace and manufacturing items and equipment that are interconnected via the internet (the Internet of Things). The Internet of Things (IoT) presents an opportunity for data-driven, interactive, and adaptive learning in varied contexts as human activity data can be combined with tool, environmental, and human-tool-environment interaction data. Opportunities are emerging to instrument, analyze, and enhance individualized learning and collective cyber-human intelligence within all learning environments: the classroom, the factory, the office, the studio, the farm, the road, the hospital, and the meeting room. This gives us the opportunity to better understand and support integrative personal and professional development.

The National Science Foundation (NSF) is funding related research through the Future of Work at the Human-Technology Frontier (FW- 
HTF). One example is the Intelligent Cognitive Assistants (ICA) research that is focused on the creation of systems that demonstrate harnessing of machine intelligence to work collaboratively and enhance human cognitive and physical capabilities. This physico-cognitive systems research is focused on contextual knowledge, sociotechnical systems, and natural human-ICA interfacing. As a follow up, the NSF has proposed using brain-like computing as the logic unit for ICAs.

The fast-evolving computing interfaces and mobile computing platforms will gradually allow humans to interact with embedded computing intelligence in manners that are highly customized to the environment. For example, in the Shirley Ryan Ability Lab of Chicago, sensors in the rooms of patients use radio-frequency identification (RFID) tags to recognize which doctor has entered the patient's room and project information pertinent to the interaction of that doctor with a specific patient on the patient's health screen above their bed. Doctors can customize consultation and treatment parameters. The doctor's attention can shift from the routine task of completing charts to the higher-level tasks of interacting with the patient and making decisions. In a recent publication, $\mathrm{Ri}$ kakis (2018) discusses current IoT applications being developed by his team that allow therapists to remotely supervise and adapt interactive rehabilitation at the home. These applications make it possible for more patients to receive cost-effective therapy while minimizing travel. The interactive, data informed nature of the therapy engages patients in their recovery while also upskilling therapists to use IoT applications and high-dimensional data for adaptive decision making. Rikakis also recommends designing and supporting cyber-human learning in a way that leverages the ability of experts for interconnected decision-making across multiple layers of skills and the ability of comput- ers to provide detailed longitudinal data.

IoT-supported training and learning can also expand and leverage the emerging landscape of smart manufacturing and cyber-supported services. For example, the emerging idea of collaborative robots (cobots) aims to use worker expertise for realization of higher-level tasks while passing lower-level tasks associated with the 3 Ds (dirty, dull, dangerous) to robots that are controlled by the worker. This approach allows the worker to learn new skills (operation, control, and maintenance of robots) while at the same time increasing efficiency, productivity, and safety (McAfee \& Brynjolfsson, 2017). Caterpillar Inc. provides technologies to companies for upskilling construction workers and supporting more efficient production schedules. For example, construction crews can combine drone supported scanning and modeling of road sites with robotic construction tools to reduce road construction time by $50 \%$ while also significantly increasing fuel efficiency and site safety (CAT, Inc., 2020). At the Adaptive Lifelong Learning Workshop held in October 2019, GE Appliances participants proposed a seemingly futuristic scenario in which technicians will use mobile $3 \mathrm{D}$ printers to create customized appliance parts during troubleshooting and maintenance visits to homes thus eliminating waiting time and follow up visits. The worker upskilling, environmental sustainability, and service quality potential of such approaches is significant.

\subsubsection{Virtual and Augmented Reality}

Alongside the Internet of Things, virtual reality and augmented reality (VR and AR) are also fast evolving computing interfaces that can enhance learning and improve collaboration (Henderson, et al., 2009). AR can provide just-in-time assistance to any learner or worker performing a complex task. For example, a digital image of 
the components of a circuit and their functionality can be overlaid on the physical electric circuit that someone is studying or fixing (Bohn, 2019). Combined with remote assistance from experts for more complex challenges, AR-assisted tech support can allow each and every person to become part of their own technical support team. This pluralized access to technology can get more young people excited and empowered to join the tech workforce. Similar AR approaches can be used to continuously support and upskill current technicians on the job as tools and platforms continuously evolve and complexify. Critically, in these scenarios, technology does not, and should not, replace the human technician. Rather, it allows an individual to reskill and provide support to a large number of clients as the need for tech support of smart infrastructure increases.

Like augmented reality, virtual reality can provide immersive visualizations of physical spaces to allow learners to develop skills using realistic scenarios. For instance, VR can simulate certain kinds of laboratories so that research can be conducted without risks typically associated with hazardous work environments (Thalheimer, 2015). Likewise, for language learning VR can simulate immersion in a faraway setting, e.g., a student in Malawi can virtually visit Kyrgyzstan, minimizing the logistical barriers of time, distance, and cost. Moreover, VR applications have shown promise in creating educational experiences that benefit students with special needs. The Jackson School in Victoria, Australia, for example, has integrated VR sessions with relaxation and/or meditative applications and experiences into its offerings with significant success (Herold, 2014). These technologies can also aid in detection and responsiveness to learning disabilities (e.g., dyslexia). Determinations as to the degree of attention required can be made by storing large data sets associated with
When technology-supported learning is designed by learning experts, and supported by cocreation processes, the resulting data can be both big data and good data.

eyeball movement and analyzing thousands of such data sets. This can be combined with natural language processing (NLP) and deep learning to offer human brain-like functionality in assessing writing skills, subjective responses to questions, and so on. Finally, it can help to predict paths and help with interventions to assist the realization of the paths (Ginda, 2019; Madni, 2015).

\subsubsection{Big and Good Data and Al-Supported Learning}

Each of the above technology-assisted learning and training scenarios rely on increased amounts of high-dimensional data for understanding human learning, its interactions with technology, and its interactions with the overall relational environment. When technology-supported learning is designed by experts, the resulting data can be both big data and good data (data that can be used to understand and improve learning) (Koedinger et al., 2013).

Good data can lead to meaningful and impactful improvements in AI for adaptive learning. As with the current intelligent tutors, we can develop technology-supported learning where cyber and human intelligence work together to deal with simple and complex skills in an integrative and adaptive manner. The aim of this type of learning is to advance human capability (of the learner and 
the trainer) rather than replace their human capital. Combined with appropriate socioeconomic mechanisms that address issues such as the digital divide and persistent inequalities of access due to gender, race, or ethnicity as well as other socio-technical solutions to security and privacy (UNESCO, 2019), cyber-human adaptive learning at scale can increase access to learning and efficiency of learning (Georgia Tech, 2018a). In fact, the World Economic Forum discussion of Industry 4.0 calls for smart factories that take advantage of the Internet of Things while also advancing inclusive and equitable growth of human capital (World Economic Forum, 2016a; 2016b).

The growth of technology-supported learning across all sectors of society and the economy can also help produce data-supported advising for individualized learning pathways and careers. Data-supported advising is already showing promise within universities helping to improve student retention and degree completion for all students including underserved populations. For example, Georgia State University's GPS Advising uses predictive analytics and a system of more than 800 alerts to track all undergraduates daily, identify at-risk behaviors, and have advisers respond to alerts by intervening in a timely manner to get stu-

Companies are shifting from a "learn-to-do" paradigm for employees to a "do-to-learn" approach across individuals' careers. This means that expert tool-services must also become powerful lifelong learning platforms. dents back on track. Since the University initiated this technology-assisted advising in 2012, freshman fall-to-spring retention rates have increased by $5 \%$ and graduating seniors are taking fewer excess courses in completing their degrees. This past academic year, the system generated more than 55,000 individual meetings between advisers and students to discuss specific alerts, all aimed at getting students back on path to graduation (Georgia State University, 2020). It is important to note in this example that students and advisors work in tandem with technology to produce effective adaptive learning pathways and experiences.

In addition to universities, companies like $\mathrm{Au}-$ todesk (a software company that focuses on architecture, engineering, construction, manufacturing, and beyond) are shifting away from a "learn-to-do" paradigm and preparing for a "do-to-learn" world where the imperative for continuous professional and personal growth drives the creation of new infrastructures to support seamless learning across secondary and higher education and throughout the arc of one's career.

In Autodesk's particular case, this means that expert tool-services must also become powerful lifelong learning platforms. These platforms will allow users to simulate with data-rich visualizations what they know, don't know, and need to know to succeed. Essential to this research is that users and learners be able to securely self-simulate their potential futures by incorporating tool, project, and team data as well as automated badging, external learning and credentialing systems (including universities), and aggregated industry trend data.

Team knowledge and learning visualizations are a critical component of Autodesk's vision for dynamic adaptive learning systems. Autodesk researchers understand the most complex work at a 
The ability to assemble the "collective creative brain" of

a team will be crucial in the coming years. This requires toolservices that can simultaneously infer and visualize the proximal learning potential of any given team configuration.

company occurs on teams. While there has been considerable experimentation with related organizational forms (e.g., agile development frameworks) and some progress with supporting technologies (e.g., Slack-like tools) there has been a paucity of research and productization in assembling teams with the optimal collective knowledge to address specific complex project challenges. Autodesk believes that the ability to assemble the "collective creative brain" of a team will be crucial in the coming years.

Autodesk researchers are addressing this issue by developing tool-services that allow team managers to visualize the actual data-derived skills of team members relative to the specific constraints of a project. Given the importance of teams today this function alone has considerable value, but the ultimate goal of these services should be to simultaneously infer and visualize the proximal learning potential (lateral transfer of knowledge between members) of any given team configuration. As we have discussed throughout this report, knowledge in action is both personal and relational. In the near future, relational skills, such as the ability of employees to teach and mentor on teams, will be highly valued skills supported by a range of professional development opportunities.
Common cross-sector databases of up-to-date workforce analytics that track and value the totality of skills can further enhance adaptive and inclusive career development and lifelong learning. It is therefore important to explore the potential for credentials to become a network of dynamic machine learning agents that make learning recommendations based on the movement of learners through them. Blockchain technology offers a potential approach to organizing and credentialing integrated professional and personal development learning across all types of environments and experiences. Blockchain can track every learning instance when it occurs, creating an immutable record that can be easily verified and analyzed to assess the learner's interests and competences. This can help create multiple pathways by breaking learning into smaller bite-size chunks, which can be combined in a myriad of ways. For example, institutions can offer project-based education as an alternative to college courses and certify student work done via Blockchain databases. This technology can also be used to secure collaborations between universities and industries that involve the use of shared repositories (e.g., student certification and achievement data), introduce methods to design and continuously update global professional and personal development assessment mechanisms, and verify the authenticity and accuracy of knowledge bases and repositories. The data from these repositories can then be shared with third parties such as employers or LinkedIn and integrated with learning platforms to help shape lifelong learning pathways.

The streamlined verification of integrative and continuing professional and personal development can track and certify institutional and employee training and related achievements to facilitate job transfers and career planning. For example, Maryville University is currently implementing two strategic blockchain initiatives: the $\mathrm{Ca}$ - 
reer-Focused Student Digital Profile and the Lifelong Student Digital Profile. The first initiative is built based on the eight career competencies established by the National Association of Colleges and Employers (NACE, 2019), which help Maryville students develop the domain-specific and domain-general skills that employers have been asking for. Once they complete the training, the blockchain solution will provide verifiable credentials with learning artifacts. The second initiative will address lifelong learning needs and offer both current and former Maryville students the ability to post, share, and verify their own learning records on Blockchain. New learning opportunities will be presented based on the learners' expressed needs.

Together, AI and Blockchain have significant synergistic potential not only for adaptive credentialing and advising but also for learning (Thibodeaux, 2018). For example, the Chinese adaptive learning startup Squirrel AI claims that AI has helped increase student test passing rate by $17 \%$ and reduced the course dropout rate by $56 \%$. So far, Squirrel AI has developed over 30,000 "academic concepts" (Peng, 2018). Although not in use in any formal education system yet, Amazon's Alexa has also developed over 100,000 skills and many universities in the United States are using the technology to create their own solutions such as Oral Roberts University's QM-mirror (Buckler, 2019).

To keep up with the fast pace of development of technology-assisted adaptive learning, employment and training institutions will need to make intentional investments and plans for updating content and tools as well as professional development for existing faculty and staff. For example, in the fall of 2019, University of Central Florida (UCF) initiated a focused project to develop online, blended, and adaptive-learning courses. Over the course of three years, the university will create 50 new online or blended courses and 50 adaptive-learning courses. Professional development training will be provided to approximately 120 faculty members from a minimum of five colleges and departments. Eight technology-enhanced, active-learning classrooms will be built.

The COVID-19 crisis has further emphasized the need for well-structured alternatives to traditional knowledge dissemination mechanisms and increased the pressure for proactive and significant investments in technology-assisted adaptive learning. Cross-sector partnership may be the most effective avenue to handling the complexity, cost and urgency for such learning at scale. For example, the Carnegie Mellon Simon Initiative aims to build a cross-sector learning ecosystem supported by technological infrastructure to improve educational practices and develop new "intelligent tools" that are easy for faculty and learners to use. The initiative aims to make all of the developed tools and methods available globally for any individuals or institutions to adopt (Mission, 2020).

The promising tools and approaches surveyed in this chapter are not without risks to their users and the societies in which they flourish (Goel \& Polepeddi, 2016; Kadel et al., 2019). These technologies hold the potential to create much wider access to knowledge and learning. At the same time, they have the potential to exacerbate existing stratifications within societies if they are not available widely and equitably. For adaptive learning to facilitate the democratization of knowledge, opportunities to access and use the tools and technologies must be universal. Neither the networks nor the technologies that may facilitate them are necessarily or intrinsically more participatory or democratic (Davies \& Spicer, 2015) without intentional commitments on the part of members to make them so. Moreover, there are significant privacy and security concerns as the amount and reach of data 
collection continues to expand exponentially. Clear policy and security approaches are needed to ensure that this information is protected and that individuals "own" their records and data. Realizing the potential of these approaches and tools requires serious discussion and action on the part of every member and sector of society (government, industry, education, and communities) to ensure that the expansion and adoption of such approaches do, in fact, expand equity, inclusion, and human flourishing, rather than re-entrench and intensify existing inequalities.

In Chapter III we present a number of efforts under way to increase equitable access to adaptive learning. In Chapter $I V$ we propose the future development of cross-sector Point of Need Learning Platforms that utilize and advance combinations of the learning methodologies and technologies referenced in this chapter to support the inclusivity and adaptivity of integrative personal and professional development at scale. As we look toward the future, we envision that the wide embodiment of IPPD-based adaptive learning will create participants who have deep commitments to the values of discourse, collaboration, and participation with which they will work with others to build truly democratic learning societies by addressing all of the necessary social, economic, and political challenges inherent in such a project. 
1

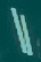

1

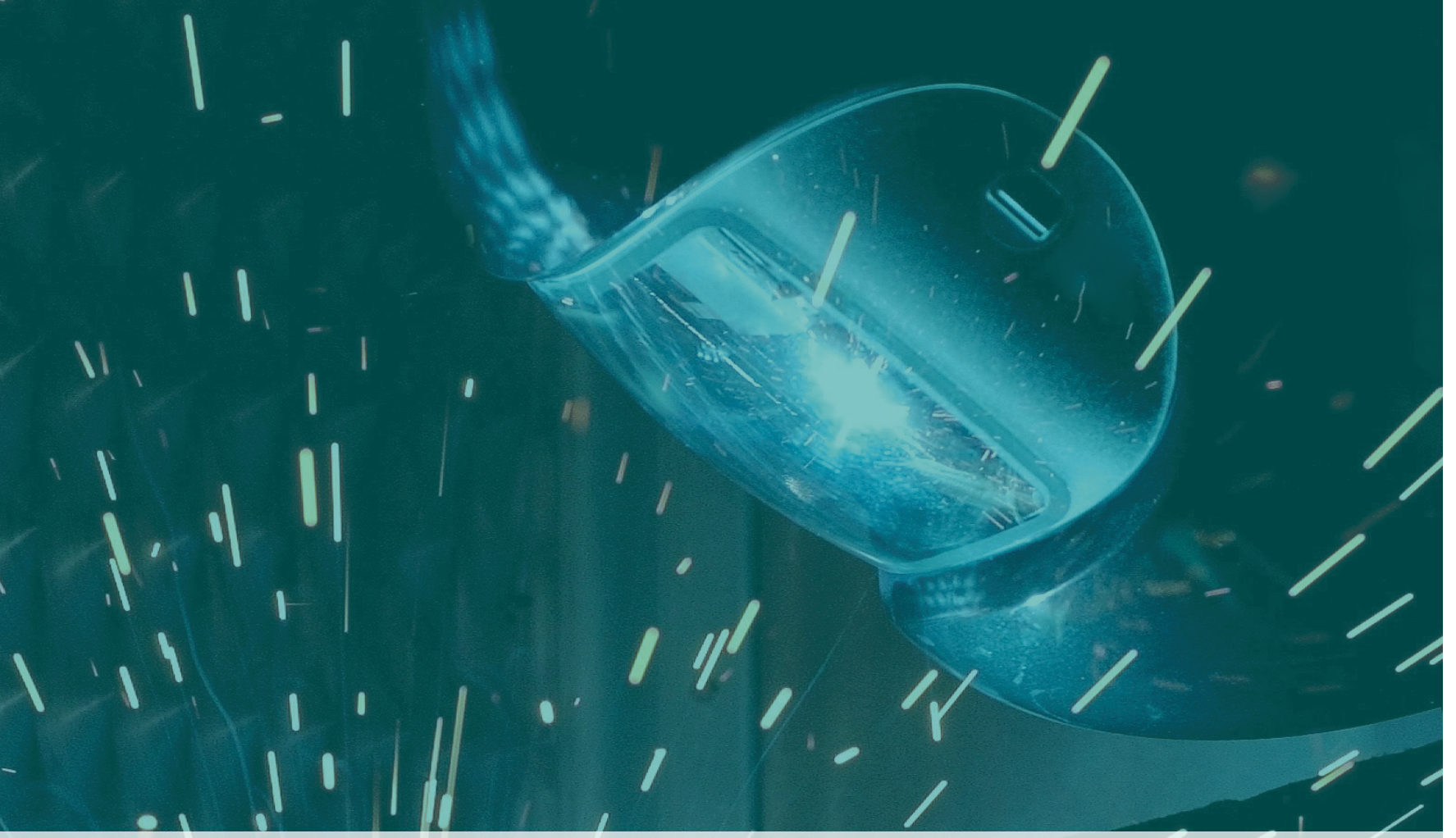

\section{Chapter III:}

Adaptive Learning Pathways: Examples from Higher Education, Industry, and Across Sectors

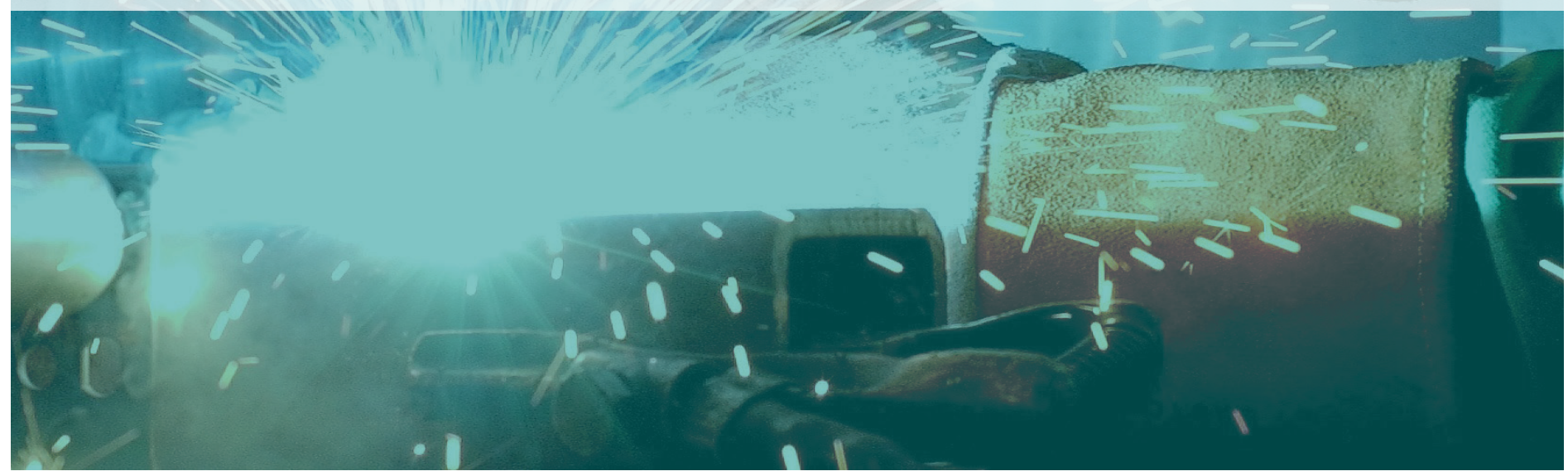




\title{
CHAPTER III
}

\section{Adaptive Learning Pathways: Examples from Higher Education, Industry, and Across Sectors}

\author{
Authors: Rebecca Clark-Stallkamp, Shari Garmise \\ Co-authors: Thanassis Rikakis, Amy Arnold, Jared Keyel \\ Contributors: Andrew McCoy, Chip Blankenship, Colin Potts, Chrystal Harris, David Hare, \\ Jena Joo, Julie Greenwood, Kristin Wingfeld, Manny Contomanolis, Marsha Semmel, \\ Mukul Kumar, Randy Swearer, Robert Smith, Scott Bess, Sherrell Ashburn, Tom Quick
}

$\mathrm{I}$

f we are to prepare people to meet the needs of the $21^{\text {st }}$ century workforce, we must be able to offer multifaceted learning opportunities. The education we provide must be customizable, just-in-time, and lifelong; and it must integrate professional and personal development within a pluralistic societal context. This goal, however, cannot be met by higher education alone. What we need are Quintuple Helix Knowledge ecosystems - cross-sector partnerships that span the five sectors of education, industry, government, civil society, and socio-ecological environments (Carayannis, 2018; Rikakis, et al., 2019). The Quintuple Helix embodies what Ann Balsamo (2010) calls a "culture of participation" in which intelligence is assumed to be distributed, multimodal, developed, practiced, and expressed through "the use of technologically-mediated informational and social networks" (Balsamo, 2010, p. 424).

To achieve this new kind of distributed, adaptive learning, we will have to rethink current linear, fixed-term paradigms in education and find ways to develop new models that afford lifelong learning capabilities, increase access through multiple modalities, expand alternative cost structures, while enhancing transferability
To achieve distributed, adaptive learning, we need cross-sector partnerships that span the five sectors of education, industry, government, civil society, and socio-ecological environments.

of learning and transparency of learning outcomes. This means being willing to cross traditional boundaries that artificially divide education, community, and economy into separate sectors.

Fortunately, none of this is hypothetical or futuristic. Very real pilots and trials exist in educational institutions, industry, and communities, and in many cases, they cut across sectors. In this chapter, we survey a few of these pilots and trials to provide evidence of what is already occurring and to exhibit what is possible. First, we single out a few innovative college and university programs before turning to industry. Finally, we close the chapter by exploring a few cross-sector programs. 


\subsection{Adaptive Pathways in Higher Education}

A number of universities recognize the critical role of adaptive and integrative education in developing lifelong learners who can easily navigate a more mobile and inclusive workforce. Realizing that the traditional higher education model is one-size-fits-all, these universities are developing new pathways that align with the needs of learners at any number of different points in their lives, whether they are out of work, between jobs, exploring upskilling or reskilling, or discovering career possibilities during $\mathrm{K}-12$. The fact is that most every learner now needs this adaptivity in order to continually develop new skills to stay ahead of perpetual change in business, technology, and industry. These institutions are adjusting to meet the unique needs, interests, and aspirations of today's diverse body of learners. While we primarily focus on North American universities, similar programs exist around the world.

Multiple colleges and universities have developed innovative undergraduate programs that emphasize the discovery and development of personal knowledge for the $21^{\text {st }}$ century. Here are just a few examples:

Arizona State University (ASU). ASU has been out in front in its efforts to serve the needs of learners everywhere. While developing ASU's highly publicized partnership with Starbucks, which launched in 2014, university leaders recognized the growing need to deliver affordable, high-quality programs to underserved and underrepresented communities from around the world. EdPlus was created to be the central enterprise unit at ASU that focuses on the "design and scalable delivery of digital teaching and learning models to increase student success and reduce barriers to achievement in higher education." EdPlus programs enable students, wherever they may be, to access fully on- line courses and programs so that they can "reach important milestones, improve skills, and engage with a world of problem solvers like themselves" (EdPlus, 2018). This model of digitally-enhanced education incorporates industry project-based learning, collaborative university programming, lifelong learning support, and personalized professional development.

By 2018 ASU's EdPlus had graduated over 7,000 online students which has substantially risen from the initial 1,200 enrolled in 2012. The program has grown exponentially in enrollment, managed programs, and collaborations. Besides the Starbucks partnership, ASU has developed massive initiatives with the Mayo Clinic and Adidas while expanding research being conducted in the ActionLab, an innovative research space dedicated specifically to learning and teaching with technology integration. It is evident that ASU seeks new ways to connect the learner to every opportunity available. For example, instead of competing for enrollment increases, PLuS Alliance, which is part of EdPlus, shares students between various academic institutions. Instead of traditional enrollment competition, these universities work together to leverage their resources for the learner to ensure access to viable learning pathways regardless of social, cultural, and economic background.

Bennington College. Bennington has made the concept of field work central to its educational programs since the college was founded in 1932. Every Bennington student is required to complete 200 hours of qualifying field work each year. They do so during a six-week Field Work Term (FWT), which is held every January and February when no academic classes are being offered on campus. Students work in a variety of fields and geographic locations pursuing interests that they discovered or developed while at Bennington. The FWT allows 
students to "map a territory for study and practice that goes beyond the bounds of a traditional major and hones their ability to thrive in a world without givens, to tolerate ambiguity, and to find solutions even when a path is not laid out before them" (Bennington College, n.d.). In the process, they are getting practical experience while making professional connections that encourage them to "discover both their role in and responsibilities to the world" (Bennington College, n.d.).

\section{Brown University. Brown's Open Curriculum} is tailored to students who want "the freedom to study what they choose and the flexibility to discover what they love." They are encouraged to be the "architects of their own education" by developing their own personalized course of study. The idea is that by making students responsible for their own intellectual and creative development, they will become "deeply creative thinkers, intellectual risk-takers, and entrepreneurial problem solvers." Brown expects graduates to leave the university "prepared to thrive as independent, innovative leaders no matter what path they pursue" (Brown University, n.d.).

George Mason University (GMU) is working with Northern Virginia Community College (NOVA) to eliminate transfer barriers for community college students and create streamlined pathways toward bachelor's degree completion in the key sectors of technology, health, and education (George Mason University, 2019). NOVA students with less than 30 credits completed can join the ADVANCE program at GMU and prepare to transfer into a GMU bachelor's program (George Mason University, 2019). NOVA and GMU are collaboratively designing the joint degree pathways in close partnership with employers.

Georgia Tech has also taken significant steps to rethink the traditional university model. The uni- versity advances and implements the ideas around the "sharing, experiential, entrepreneurial, subscription, and partnership" university and strives to be a "Deliberately Innovative Organization," which focuses on whole person education, new advising strategies and methods, and a distributed worldwide presence (Georgia Tech, 2018a, p. $6)$. The overarching focus of their work is a deep commitment to lifetime education that reconceptualizes the university not as a physical place that one enters and exits during predefined life stages but rather as a platform for learners who are diverse across age, socioeconomic status, and other backgrounds.

Grinnell College. At Grinnell, all incoming students enroll in a one-semester, four-credit course known as a First-Year Tutorial. Tutorials are taught by faculty members from all academic departments who then become advisers to their tutorial students until they declare a major field of study. It is the only required class at Grinnell outside of the requirements to complete a major (Grinnell College, n.d.-a). As explained on Grinnell's admissions page:

The rest is up to you. Because as you sharpen your strengths and your passions, you'll also discover all the places your academic interests can lead you. This requires the freedom to explore, along with focused guidance and mentorship for support. So take the lead shaping your studies - and know we'll always have your back (Grinnell College, n.d.-b).

Hult International Business School is focusing lifelong learning efforts on building business, digital, and human skills for learners. Forty-four skills were identified for this portfolio using employment data. For each of these skills a learner can target a desired maturity level. The maturity levels are drawn from the Lumina Foundation 
Model (one to eight levels), with Hult International Business School focusing on the first four levels (novice to independent) (Adelman et al., 2014). Learners can adapt their learning journey based on their current skill level, and the speed and breadth they need in acquiring a new portfolio of skills. The learning is focused on the learner demonstrating "what they can do" beyond what they know via a range of practice and authentic assessment activities.

Northeastern University. As part of its 2025 Plan, Northeastern is developing a network of campuses around the world to provide lifelong learning opportunities to aspiring learners from all walks of life. Each campus is designed to be an intercultural hub for learning and discovery in a distinctly local setting. Learners become "members" of the Northeastern Lifetime Learning Network, which gives them access to the school's professional programs from anywhere in the world wherever they live and work. As members (not limited to Northeastern graduates) they can form customized pathways of learning via nearly 200 master's and doctoral degrees, bootcamps, and certificate programs. Much of the coursework and curricula have been developed in cooperation with corporate and nonprofit partner institutions and can be delivered through multiple channels (onground, online, hybrid). Northeastern describes its dedication to diversity of learning in its mission statement as follows:

Northeastern will expand the range and impact of global experiential learning to include short-term experiences in heavily structured majors such as engineering; semester-long exchange programs with global universities; curriculum-based group projects abroad; and degree programs that incorporate one or two years of study and work in the host nation's language. Learners will also have the option of taking on a project assignment from an individual professional anywhere in our global network to master a specific skill - a flexible alternative to a full course or co-op (2020, para. 2-3).

Purdue University is collaborating with the City of Indianapolis in partnership with community, industry, and academic leaders to bridge the gap between secondary and post-secondary education. This cross-sector partnership resulted in Purdue Polytechnic High School (PPHS). The developers of PPHS recognized that many high school graduates were insufficiently prepared to succeed in technical, STEM-related post-secondary programs and high-tech careers. PPHS was designed to inspire and engage students through an immersive STEM experience that delivers experiential, hands-on learning: "Students collaborate with fellow classmates, coaches, and industry mentors to successfully complete projects that are designed by our industry partners" (Purdue University, 2019). As they develop critical thinking and problem-solving skills - not to mention confidence - they leave high school with college credit, "in-demand industry credentials," and preferred admission to Purdue Polytechnic Institute.

Another way that Purdue is expanding its reach is through its non-profit public online university, Purdue Global, which provides personalized online learning experiences aimed specifically at working adults. Purdue Global concentrates on delivering degree plans that are individually tailored to those with prior learning experiencefrom college, work, and military. By allowing students to transfer eligible prior learning (transfer, experiential, and credit by exam) they can shorten their term of study, increase the value of their prior knowledge, and save considerably on educational 
fees and tuition. Indeed, according to the Purdue Global website, online bachelor's degree students who graduated from Purdue Global 2018-2019 and applied eligible prior learning credits saved an average of $\$ 29,000$ toward the total degree (Purdue Global, 2020). This dedication to adaptive learning has certainly achieved Purdue's goal of serving the educational needs of adult learners who would otherwise not be able to return to a traditional school setting or start new educational pathways.

University of Central Florida (UCF). UCF significantly increased access to its educational programs by partnering with Florida's state colleges (two-year public institutions) on a program called Direct Connect. This program guarantees admission to UCF upon completion of an associate (AA) degree or articulated (AS) degree from one of the partner colleges, which, by policy, admit any high school graduate (University of Central Florida, n.d. -a). Over a decade of experience with the program shows that the graduation rate of Direct Connect has been approximately the same as that for students who were admitted directly from high school. Completion of the associate degree indicates that the student has already demonstrated resourcefulness and resilience. The percentage of UCF diplomas awarded to students from underrepresented groups doubled as a result of Direct Connect. More recently, UCF expanded the Direct Connect concept beyond the region by offering a direct pathway to online baccalaureate degrees from UCF to graduates of partner community colleges and state colleges. In addition, UCF Downtown opened in Fall 2019 as a physical partnership campus in Orlando where students are taught their first two years by Valencia College faculty and complete their degrees taught by UCF faculty on the same campus (University of Central Florida, n.d. -b).
The University of Waterloo. At Waterloo incoming undergraduates can choose an educational pathway that allows them to pursue their interests through a mix of classroom time and "learn by doing" experience. More than 120 courses include labs, and the university offers a co-op program with an extensive list of industry partnerships. For instance, a student who might be interested in a career in health care can choose from a variety of programs that deliver the necessary science foundation while they explore their particular interests in medicine, optometry, pharmacy, etc (University of Waterloo, 2019). It is expected that students will refine their interests over the first two or three years, after which they can apply to the professional program of their choosing.

Virginia Tech (VT). In addition to the examples above, hundreds of colleges and universities have incorporated adaptive learning at the level of an academic unit (department or school) rather than the whole institution. For instance, the Myers-Lawson School of Construction at VT utilizes a cross-sector curriculum with an innovative institutional structure and teaching approaches designed to improve adaptivity, mobility, and access. The School bridges engineering and design education at VT and uses a transformative learning experience approach to change the way that students learn Construction Management (CM). In place of theory-laden, lecture-based instruction, educators create a learning environment that favors visual learning and working collaboratively with facts and data on real world coursework (Holt et al., 2018). This approach allows CM students to reflect on learning styles, which is especially invaluable in cases where students might be struggling in a course because the instructor's teaching style does not align with their learning styles (Holt et al., 2018). 
Western Governors University (WGU) is an online, non-profit educational institution that appeals to working adults with clear career goals (Lohr, 2020). Conceptualized in 1997 by 19 governors wanting to increase constituents' access to higher education by making it more flexible and affordable, WGU operates as a competency-based university (Pichette \& Watkins, 2018). This means that learning outcomes focus on "what students know and can do" and are assessed based on learners' performance of those competencies and/or their project-based learning (Pichette \& Watkins, 2018 , p. 6). Other traits of competency-based education (CBE) offered by institutions like WGU include self-pacing, credentialing for mastery, recognition of prior knowledge, and clear embedding of competencies within the curriculum (Pinchette \& Watkins, 2018). In a Gallup survey, alumni of WGU stated that having a mentor as well as the ability to choose programs they deemed as workforce relevant were two traits that led to their satisfaction (Etherington, 2018).

\subsection{Adaptive Pathways in Industry}

In this section, we highlight a few examples of industry-sponsored programs who apply the principles of adaptive and integrative learning. These companies understand the need for their current and future employees to develop targeted skills and competencies enabling them to meet the demands of an evolving economy. Through providing new learning opportunities that aid both personal and professional growth, they ready their employees to adapt to new changes as well as advance within the company. Each entity singled out below supports an organizational culture promoting employee development because company leadership recognizes that employee development is critical to ongoing operational success.
General Electric Appliances. Through its GROW program, General Electric (GE) Appliances offers open employee workshops that are facilitated by leading experts on curated topics and taught collaboratively by industry leaders - from GE and beyond - as well as learning and development staff. The workshops focus on the four skill domains of self-leadership, leading others, leading teams, and leading businesses that are critical to GE's organizational goals and culture. These broad skills correlate with GE's desired work competencies, and they are the basis for measuring both strengths and areas of development for employees. Most importantly, these workshops engage employees by providing opportunities to apply newly learned content in practical job contexts, thus connecting broad skills development to task performance. Workshop offerings have increased in number and expanded in scope from 2017 to 2019, and many of the courses offer digitally accessible content or products enabling employees to have a blended learning experience.

Boeing. Boeing's approach to adaptive learning is based on designing an internal knowledge transfer system that is enabled through the Boeing Knowledge Network portal. It is capable of sharing information on program execution, research achievements, and process changes while link-

Companies apply the principles of adaptive and integrative learning to assist current and future employees in developing targeted skills, preparing to adapt to new changes, and advancing within the company. 
ing interface users to Boeing designated experts, communities of practice, and resources such as the Boeing Technical Journal. The Boeing Knowledge Network aims to provide continuous training in the Boeing Values-Based Leadership (Boeing 2020) model that is connected to specific educational content focused on the development of multilayer skills relevant to job functions. Some of the specifics are realized through the Degreed program that emphasizes courses in project management, data analysis, and business processes. Additionally, Boeing creates online content that enables employees to pursue various learning certificates. Two examples are the MIT xPRO class on advanced manufacturing and the edX MicroBA programs that will be completely online and cost approximately $\$ 12,000$ per employee. To upskill the non-technical workforce, Boeing has provided a $\$ 10$ million gift to establish a partnership with the National Science Foundation to accelerate training in crucial skill areas for the future US workforce (National Science Foundation, 2018). The resulting grants support design, development, implementation, and analysis of online courses in model-based engineering, model-based systems engineering, mechatronics, robotics, data science and sensor analytics, program management, and artificial intelligence. The intended outcome of the grants is development of learning systems that can maximize their effectiveness for a diverse base of learners.

$A T \& T$ Inc. enables employees to personalize learning to their specific needs and learning goals through a mapped learning system. This enables their employees to identify other jobs within the company as well as sign up for training opportunities that would facilitate advancement within the company. According to Julia Stiglitz of Coursera:

At AT\&T, they have taken all of their job categories, mapped them onto competencies, and aligned them to learning opportunities. Individuals can go onto a personalized-learning system and see if their jobs are on the decline or on the rise. They can discover jobs that they are interested in, see the associated competencies, and take advantage of learning opportunities that will enable them to make a transition. The transparency of AT\&T's system is remarkable and empowering to employees (Alturi et al., 2017, pp. 5-6).

\subsection{Adaptive Pathways that Cross Sectors}

In the previous two sections we highlight examples of adaptive learning programs from the higher education and industry sectors. Here, we draw attention to a number of innovative cross-sector partnerships that are also taking place. These partnerships include $\mathrm{K}-12$, higher education, community, industry, and government. The individuals and organizations in each sector recognize the power of collaboration for the purpose of creating effective adaptive learning programs that meet a range of different needs. Out of these cross-sector partnerships arises research on how powerful cognitive, psychomotor, and social-emotional learning occurs, especially when implementing an inquiry-based pedagogical approach.

Through the National Research Council, we have consensus study reports summarizing research in cross-sector learning and guiding future questions for further inquiry (Hein, 2009; National Research Council, 2000). Most importantly, the council's reports connect cross-sector, inquiry-based learning to society's ability to address complex issues, such as the $21^{\text {st }}$ century workforce, civil society, and issues of inclusion and equity. Cross-sector learning venues collectively cover many aspects of "lifelong, life-wide, and life-deep" learning (Dierking \& Falk, 2016, p. 2). 
Individuals and organizations

spanning $\mathrm{K}-12$, higher

education, community, industry,

and government recognize

the power of collaboration for

creating effective adaptive

learning programs.
The inclusive makeup of these partnerships ensures that individual participants are made aware of the multitude of learner-centered perspectives and needs. An increased awareness leads to pluralistic discourse and adaptive learning ecosystems. Cross-sector partnerships and interdependencies between and among multiple sectors can provide experiential learning opportunities creating virtuous cycles that support learners, industry, and societal development. For clarity of presentation, we divide such partnerships into two subsections. First, we highlight partnerships that involve industry and educational institutions ( $\mathrm{K}-12$ and higher education). Then, we focus on partnerships that span community, industry, and academia.

\subsubsection{Partnerships Bringing Together Industry and}

\section{Education}

Industry and $\mathrm{K}-12$

Located within North Central Kentucky, the Jefferson County Public School District (JCPS) provides a model of cross-sector collaboration. JCPS serves the most populous county in the state and encompasses the City of Louisville. In 2016 school leaders embarked on an ambitious effort to increase awareness of, and access to, pathways outside of the traditional college degree routeeverything from health services and information technology to manufacturing, construction, and hospitality. To do this, they shifted their focus towards graduating learners who were career ready. To make such a focus a reality, they partnered with engaged local businesses and industry, which included GE, Norton Healthcare, United Parcel Service, and Lantech. Out of these partnerships emerged the Academies of Louisville.

The Academies of Louisville launched in Fall 2017 with the mission to "evolve public high school education by equipping students with the skills and $21^{\text {st }}$ century know-how needed to thrive in an ever-changing global economy" (Jefferson County Public Schools, n.d., n.p.). JCPS's academy model requires a high school senior to complete four core courses in a specific pathway of interest combined with access to other work certifications or direct work experiences. The integration of traditional core courses such as history, math, and English into the curriculum round out each student's chosen pathway. The program got off to a good start in the 2017-2018 academic year, with 11 of the 28 JCPS High Schools participating in the new model. Since then, the number of academies has risen to 15 , and business participation has expanded exponentially, from $20 \mathrm{em}$ ployers to over 115 in Louisville. As a result, JCPS now promises that after four years in an academy, students will graduate with:

- Direct career and industry exposure

- Industry and college field trips

- Job shadowing experience

- Junior- and senior-year internships through SummerWorks

- Ability to earn college credits and industry credentials

- Ability to earn work experience through coops or apprenticeships 
- Networking opportunities with local industry professionals

- Success skills and a postsecondary transition plan

The United Way of Southwest Virginia launched the Ignite Tech Talent program to develop a pipeline of industry-specific talent in the region. Their goal is to facilitate learners, beginning with those in middle school, continuing through high school, all the way to community and fouryear college programs, to engage in information technology careers. Potential employers actively participate in each stage of the learning process via career fairs, internships, etc. Learning pathways are chosen by the learner, align to domain specific and transferable skills and provide credit while advancing education. These experiences and education culminate in full time information technology employment. To achieve this, the United Way of Southwest Virginia leverages partnerships across multiple school districts, community colleges, the workplace development board, and industries (United Way of Southwest Virginia, n.d.).

\section{Industry and higher education}

Autodesk extensively partners with secondary and higher education institutions throughout the world. The company has been able to grow these partnerships by creating a dedicated education group, while offering free full versions of all software for students and faculty together with a robust learning platform called Design Academy that enables further collaboration. Additionally, the Autodesk education group forms extensive relationships with developers of external learning platforms while partnering with community college systems and universities for the purpose of supporting curriculum development and integration of making-based pedagogies. Finally, the ed- ucation group launched a major multi-divisional initiative that builds advanced learning and credentialing systems for the purpose of integrating learners' experiences across educational segments and their entire professional lives.

California Polytechnic State University (Cal Poly) and Amazon Web Services (AWS), an Amazon.com company, partner to develop the Cal Poly Digital Transformation Hub (DxHub) to provide learners with real world problem-solving skills while also developing cloud technologies essential to addressing the digital transformation changes in government, education, and non-profit sectors. What makes DxHub unique from Amazon's point of view is that it is "adapting the AWS innovation process to engage communities of stakeholders, AWS resources, and Cal Poly and California State University subject matter experts to quickly understand problems from the viewpoint of the customer and then formulate solutions that address those needs" (Cal Poly, 2019, n.p.).

ASU established a partnership with Starbucks in order to provide tuition-free higher education to eligible company employees. The program provides full tuition reimbursement for over 80 degree programs. In a similar vein, FedEx partners with the University of Memphis to offer new pathways for their employees, $50 \%$ of whom do not have credentials post high school. As part of the program, eligible employees can earn high school equivalency credits as well as college degrees.

The Louisville chapter of the Kentucky Federation for Advanced Manufacturing Education (KY FAME) represents a partnership of regional manufacturers whose goals are to implement career pathways and apprenticeship-style educational programs that create highly-skilled workers for the $21^{\text {st }}$ century. The KY FAME model allows associated manufacturing employers to hire employ- 
ees to work three days a week while attending a local educational partner for two days a week. Over a period of two years, the goal is for the employee to simultaneously earn an associate's degree while gaining valuable work experience. Additionally, the college credits earned by the employee are transferable to a four-year college degree, thus providing an additional pathway for the employee.

During the formation of KY FAME Louisville, partners from manufacturing sought an ideal academic partner that would be local in proximity and dually serve as support for learners and also the community. They chose Jefferson Community and Technical College (JCTC) as a key partner. JCTC responded by rapidly developing and implementing an advanced manufacturing technology curriculum. This reciprocal partnership serves both the college and industry by providing workplace opportunities for learners while aligning with local industries' needs. In doing so, KY FAME generates a reputation for developing workers that meet $21^{\text {st }}$ century skill requirements. Since 2015 the program has grown to 50 annual participants. Likewise, the community college will open a new facility in Fall 2020 dedicated entirely to advanced manufacturing.

Cross-sector partnerships may span both local and national dimensions. For example, Advanced Robotics for Manufacturing (ARM), headquartered in Pittsburgh, the home of Carnegie Mellon University's (CMU) National Robotics Engineering Center (NREC), serves as the nation's largest learning collaborative in robotics and workforce innovation. ARM and CMU partner to build the CS-STEM Network (CS2N), an inexpensive, custom-built learning management system (LMS) to address national workforce development issues (Carnegie Mellon Robotics Academy, 2020). In order to close the gap between needed skills by in- dustry and future graduates with aligning interests, the platform provides flexible, robust learning that provides obtainable skills directly related to robotics work. This platform allows educators and industry representatives to easily integrate new content. CS2N updates existing pre-apprenticeship community-college level certifications and associate degree programs from across the nation to address the evolving needs of its industry members. CS2N also allows for "customizable online training materials that are available $24 / 7$, micro-certifications that guide students toward a certification, the ability for instructors to create classes, and automated assessment features that enable instructors to track students' progress" within the LMS (Carnegie Mellon University, 2019, n.p.). Through the $\mathrm{CS} 2 \mathrm{~N}$, learners are able to track personal progress, peer assess work, and share accomplishments on social media networks, personal web pages, or with colleagues.

FirstBuild based in Louisville, Kentucky and backed by GE Appliances, identifies as a "co-creation community" that serves as a cross-sector partnership model between the greater Louisville community and GE Appliances. By moving part of its innovation process beyond its brick and mortar location to an open community of practice, where community members learn to design and innovate through participation in a makerspace, GE helps to grow community talent and gain insight for innovation, beta testing, marketing, and manufacturing on behalf of its design department. As GE's projects undergo the feedback cycle with the local community, the company harnesses the resulting collective knowledge for product improvement.

In the greater Washington, D.C. metropolitan area, Alpha Corporation (Alpha), a woman-owned engineering and construction consulting firm, has focused on building forums for cross-sector col- 
laboration between startup communities, state and local governments, academic intuitions, and other stakeholders in the built environment. This initiative has emphasized providing practical and mutual opportunities for education, ideation, and commercialization to organizations across the highly complex and often 'slow-to-adapt' design and construction industry (Agarwal, Chandrasekaran, \& Sridhar, 2016). In taking this approach, Alpha looks to bridge the gap between theoretical solutions and industrial value by increasing project-based learning environments to support buildings, civil infrastructure, transportation, and utilities. This work has led to the creation of academic and commercial partnerships to foster the increased integration, implementation, and adoption of digital solutions across architecture, engineering, construction, and project controls.

The Northern Virginia Smart Region Initiative (NVSRI) focuses on strengthening the regional technology cluster in Northern Virginia through collaborative learning for professionals, and in 2019 received an i6 Grant from the US Economic Development Administration (EDA). NVSRI brings together local and national stakeholders in the design and construction industry from across the Northern Virginia region. These stakeholders include Arlington City and the City of Fairfax, Virginia Tech, Northern Virginia Community College, Amazon Web Services, Alpha, the Center for Innovative Technology (CIT), Smart City Works startup actuator, Refraction coworking community and Cushman \& Wakefield. Together, NVSRI is focused on mitigating the risk profile of early-stage construction and property technology startups throughout the region, while at the same time enabling easier access to project-based resources and pilot opportunities (Smart City Works, Inc. et al., 2019; "Northern Virginia Smart Region Initiative," n.d.). As a result, early-stage organiza- tions working to navigate the complex value chain of the built environment have a clearer path to realization while existing industry stakeholders are able to better understand the advancements and changes to the industry.

\subsubsection{Community, Academia, and Industry}

Community partnerships integral to diversifying and innovating learning pathways

The Institute for the Future's (IFF) 2019 book, Partnership Power: Essential Museum Strategies for Today's Networked World provides guidance for museum professionals wishing to create and sustain effective learning partnerships and collaborations. As such, the institute, located in Palo Alto, California, collaborates with the Cincinnati, Ohio-based non-profit KnowledgeWorks to produce regular "navigating the future of learning" forecasts that identify drivers of change, thematic provocations related to each driver, and examples of actual projects currently addressing these drivers (KnowledgeWorks Foundation, 2020). Similar collaborations that use systems theory as a foundation and have a goal of creating collective impact have the ability to span geographic location for the purpose of addressing complex challenges related to today's rapidly changing world.

Universities have much to contribute to their communities, not only by building town-gown relationships but also by actively engaging through community service and volunteerism. One such example is Fort Valley State University's iHelp Center. The iHelp Center is working with a network of community partners to "flood the streets with iHelp scholars and volunteers" (iHelp Center, 2020). The university aims to address genuine needs in the community while improving student retention by making volunteerism compulsory (Association of Public \& Land Grant Universi- 
ties [APLU], 2019). Using the concept of "communiversity," iHelp prepares students to be service-centered leaders of the future (iHelp Center, 2020). Community needs are also being addressed through a partnership between the local University of California, Riverside; the Community Foundation; and Riverside Unified School District. The partnership provides service-learning opportunities and community-based academic internships for students, while providing the university with a better understanding of the Riverside community, thus increasing its capacity for affecting positive change within the region (APLU, 2019).

\section{Community support for non-traditional learners}

Wayne State University partners with the Detroit Regional Chamber of Commerce and other community stakeholders to re-engage adult learners who have completed some college but left school prior to degree completion. This partnership serves that specific audience by providing new information and resources regarding higher education opportunities in the area. Using artificial intelligence, prospective students use the platform to ask questions about college 24/7 through Facebook Messenger. This effort is part of a much broader partnership between Wayne State University and the Detroit Regional Chamber that supports adult learners in making progress toward the Detroit-wide goal of boosting college attainment (Lumina Convening, 2019; Wayne State University, 2019b).

In Northeast Ohio, Cleveland State University and College Now Greater Cleveland collaborate on a grant-funded project called (Re)Connect to College, designed to help "comeback" students earn their degrees. Together they identify students who left the university before graduating and help them re-enroll. Students who might have left school due to affordability issues can receive fi- nancial assistance. Once they are re-enrolled, students have access to bolstered academic advising, which helps keep them on track toward a degree (APLU, 2019). Not only does this program benefit students, it helps the Cleveland area by increasing the talent pool for local employers. After helping 230 former students return to their studies in its first year, (Re)Connect to College is now scaling up its efforts by implementing targeted outreach strategies using historical data; providing more comprehensive student support services; tracking employment outcomes for participating students; and developing new models for broadened outreach to students with some college credits but no degree, including students who did not attend Cleveland State University (APLU, 2019).

The Phoenix Rising Initiative at the University of Lynchburg is a grant-funded workforce program for young adults ages 18-24 who have been involved in the criminal justice system and thus are seen as disengaged youth. The program utilizes the Gallup StrengthsFinder assessment to determine the participants' talents and strengths. Each participant is then connected to Journeys, an online interface for career and technical education, to explore career options (Journeys, n.d.). The "journey" is undergirded with a curriculum, co-developed for Phoenix Rising by Edmin.com and The Learning Company in Durham, North Carolina.

The Journeys Map App was designed based on the realization that there is a high ratio in $\mathrm{K}-12$ of students to career counselors, specifically about 482 students to one counselor, and that many students are in danger of being left behind in terms of career guidance (American School Counseling Association, 2015). Journeys is a learner-centric platform designed to create personalized and highly relevant pathways based on an individual's interests, strengths and skills. Journeys also serves 
as an aggregator of data from a wide range of sources to ensure learners of all ages can explore their options. Examples include O*NET OnLine, College Scorecard, and Indeed.com so that a large amount of data is provided with each search result.

\section{Non-profit-led cross-cutting partnerships for sharing resources}

The Association of Public and Land Grant Universities (APLU) has a number of commissions that bring together representatives from across member universities to address critical issues of the day. The Coalition of Urban Serving Universities (USU) serves as one such commission. USU is a network of public urban research universities that leverages the intellectual capital and economic power of their institutions in order to improve their communities. "Guided by the belief that public urban universities are anchors in their regions, USU undertakes a variety of efforts to build a skilled workforce, drive robust economic growth, address inequities, and enhance community sustainability. To achieve these aims, USU institutions partner with key stakeholders in their communities such as $\mathrm{K}-12$ systems, local businesses, health systems, workforce organizations, community organizations and philanthropic foundations" (Association of Public and Land Grant Universities \& Coalition of Urban Serving Universities [APLU \& USU], n.d., n.p.).

One way the APLU-USU partnership advances its goals is through Collaborative Opportunity Grants (COGs), which support public urban universities working to advance student success, degree completion, and community transformation. Institutions awarded COGs undertake a variety of nascent reforms touching virtually every aspect of the student experience to establish the environment necessary for students to thrive. All COG efforts must center on collaboration between a public university and an external organization such as another university, community college, school district or local government (APLU, 2019). All COG projects must align with at least one of five priority investment areas: Strengthening the $\mathrm{K}-12$ pipeline; rethinking financial aid; engaging faculty; partnering with employers and workforce organizations; and leveraging community assets (APLU, 2019). Since 2017, APLU and USU have awarded grants to 19 institutions. Of those, 14 invest in some type of partnership that focuses on three issues related to adaptive learning through cross-sector approaches: Building new pathways; better integrating experience into the curriculum; and creating better transitions in and out of school (APLU, 2019).

Ithaka $\mathrm{S}+\mathrm{R}$ is a non-profit organization that provides research and strategic guidance to help the academic and cultural communities serve the public good and navigate economic, technological, and demographic change. The organization partners with higher education institutions, consortia, state systems, philanthropies, and other education organizations to collaboratively design and evaluate projects that make higher education more accessible to diverse learner populations. The Adaptive Learning Statistics (ALiS) is one example of Ithaka S+R's work. In 2017, Ithaka $\mathrm{S}+\mathrm{R}$ co-led a multi-year pilot initiative in Maryland which brought together faculty from multiple two- and four-year institutions to develop and adopt a common adaptive learning courseware to teach introductory statistics using active learning and flipped classroom pedagogical approaches. The details of the project findings and lessons can be found in the final report (Joo \& Spies, 2019). One lesson worth highlighting is that the cross-institutional collaborations created by the pilot enriched ongoing conversations about improving math education, both within and across the partic- 
ipating institutions. The project also contributed to the statewide discussions around developing and sharing of openly licensed instructional materials and resources among faculty across Maryland colleges and universities. Ithaka $\mathrm{S}+\mathrm{R}$ also recently released a playbook on how to develop successful collaborative networks in and around higher education to drive systemic change that will have potential for far-reaching social impact (Joo, Selingo, \& Alamuddin, 2019). The playbook provides a conceptual grounding for large-scale collaborative networks that tackle cross-cutting challenges of student success, economic mobility, and racial and socioeconomic equity. It also unpacks a set of critical steps for starting and sustaining successful networks, with rich examples from the field to illustrate.

An Achievable Dream (AAD) is a unique collaboration among public school systems and community and corporate partners in Eastern Virginia. AAD, Inc., a 501 (c)(3), promotes the educational success of students that have been identified as requiring additional interventions due to social risk factors. AAD provides a holistic approach to education for those students who will best benefit from extended learning time, social and moral learning, additional enrichment experiences, additional technology, and parent/student contracts. AAD recruits and coordinates broad-based collaboration with health systems, local military, fire department, emergency responders, law enforcement, colleges and universities, sponsoring corporations, families, local parks and recreation, local businesses and civic groups, and private donors. Students in these schools score as well as, or higher than, other students in the state of Virginia on the state's Standards of Learning (SOL) exams. Other outcomes include a $100 \%$ graduation rate with the majority of students enrolling in honors or Advanced Placement courses during their high school careers. Of these students, 95\% attend college and $5 \%$ enter the military. Members of the class of 2017 received \$2 million in scholarship funds (Results, 2020).

CMR Institute, a non-profit healthcare education organization in Roanoke, Virginia, leverages a variety of delivery strategies to provide partners in the pharmaceutical and life sciences industries with flexible, customized, and continuous learning opportunities. The CMR catalog of over 100 eLearning courses is extended through a variety of instructional approaches, including microlearning, podcasts, videos, webinars, and the option of in-person specialized workshops. In addition to supporting industry partners through innovative, technology-mediated strategies, CMR has also collaborated with higher education institutions to develop credit-bearing learning programs for industry professionals.

\subsection{On-Ramps and Off-Ramps}

The development of various new pathways between institutions, industry, community, and government cannot be implemented without due consideration of viable on-ramps and off-ramps that facilitate transitions and cross-sector interdependencies for supporting learners' extraneous needs (Weise et al., 2019). On- and off-ramps need well-designed entry and exit points in order to (a) advance learners' economic mobility in the short and long term, (b) supply high-demand industries with skilled workers, and (c) catalyze change within society to re-envision traditional pathways and redesign the structures that exist for a broader array of learners (especially income constrained learners and workers). These on-ramps consider their learners' needs with wrap-around support systems such as transportation, childcare, career navigation, basic needs, and financial aid. Onramps also acknowledge the need for a core cur- 
riculum for bridging or upgrading, as well as other forms of professional development. Ramps need to encompass re-engagement services and strategies that would enable learners to achieve learning goals as they require them through on-the-job experiential learning, competency-based assessments, and integration of career and academic planning (Weise et al., 2019). Ultimately, ramps bridge gaps between sectors and help leverage partnerships to develop greater access and mobility. Many of the cross-sector pathway examples in this report are effective because of built-in support mechanisms developed as integral parts of the innovative changes being implemented.

\subsection{Expanded Access and Reduced Cost}

In order to create successful knowledge democracies that can cross all sectors of society, there must be effective intercommunication, exchanging of resources, and strong interdependent relationships. Essentially, sectors operating in silos need to reach out and start dialogues about how they can support accessibility to knowledge for all their constituents. The examples given in this chapter show that such collaborations already exist and succeed while significantly advancing inclusion. If a learner is unable to afford an institutional pathway such as a traditional four-year college degree, there are alternative paths that offer equal value at a significantly reduced cost across different sectors.

The cost issue must be faced head on, particularly because historically high income and wealth inequality directly impact many learners' opportunities to access the education they need (Charlotte Report; Haveman \& Sneeding, 2006). Education is no longer required only for the advantaged few in the knowledge economy (APLU \& USU, 2019). Instead, certain levels of training or learning are a required necessity to work, live, and contribute. Too many present-day institutions focus on the overserved and well-educated populations of America, which makes them unaffordable to a large swathe of prospective learners (Goldrick-Rab, 2016). As The New York Times put it in a recent opinion piece, the cost of college is "far greater than [even] tuition," with many people deferring significant life events such as marriage or homeownership as a result of student loan debt, and many people completely forgoing further education altogether or seeking alternatively undervalued pathways to learn (Is It Still Possible to Pay for College?, 2019, para. 1). New financial models that allow a diversified learner population to access affordable and more flexible learning opportunities will decrease barriers to various modes of learning and to the overall knowledge economy.

Inclusion necessitates varied pathways with alternative cost models as well as expanded admissions models for accommodating a more diverse learner population and many types of personal knowledge. Even moderate adaptations to admissions criteria and processes that are combined with support structures for different types of learners can have significant effect on inclusion. ASU, for example, is moving towards an earned admission model. Instead of paying tuition up front or producing proof of suitability to study at the institution, ASU provides courses online to progress towards admissions to an ASU degree. To enroll, ASU requires no transcripts, no formal application, and eight weeks of time to complete a course.

Inclusion necessitates varied pathways with expanded admissions structures and new financial models. 
The most significant aspect is that ASU does not require payment for a course until it is completed and passed by the student, which reduces the risk and financial stress associated with applying for a traditional four-year degree. Earned admission allows students who have exited traditionally restrictive educational pathways with debt and low GPAs to access learning on their own terms. Students can pursue a pathway of their own choosing while demonstrating the ability to succeed based on personal merit and motivations. Moreover, when a student achieves admission to ASU, earned admission credits are transferred towards the degree pursued.

Purdue Global's access model is saving its students significant amounts of money by allowing the transfer of non-traditional credit via portfolio assessment. In 2018, incoming Purdue Global students who passed EL206 and submitted a portfolio for evaluation earned an average of 33 quarter credit hours toward their Purdue Global undergraduate degrees. The National University of Singapore presents another example of rethinking financial as well as access models across an ecosystem of institutions. In 2018 the university's programs were reassessed and restructured with several other local universities in eight priority or emerging industries to provide better enrollment access and reduced the financial burden for current students and alumni (APLU \& USU, 2019). A number of American universities are implementing adaptive approaches to admissions as well as cost structures - including the UCF, Georgia State, and the University of Maryland, Baltimore County (UMBC) - with a positive impact on the diversity of the student body as well as completion percentages (Georgia State University, 2019).

Another important way to rethink educational costs and access is through Open Education (OE).
OE has increased access to various pathways and affordable learning credits by reducing direct material costs for the learner. One of the most promising aspects of $\mathrm{OE}$ are Open Educational Resources (OERs) - free textbooks and other learning resources that can be retained, reused, revised, remixed, and redistributed (Bliss \& Smith, 2017) thanks to the use of open licensing (e.g., Creative Commons). Many US institutions are implementing OER usage through new approaches to instructional design. Librarians across institutions in the US digitally curate OER repositories and promote usage of the materials in professional development workshops for faculty. As a result, OERs are saving learners millions of dollars per annum in higher education (Bliss \& Smith, 2017).

\subsection{Cross-sector, Learner-Centric Credentialing}

A key feature coming out of the cross-sector paradigm shift that we propose is the need for a transparent system of credentialing. The fast-paced and changing nature of the $21^{\text {st }}$ century economy requires it. Learners at all life stages must be able to skill up or re-skill quickly in order to smoothly transition in, out, and across the workforce. This is only possible if there is full transparency when it comes to documenting skills attained from learning experiences. One assumed way to achieve this is through stackable credentials or badges earned in competency-based frameworks. Collins and Halverson (2018) explain that eventually course streams and disciplines could be streamlined to reflect the competencies needed for jobs. Instead of earning a degree, a learner would earn stackable badges or credentials that employers require for certain sectors (Collins \& Halverson, 2018).

Stackable badging, however, is only one way to reimagine credentialing - and it is limited by the fact that it tends to reify internal institutional 
credentialing issues. We need to shift the growing interest in developing new forms of credentialing beyond the narrow scope of training task performance or building specialized skills. Portable credentialing should address integrative personal and professional development (see Chapter I) and encompass sectors beyond the confines of academic institutions. If the goal is to increase access and build seamless, integrated, and customizable education and training pathways across sectors, then a shift to competency-based or skill-based learning is only a partial response to placing the learner at the center of transparent credentials. Lee Rubenstein stresses the importance of alternative and learner-centric forms of credentialing:

Leaders need to understand and value the alternative credentials that are available. If I'm an employer, I need to be saying, "Here are the 12 competencies that I need you to get. I don't care where you get them. You don't need to spend $\$ 200,000$ in four years to go do that. You just need to show us some proof" (Alturi et al., 2017, p. 4). The idea that you enter at the bottom and four-plus years later you end at the top and you're done is a fiction. It doesn't mean anything anymore. Learners need to be able to enter at any different point along the way, take what they need, and get going to do whatever it is they wanted to do. We have to try to find a way to help alternative credentials become a currency among learners that is respected and valued by employers (Alturi et al., 2017).

The learning transcript is currently owned and determined by the institution from which a learner has graduated. To advance inclusive and integrative personal knowledge, we must ask if there can be a common platform for learners to: (a) earn credentials, (b) organize and own the record of their credentials, and (c) carry their credentials from sector to sector throughout their lives (Whitney, 2010).

A major concern of alternative forms of credentialing is how to prove skill attainment and ensure quality and mobility of control. To address these issues, the University of Melbourne is developing a blockchain-based credential system designed and owned by learners (APLU \& USU, 2019). Blockchain algorithms secure credential information, learner data, and ensure the survivability of the learning record, allowing learners to own their academic records and achievements and successfully track them over multiple institutions and many years (Knowledge Media Institute \& The Open University, 2018). A unique feature of blockchain is the ability to let learners post their verifiable learning artifacts such as a video clip, a piece of music, or a computer programming code, which can provide instantaneous audio and visual evidence of a learner's mastery and proficiency of certain knowledge subjects and skills. Blockchain can be used to provide a sharable and verifiable learning transcript that incorporates digital badges, certificates, awards, and micro-credentials alongside transcripts. Other cooperatives such as the Digital Credentials Consortium (DCC) led by MIT are also focusing on transparency of learner records. Comprising nine universities from five countries, DCC is working to create a shared platform and standards to issue and verify what students have learned across sectors - not just the educational institutions that they might have attended (McKenzie, 2019). In both examples, the goal is to increase reporting of skills attained across sectors and depict learning that engages both personal and professional development.

A number of organizations and higher education institutions are exploring the possibilities of 
broader based, all-encompassing platforms for credentialing. For example, the American Association of Collegiate Registrars and Admissions Officers (AACRAO) and the Association of Student Personnel Administrators (NASPA) channel the idea of electronic medical records (Green \& Parnell, 2017). Reasoning that if an electronic medical record can follow a patient throughout the medical system, then it is possible for an educational equivalent to track and detail all experiences and knowledge from various activities in work, education, and community interaction (Whitney, 2010). Known as Comprehensive Student Records
(CSRs) or Electronic Learning Records (ELRs), the AACRAO and NASPA published a report in 2017 for pilot projects in several universities on CSRs (Green \& Parnell, 2017). The results indicate that CSRs demonstrate a broader set of competencies and skills to employers while easing employer risk in hiring. Most important, CSRs emphasize learner access and control of their transcript while allowing for transparency in educational reporting throughout a learner's lifespan (Green \& Parnell, 2017). While research is in its infancy, the good news is that interest in and need for these platforms is growing. 


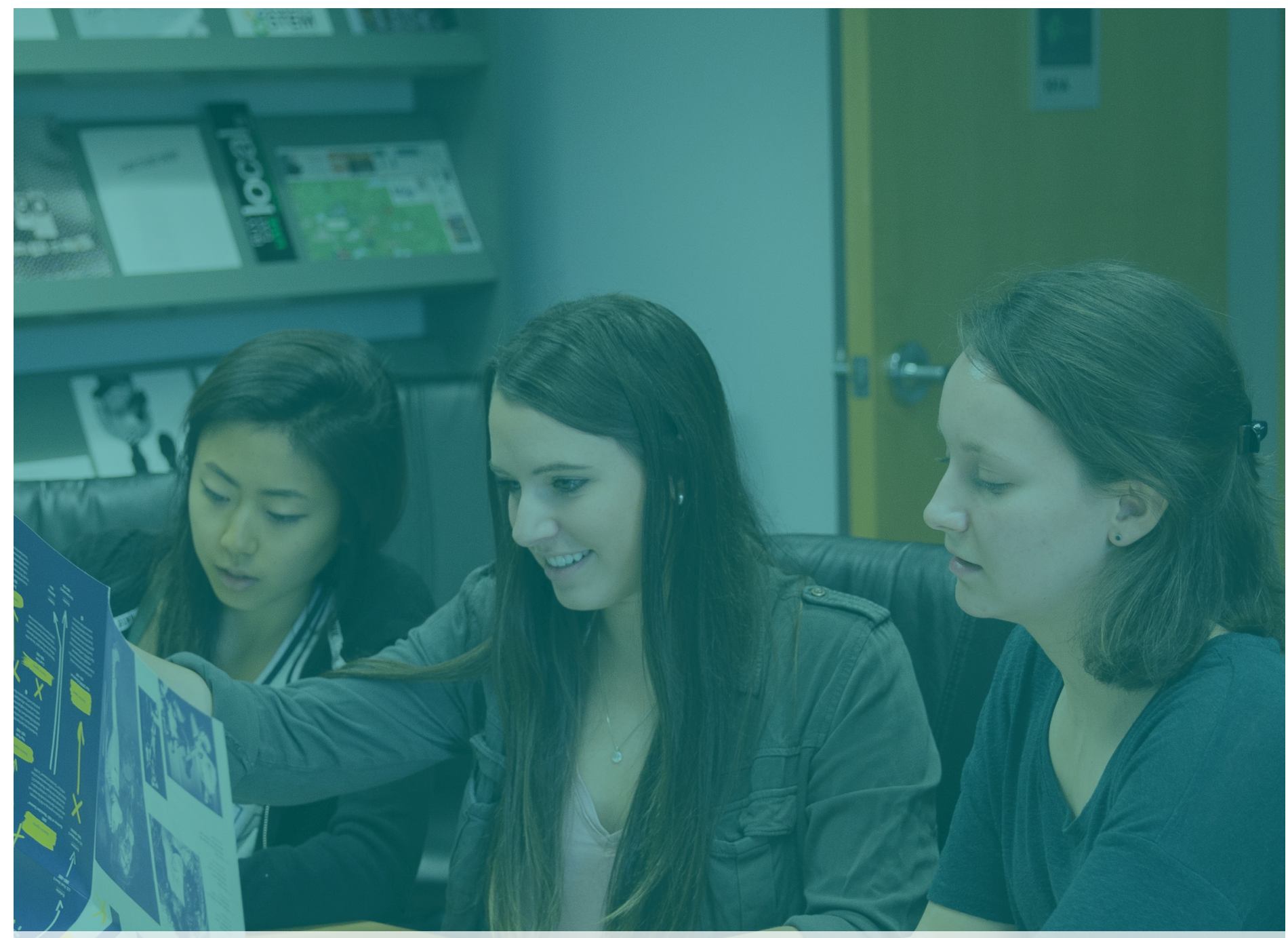

Chapter IV:

Point of Need Learning and Inclusive Learning Societies

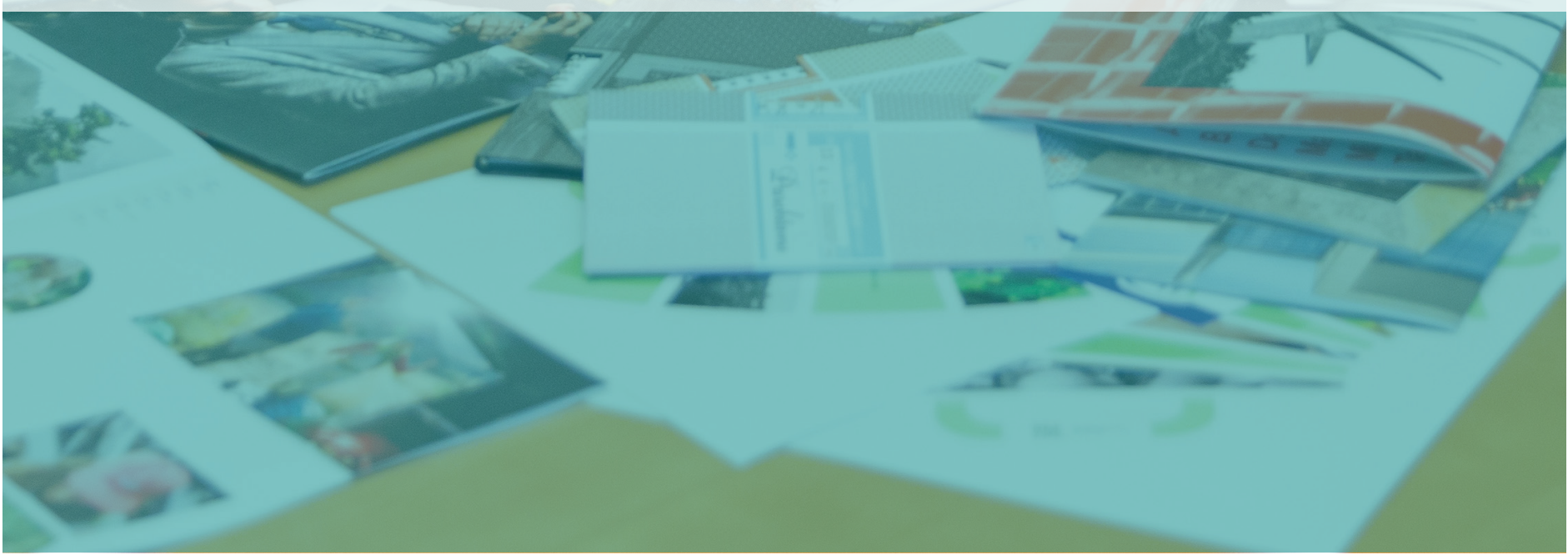




\title{
CHAPTER IV
}

\section{Point of Need Learning and Inclusive Learning Societies}

\author{
Authors: Jared Keyel, Thanassis Rikakis, Anne Khademian \\ Contributors: Todd Nicewonger, Sylvester Johnson, Dale Whittaker, Michael Richey, \\ Taran Cardone, Rebecca Clark-Stallkamp, Catherine Amelink, Ralph Hall, Matt Holt
}

W e conclude this report by returning to the theme of social inclusion. In previous chapters, we have discussed the interconnected nature of inclusion, adaptation, and integrative development. Figure 4.1 shows how this interconnectedness works in practice: Learning environments that leverage inclusive, relational knowledge provide support for the integrated professional and personal development of individual participants. Integrative development brings forth the different skills, competencies, and aspirations of learners, which drives learning adaptation. Adaptation supports difference, thus creating diverse relational contexts.

Throughout this report, we have elaborated many promising examples of individuals, organizations, and institutions working to implement adaptive lifelong learning. However, each of these examples on its own presents only one piece of the puzzle. What is necessary, we believe, is a paradigm shift in social inclusion spurred by the wide adoption of integrative and inclusive adaptive lifelong learning. Indeed, given sufficient time, wide adoption of these learning practices can address one of the many crucial dimensions that lead to the emergence of inclusive learning societies (Rees \& Bartlett, 1999b; UNESCO, 2000).
Developing learning societies in which members are committed to lifelong learning for all requires addressing a number of complex challenges. It necessitates, for example, understanding and addressing the linkages between learning, health, nutrition, and a safe environment (UNESCO, 2000). It also requires work at all levels and within all sectors of societies to rectify inequalities based upon gender, race, class, ethnicity, and religion (UNESCO, 2019). Serious and ongoing questions concerning the appropriate combinations and safe deployment of technologies, how to train and support committed educators, and how to create high-quality learning materials must all be addressed. Governments, industry, and civil society each have parts to play in the funding and development of learning throughout the lifespans of all members of society. Moreover, the established missions and related value systems of educational institutions also need to be examined.

In the remainder of this chapter, we explore what it will take to get us on the path to a paradigm shift in social inclusion. We propose leveraging existing and emerging cooperative learning communities that engage all layers of skills in our Integrative Professional and Personal Development (IPPD) model. The next step is to create Point of 
Figure 4.1

\section{Inclusion, Integration, and Adaptation are Interrelated}

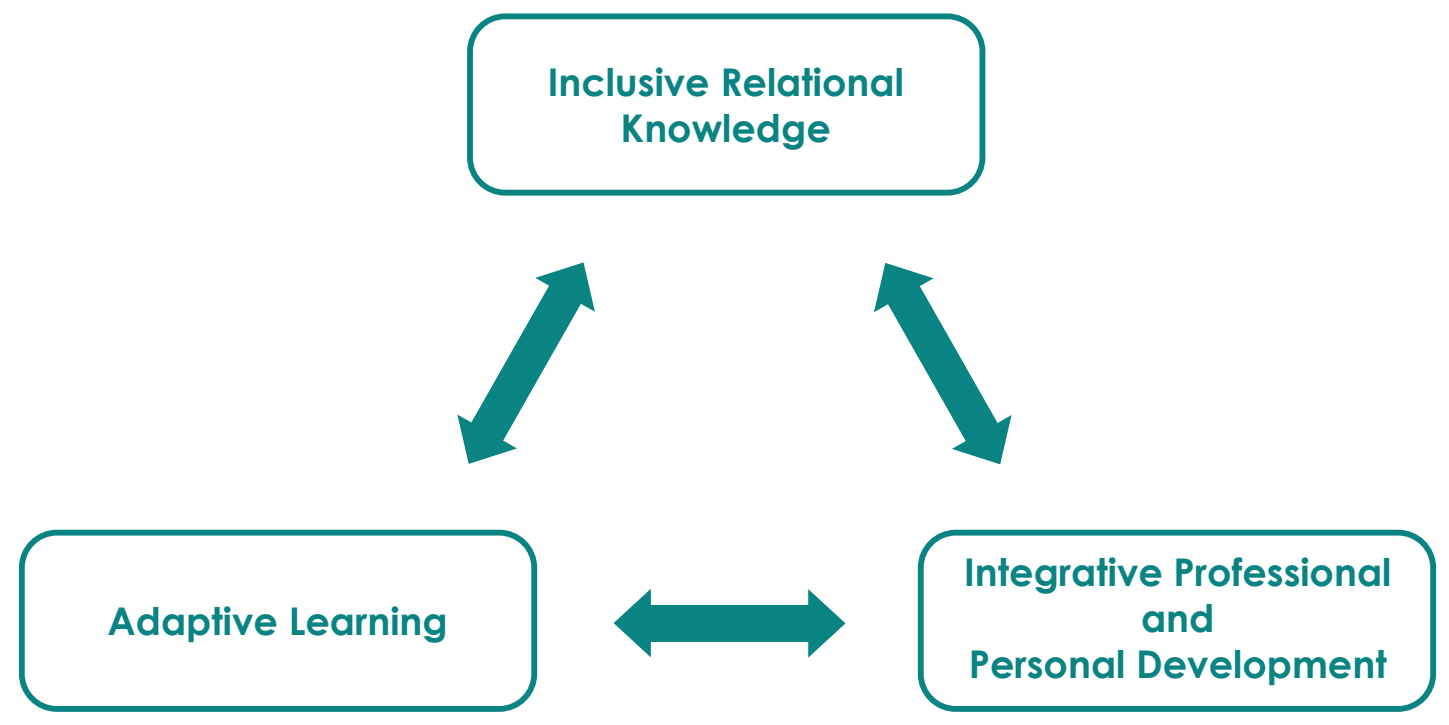

Need Learning Platforms (PNLP) that can begin to connect smaller communities of integrative learners into inclusive, adaptive learning networks. The interaction of novel learning practices in these networks with established practices from existing organizations can disrupt the current paradigm and gradually lead to societal change and an inclusive knowledge economy.

\subsection{Participatory Knowledge and Flatter Organizations}

If learning and knowledge practices are to change, it is vital that we expand our understanding of knowledge. We must move beyond societal and organizational biases that favor only outcome-based, institutional, and standardized knowledge and instead engage with the full spectrum of knowledge and its varied types and manifestations (Hope \& Martelli, 2019). Inclusive learning societies, as we envision them, are built upon the process of participation in learning. Members of a learning society seek to embody process-oriented creation and dissemination of knowledge. As a result, participation in itself becomes a form of knowledge. Adaptive learning practices that incorporate participation as a means of addressing diverse personal knowledge needs have a much better chance of identifying - and valuing - all types of knowledge. This, in turn, increases inclusion, which leads to further adaptation.

Pateman (1970) notes that as far back as the $18^{\text {th }}$ and $19^{\text {th }}$ centuries, thinkers including JeanJacques Rousseau and John Stuart Mill held that democratic participation throughout society is itself a form of education. Both philosophers understood that participation - control over the process and outcomes of the decisions affecting one's life - can teach citizens to better understand the viewpoints and needs of others. In fact, the more one participates, the better able one is to do so. Daily interaction, dialogue, and co-creation with others can open up new possibilities for pursuing and developing a wider array of knowledge and achieving self-actualization. Crucially as well, studies have shown that individuals are happier 
and have higher levels of satisfaction when they can participate deeply in the creative endeavors of their workplace (Knudsen, Busck, \& Lind, 2011; Pateman, 1970; Rothschild-Whitt \& Whitt, 1986).

Learning through the process of inclusive participation leads to relational structures that are flatter, less rigid, and less hierarchical than traditional organizational approaches to knowledge. Because everyone is learning from everyone else, the interactions and organizational structures become less hierarchical. Knowledge, in such settings, is not viewed as power but rather as a fundamental building block of inclusive growth. The more each member of the community knows, and the greater access each has to knowledge co-creation, the better off all members become (Rothschild-Whitt, 1979, 1986). Less hierarchical modes of interaction can create a virtuous cycle in which individuals are able to learn with a commitment to valuing and working across multiple knowledge practices, and continue to build deeper capacities to do so from their engagement with others (Pateman, 1970). This builds reciprocal trust in and between learners and learning institutions while facilitating community building and the emergence of inclusive learning societies. Because these societies focus on the process of inclusive participation and therefore facilitate much flatter interactions and relationships within and across organizations, they

\section{Inclusive learning societies} are built upon participation in learning, which leads to flatter, relational structures that incorporate a much wider set of experiences.

incorporate a much wider set of experiences. As a result, this diversity of experiences, approaches, and understandings creates richness and dynamicity. When members exist and interact in the midst of complex and diverse networks, dialogue begins to emerge that crosses and transcends boundaries and fundamentally deconstructs pre-existing presuppositions (Osborne, 2015). Having said this, it is important to explain that we are not arguing against outcome-based knowledge practices. Rather, we are proposing that communities that achieve inclusion through participatory processes are also able to produce transformative outcomes (Page, 2007; Schuler, De Cindio, \& De Liddo, 2015).

In the Introduction, we presented a four-dimensional model of inclusive knowledge. We can now add to this model a fifth, organizational dimension. If we think of organizational forms and practices as existing on a continuum, then at the

Figure 4.2

\section{Continua of Inclusive Knowledge}

\author{
Outcome-focused \\ Institutionalized \\ Segregated \\ Standardized \\ Hierarchical
}

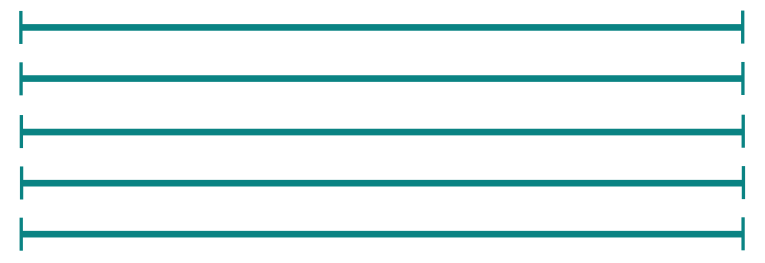

Process-focused

Personal

Integrative

Adaptive

Cooperative 
far left we would find strictly hierarchical structures under which members have rigid, narrowly defined roles and tasks and all decision-making processes flow from the top down. At the far right, we would find organizations with completely flat structures in which every member has equal opportunities for participation. Although the majority of current organizations occupy the middle to left side of this continuum, a growing number of organizations are experimenting with practices on the right side of the continuum (Democracy at Work Institute, 2018).

\subsection{Communities of Integrative Learners as Pilots for Learning Societies}

Communities of Practice (COP) embrace characteristics that span the full breadth of the five dimensions of our knowledge representation, with emphasis on the right side of the continua. COPs are social networks that develop a shared knowledge base and adopt a core practice or initiative (Barab et al., 2002; Wenger, 1998). Learning is bi-directional between novices and experts, thus promoting flat and diverse peer-to-peer relational structures. Participatory learning leads to dynamic concepts of the practices that facilitate further inclusion and adaptation. Collins (2006) argues that COPs have historically existed in cultures where apprenticeship was a key means of learning new skills or competencies. Today, communities of practice exist both online and in traditional mediums. One type of COP that has gained a lot of attention recently is the maker community. Maker communities bring together practitioners from all sectors of the knowledge economy in an effort to connect age-old learning through crafts with some of the most cutting-edge fabrication and knowledge-sharing technologies. They are also defined by their emergent making practices rather than the homogeneous practices of a specialized cohort (Galaleldin \& Anis, 2017). Through their inclu- sive processes, maker communities as a whole are beginning to redefine manufacturing for the $21^{\text {st }}$ century (Schmidt, 2017).

The desire for integrative approaches to grand societal challenges has led numerous universities to explore transdisciplinary and trans-sectoral COP over the past 15 years (National Academy of Science, 2004; Popowitz, 2018). In her 2008 paper, Klein identifies three main clusters of interdisciplinary and transdisciplinary discovery: (1) international networks of interdisciplinary research, (2) transdisciplinary team science, and (3) transdisciplinary, trans-sectoral problem-oriented research with stakeholders in society. Realizing cluster three is particularly challenging because of its trans-sectoral nature, heterogeneity of practices, and expanded notion of expertise (e.g., expertise can arise from experience as well as formal study). Traditional organizational structures in academia are almost orthogonal to these approaches. Therefore, academia is adopting COPs as a pathway for jump starting much-needed trans-sectoral, transdisciplinary activity within higher education (Crow \& Dabars, 2015; ESSENCE, 2016).

Over the past 50 years, transdisciplinarity has tended to be seen as a pluralistic, process-focused practice that can synergize with and continuously deconstruct (contextualize, decontextualize, and recontextualize) the disconnected, domain-specific practices of academia (Derrida, 2004; Foucault, 1969; Nicolescu, 2002; Osborne, 2015). Contextualizing specialized work within dynamic multi-perspective discourse is seen as a promising avenue for collectively addressing complex societal challenges (Darberllay, 2015). As early as 1972, Jantsch proposed a transdisciplinary university that he conceptualized as a four-layer hierarchy moving from the specific to the general (Jantsch, 1972). On the first two layers, learners 
and researchers focus on domain-specific empirical and pragmatic knowledge. At the third layer they turn to domain-general systems approaches, while at the fourth layer they consider societal purpose, meaning, and values. This multilayer approach to knowledge integration acknowledges the difficulty of connecting pluralistic societal discourse about life's purpose and values directly to domain-specific discovery. It proposes a graduated approach to knowledge integration that is paralleled by a measured shift of focus from outcome to process and from concrete to abstract.

We know, however, that knowledge is both personal and relational. Multilayered collective intelligence requires learners to embody the different layers and be cognizant of the full complexity of societal problems and the need for collaborative solutions. In turn, learners must rely on communities of trust that value and support integrative personal and professional development across skill layers and differentiated contributions to collaborative contexts. COPs have the potential to facilitate this interconnectivity of multilayered personal knowledge and multilayered relational knowledge.

They provide a nexus for social learning where highly abstract ideas (i.e., making as reflection), domain-general ideas (i.e., design for additive manufacturing), and highly specific processes (i.e., improving the filaments for metal 3D printing) can coexist and co-inform. By spanning multiple sectors of knowledge ecosystems, COPs gain a continuous flow of new and diverse perspectives while also endowing members with new insights and abilities, which they can then transfer to their domain-specific and domain-general contexts as well as other relational contexts (Wenger, 2000). Therefore, mobility across skills layers and practices is central — both to the participants and to the organizational structure. With this in mind, we believe that cooperative communities of learners structured around transdisciplinary themes of societal impact that structurally engage all layers of skills of the IPPD model are ideal for exploring the recommendations of this report.

An example of what we have in mind is the Beyond Boundaries initiative at Virginia Tech, which developed transdisciplinary themes as the fourth layer of a hierarchical structure of knowledge discovery and dissemination (Bleizner, Grant, \& Rikakis, 2016). The hierarchy progresses gradually from the domain-specific to the domain-general and from outcome-focused to process-focused. Departments form the base layer followed by the college (layer two), the interdisciplinary team science (layer three), and transdisciplinary cross-sector discourse (layer four). The connectivity of transdisciplinary themes with the disciplinary and interdisciplinary structures of the university depends to a large extent on the participants (faculty, students, community, and industry partners). These participants move easily and continuously among concerns of their disciplines, interdisciplinary centers, and transdisciplinary societal purpose discourse. To emphasize the critical role of integrative

Multilayered collective intelligence requires learners to embody the different skill layers and recognize the need for collaborative solutions. In turn, learners must rely on communities of trust that value integrative development and collaboration. 
knowledge practitioners, multilayer COPs were organized around each transdisciplinary theme and were tagged as talent "destination areas." Destination area COPs are envisioned as dynamic social nexuses. They are deliberately designed not to be independent units with buildings, directors, or other organizational and bureaucratic structures because this risks turning them into their own silos or relics of the past that are hard to sunset once new societal challenges have surfaced (Amelink \& Nicewonger, 2019; Nicewonger \& Amelink, 2019; Popowitz, 2018). Transdisciplinary knowledge is embodied in the participants of the COPs, not in an institutional unit, and engages all skill layers of the IPPD model. The knowledge of the community and of individuals continuously adapts as new perspectives emerge through pluralistic discourse and new members join the community. As new societal challenges emerge, these lifelong learners can easily transfer their multilayered, transdisciplinary abilities to new contexts.

Although transdisciplinary COPs hold significant promise for advancing inclusive and integrative adaptive learning in higher education, the sustainability of these communities within traditional academia remains a challenge (Popowitz, 2018). The working groups that we will launch following this report will explore in depth the opportunities and challenges of transdisciplinary, adaptive learning in academia. The groups will engage in quantitative and qualitative research informed by multiple sources and perspectives. One such source will be an extensive ethnographic research project being led by Todd Nicewonger that examines the sociocultural experiences of faculty involved in inter-/transdisciplinary initiatives in US higher education. The project provides a critical look at the issues these faculty and staff face as they work on developing collaborations with colleagues from diverse disciplinary backgrounds. In the process, this project provides a vehicle for the voices of participants, who share stories and examples that touch on both the difficulties and misconceptions underlying these initiatives, as well as the creative strategies that are emerging out of this work. The work illustrates the importance of hearing and reflecting on the experiences of people who are engaged in inter-/transdisciplinary activities and practices.

Besides universities, a number of other organizations (schools, businesses, and non-governmental organizations) have been exploring new ways to engender cooperation with flatter decision-making, ongoing education, and reciprocal valuing of different types of knowledge and practice. These examples, too, provide valuable insights into developing inclusive learning societies. The much-studied Toyota Production System, for example, incorporates a deep commitment to problem-solving through continuous interchange, communication, and experimentation among managers, production line technicians, engineers, and many others. As Spear (2004) argues, the basic Toyota philosophy is that "any operating system can be improved if enough people at every level are looking and experimenting closely enough (para. 31)." This practice allows employees to engage in continuous learning and sharing of information with one another at all levels.

Many businesses are working to achieve participatory knowledge ecosystems through what Rothschild and Whitt (1986) call demystification. This is the process by which "formerly exclusive, obscure, or esoteric bodies of knowledge are simplified, explicated, and made available to the membership at large" (p. 190). Such processes enable members to build a macro-picture of their workplace, learning about an entire organization and the various tasks, facets, and functions 
required to operate it. Wolff and Resnick (2012) argue that building strong relationships among different firms is a strategy to further increase learning opportunities and sharing of knowledge because it creates an ecosystem in which members can learn from partners in other businesses and build connections for support and training across organizations. A robust learning society can thus emerge by connecting individual flat and dynamic organizations into a knowledge network organized around a trans-sectoral practice or theme with potential for significant societal impact.

The Mondragon Corporation in the Basque region of Spain is a well-known and successful example of a democratic business ecosystem. Founded in 1956, Mondragon is not a single business but rather an interconnected complex of cooperatives each producing different products and services and each retaining the capacity to make its own decisions. The majority of its 74,000 employees have the right to vote on important business decisions and the corporation is known for its commitments to educational initiatives and community development. Mondragon's cooperatives operate according to the principle of "learning by doing," which is essentially the educational idea that people can learn to do something through practice and reflection - as long as they have access to resources, support, and training. It is also about "having confidence in people that they can have success using their labour through trial and innovation" (Heales et al., 2017, p. 31).

Mondragon's yearly revenues of $€ 12$ billion (approximately $\$ 13.2$ billion), combined with its democratic organization, has enabled the corporation to accumulate sufficient capital to develop what has been called a "social innovation eco-system," which includes a university, medical services, and other community supports (Heales et al., 2017, p. 45). Mon- dragon invests heavily in education by, among other things, creating schools and training facilities that are open to employees and non-employees alike (Heales et al., 2017, p. 52). Many organizations around the world have learned from Mondragon's approach. One example is the Evergreen Cooperative Initiative, a network of employee-run businesses in Cleveland, Ohio, operating with a commitment to community reinvestment and environmentally sustainable economic development in partnership with local institutions such as Case Western Reserve University and the municipal government (Alperovitz, 2013).

\subsection{Point of Need Learning Platforms}

Learning communities, either in education or industry, that embrace flatter, participatory organizational structures provide ideal relational contexts in which to explore the integrative and adaptive lifelong learning practices and recommendations of this report. We propose that Point of Need Learning Platforms (PNLP) can connect smaller participatory knowledge projects into large scale inclusive and adaptive learning networks. Indeed, based on all the work presented in this report thus far, we argue that the key value these platforms bring to the table is participation. A successful PNLP can facilitate participation for anyone interested regardless of background or previous experience.

PNLPs can be developed by adopting, experimenting with, and evolving many of the recommendations of this report. We propose that PNLPs be created and continuously developed by cross-sector communities of integrative learners spanning $\mathrm{K}-12$, higher education, industry, and community organizations. Each PNLP can be structured around a transdisciplinary, trans-sectoral collective intelligence theme such as the World Economic Forum discussion of Industry 4.0 that places technological and economic develop- 
Point of Need Learning Platforms (PNLPs) are cyber-physical platforms dynamically structured around transdisciplinary and trans-sectoral themes of societal impact. PNLPs contain modular content developed by all participating sectors and allow any learner to map their existing skills to current and emerging training and employment pathways.

ment within a systems context that also engages the support of the five $P_{\mathrm{s}}$ : people, peace, planet, prosperity, and partnership (United Nations General Assembly, 2015; World Economic Forum, 2016b). As discussed in Section 4.2, these themes require diverse perspectives and necessitate concurrent application and development of interconnected domain-specific, domain-general, and life skills by all participants. Because every active learner has domain-general and life skills, these skills can become their entry point into any transdisciplinary PNLP. Some learners may start their participation at the edge of a transdisciplinary theme and its corresponding PNLP. But as is the case with traditional COPs, increased participation will assist each learner with interconnected development of customized networks of life, domain-general, and domain-specific skills that can lead the learner to the core of the community.

PNLPs embrace all the structural characteristics of IPPD-based adaptive learning platforms that are presented in Chapter II (Section 2.4). They are cyber-physical/cyber-human platforms that allow diverse learners to map their existing skills to current and emerging training and employment pathways. PNLPs are continuously updated through broad, cross-sector participation supported by high-dimensional workforce and learning analytics. For example, if two very distinct activities - such as working at a motorbike shop and taking an online math course-have repeatedly been shown to assist learners in developing particular skills related to Industry 4.0, both experiences can be included as part of a PNLP on Industry 4.0 along with adaptive pathways that can mature these skills and connect them to Industry 4.0 competencies. The connection of these experiences within a PNLP may also inform the redesign of the math course and the workflow in the bike shop. PNLPs organize content in modules and provide flexible connectivity between modules. Modules utilize and combine different learning modalities ranging from in-person, hands-on experiences to distributed, asynchronous learning and team-based explorations of complex problems. Learning is enhanced by using cutting-edge technologies such as interactive content applications, cognitive tutors, augmented reality, and robots. The use of these enabling technologies facilitates the development of descriptive and predictive analytics to help inform mentoring and advising.

A PNLP promotes learner agency and mobility within and across personal knowledge layers (domain-specific, domain-general, life skills, and relatedness), knowledge types (explicit, implicit, and tacit), and learning domains (cognitive, affective, and psychomotor). PNLPs are thus well positioned to accommodate and connect different learning experiences with the needs of all types of learners, including $\mathrm{K}-12$, higher education, the current workforce, those who are reskilling, and those rejoining the workforce. By recognizing and 
leveraging the existing diverse skills of learners, drawing resources (educators and trainers, learners and learning content, labs and facilities) from across sectors, and connecting learners to accessible learning contexts (e.g., a partner facility close to their home) the PNLP can minimize cost to the learner. PNLPs reduce the need for lengthy full-time residential learning and the need for the creation of large, standalone, and expensive infrastructures of residential learning, which in certain cases might also be duplicative if, for instance, two higher education institutions in the same state are developing similar expensive labs that end up competing with each other. As an adaptive platform, the PNLP integrates multiple on-and-off ramps and diverse forms of credentialing including individualized electronic learning records owned and managed by the learner. We propose that universal, free-at-the-point-of-use PNLPs represent an adaptive, inclusive, efficient, and feasible approach to meeting the needs of a vast array of learners.

The business model for a PNLP is based on extensive participation resulting from widespread demand. Entities and individuals from different sectors join a PNLP because they want to be a member of a community that can tackle a transdisciplinary theme of societal impact by addressing the totality of the problem space (technical, financial, societal, environmental, etc.). All participants realize that the continuous and multilayered integrative learning necessary for tackling the theme requires broad participation across all societal sectors. The largest contribution that individual participants bring is their knowledge and active engagement. This model presupposes that resource-rich entities will be open to subsidize the participation of resource-constrained entities because they value integrative learning through comprehensive participation.
It is also important to highlight that a PNLP is not a traditional online learning platform although it can synergize with existing distributed learning platforms such as Coursera or edX. A PNLP places each module of learning in the context of IPPD that can support collective intelligence for addressing complex and current societal themes. For example, a learner may engage calculus or programming in an Industry 4.0 focused PNLP, but that domain-specific learning would be connected to domain-general skills (e.g., computational thinking) and life skills (e.g., collaboration) that help integrate specific knowledge into complex problem solving for Industry 4.0. In this case, the PNLP helps develop an integrative learner who can do computer science; it does not credential a computer scientist. Furthermore, a PNLP recognizes and leverages all types of knowledge in action (i.e., knowledge acquired through formal training and life experiences) and combines all modes of learning (e.g., hands-on apprenticeships in facilities of partners, online modules with peer mentoring, and team-based projects embedded in society).

The ARM initiative mentioned in Chapter III may be an ideal context for establishing a PNLP that connects many communities from different sectors, all of which are engaged in robotics for manufacturing research and training. As discussed in the Resource section, the Calhoun Center is facilitating the creation of a cross-sector COP that aims to gradually develop a PNLP on Industry 4.0 for Sustainable Development. An ARM or Industry 4.0 PNLP could connect small exploratory communities within existing organizations into a large trans-sectoral community that practices inclusive adaptive lifelong learning. As we discuss in the next section, the resulting large community can produce transformative knowledge paradigms within the community itself and help gradually 
shift some of the existing knowledge practices of affiliated organizations towards more adaptive and inclusive approaches. This combination of disruptive and gradual change has the potential to support the emergence of an inclusive knowledge economy.

\subsection{Predictive Modeling of Practices Within an Inclusive Knowledge Economy}

Throughout this report, we have contrasted the knowledge practices of the $20^{\text {th }}$ century with those that are demanded of us in the $21^{\text {st }}$ century. We have argued that the majority of institutionalized knowledge practices of the $20^{\text {th }}$ century can be found on the left side of our five-dimensional knowledge continuum (Rikakis et al., 2019). Based on the notion that knowledge should be standardized, outcome-focused, and disseminated via silos, these practices have been safeguarded through strong gate-keeping mechanisms and dominant bureaucracies. The growth of interdisciplinarity over the past 50 years (Knight, 2013; Sa, 2008; Sciences, 2005), as well as the more recent expansion of adaptive and inclusive practices highlighted in this report have fostered a gradual shift to the right. Still, this gradual shift has been slow in producing the scope of change necessary for developing an inclusive $21^{\text {st }}$ century knowledge economy. Many employment needs (Hart, 2016), knowledge needs (Donovan, 2015; Madrigal, 2017), and socioeconomic sustainability needs (Carayannis, 2019) remain unaddressed. The 2020 COVID-19 pandemic is a recent example of the need to address interconnected issues of health, socioeconomic and racial inequalities, and exclusion from the learning and knowledge enterprise. Established knowledge practices are producing significant advances that are life-saving and unimaginable even 25 years ago. However, the focus on segregated specialization has limited our capacity to adopt integrative system approach- es to complex socioeconomic problems (Basken, 2020). Our educational institutions are optimized for a subset of learners and learning practices but are not nearly dynamic enough to adapt to new learning modes and expansive learning needs. The learning societies and inclusive knowledge economy that this report is exploring would situate us to more effectively mitigate and address these complex challenges.

As we have shown in this report, the best way to engage successfully with the complexity of $21^{\text {st }}$ century socioeconomic problems is to first acknowledge and then cultivate the strong relationship between adaptive and integrative development of lifelong learners and pluralistic relational contexts. At the same time, we have argued that small pluralistic communities of adaptive learners within otherwise traditional institutions may not have the necessary synergies to succeed and scale their activity. The fact is that adaptive and integrative learning practices do not synergize well with the dominant markers of the previous century-e.g., national rankings that promote exclusion as a sign of success, standardized testing that rewards homogeneity of perspectives, and hiring practices that focus primarily on knowledge as a product and individual achievement (Crow \& Dabars, 2020). Because the majority of institutions of learning continue to focus on practices on the left side of our five-dimensional representation, a single institution or single learning/training unit within an institution that attempts to shift its practices decidedly to the right may find itself excluded from the national learning establishment, and its members may find their career mobility significantly reduced (Adler, 2015).

In their recent book, Crow and Dabars (2020) suggest that one solution to this problem is for like-minded institutions to come together and form 
alliances so that they can advance inclusive, integrative and dynamic learning practices at scale. This is certainly an intriguing idea, but it may be unrealistic to ask the majority of well-established professionals in current knowledge institutions to incorporate the adaptive learning recommendations of this report. In many cases, their personal knowledge models are likely far away from the models proposed in the report. Furthermore, there is significant evidence to suggest that building exploratory transdisciplinary communities for adaptive learning on the foundation of institutionalized, outcome-based, and siloed knowledge leads to these communities failing or gradually morphing into more traditional approaches and siloed practices (Popowitz, 2018; Samuels, 2015).

Rather than building entirely new exploratory communities from scratch, we propose identifying individuals and communities within existing knowledge and employment institutions who are already practicing adaptive learning within pluralistic relational contexts and find ways to connect those individuals and groups with large networks of adaptive learning outside of their institutions. The key to facilitating such connections is PNLPs, which have the potential to greatly increase the impact for these alliances, thus increasing their potential for committed participation and success.

Combining emerging practices from networks of adaptive learning with current practices from traditional learning units will lead to more balanced distributions of practices that span the full range of the five dimensions of our inclusive knowledge representation. The availability of an expanded palette of practices will encourage knowledge-practitioner mobility by enabling learners to explore the different available practices and combinations. Mobile knowledge practitioners will gradually embody multiple per- spectives (i.e., disciplinary, interdisciplinary, and transdisciplinary). Traditional polarities (i.e., local vs. global or adaptive vs. standardized) will coexist within these practitioners as synergistic points of view (Chaterjee, 2019). These "impartially-partial" knowledge practitioners (Chatterjee, 2019; Oxford Consortium, 2019) will personify the philosophical concept of The View from Nowhere (Nagel, 1986). They will be partial (i.e., passionate) about their experiences and points of view but also impartial in that they are aware of the wide spectrum of possible experiences, the limitations of individual points of view, and the richness that results from the interaction of different experiences.

The acceptance of multiple realities by members of knowledge ecosystems (Nicolescu, 2002) can in turn advance multi-perspective reflective practice (Darbellay, 2015; Osborne, 2015). When integral combinations of common and differentiated features are embodied by individual members

\section{Our model for predicting} institutional change allows for informed discourse between a radical paradigm shift and the gradual change processes embedded in existing institutions. Combining emerging and current practices can lead to balanced distributions of practices that span the full range of the five dimensions of our inclusive knowledge representation. 
and communities of knowledge, high network density across both homogeneous and heterogeneous practices can emerge, leading to the transformation of existing knowledge organization and socioeconomic outcomes (Eagle, Macy, \& Claxton, 2010; Grabher \& Stark, 1997; Reagans \& Zuckerman, 2001; Tegarden et al., 2009). Diversity in ideas and practices will increase individual and team creativity and help teams avoid getting stuck on local maxima (Page, 2007). This pluralistic discourse can then gradually establish at scale the notions of inclusive knowledge discussed in our introduction, thereby setting the stage for adaptive lifelong learning at scale.

How should we think about this expansion of knowledge production and dissemination across the five dimensions of inclusive knowledge? One possible approach is to model the expansion process as a one-dimensional random walk along each knowledge dimension the outcomes of which are binomial at any step. The outcomes of a large number of such steps can, under fairly general conditions, be shown to be approximately Gaussian as a result of the Central Limit Theorem (Gnedenko \& Kolmogorov, 1954; Hermans \& Lentz, 2013). Although one can expect the knowledge features used on each dimension to span a broad scope, the overall distribution of feature usage, across all participating learners over time, will behave in a manner consistent with a normal distribution, with a larger number of experienced features accumulating near the center. Figure 4.3 represents the normal distribution outcome of this modeling process over each of the five dimensions.

Moreover, the expansion can also be modeled as probabilistic decision making in uncertainty through a "many in one" approach. This approach is based on the assumption that, by and large, learning societies of the $21^{\text {st }}$ century will be serving an inclusive citizenry capable of a high level of dialectical bootstrapping (Herzog \& Hertwig, 2009). These individuals will have a heightened awareness of the relation of their individual knowledge to the full scope of societal knowledge. They will also be able to engage different viewpoints, which will enable them to improve their personal knowledge continuously. The collective decision making of these individuals then becomes the base of an updated "wisdom of crowds" model that is not biased toward "shallow, lowest common denominator information, at the expense of novel or specialized knowledge" (Prelec, Seung, \& McCoy, 2017).

A more intuitive way to understand the "random walk" and "wisdom of crowds" models of knowledge expansion is to think of it in terms of people making "satisficing" decisions in complexity (Simon, 1957). "Satisficing," a combination of "satisfying" and "sufficing," is an idea that dates back to Ancient Greek philosophy. In short, the idea is that when people are facing problems, the solutions to which span a large continuum, adopting solutions near the middle of the continuum is a great starting point for addressing the majority of needs (Plato \& Richards, 1966). Then, by taking gradual steps to the left and right of center, good solutions can be found for most problems (Dewey 1906, 1933). For example, various combinations of standardized and adaptive learning pathways can produce quality control and access at scale across many different types of learners. As discussed in Chapter I, an experienced craftsperson and a college graduate may vary considerably in their personal knowledge when they need to use derivatives for optimization. A PNLP that balances participatory process with outcome will have pathways that, on the one hand, allow the craftsperson to gradually translate tacit knowledge of optimization into understanding of the notion 
Figure 4.3

\section{$21^{\text {st }}$ Century Inclusive Knowledge Representation}

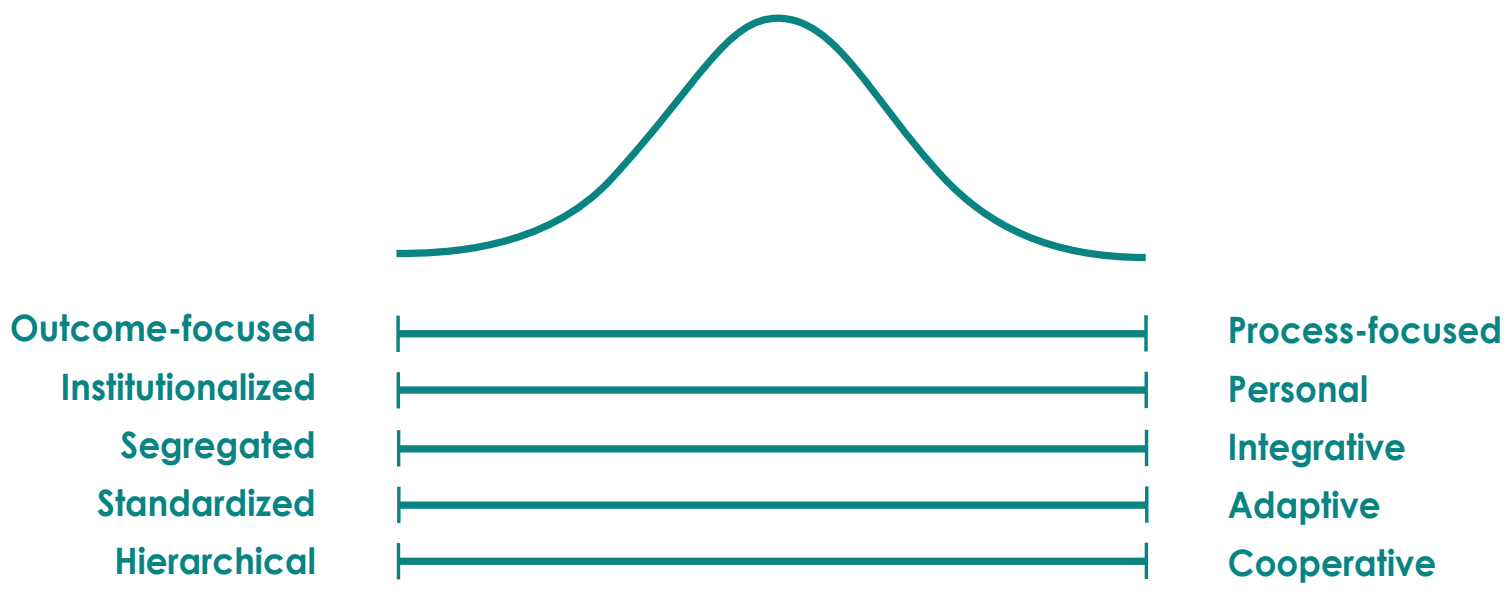

of derivatives and, on the other, allow the college graduate to translate symbol-based expertise in derivatives to real-world optimization problems. By including both types of learners into the same community, we provide opportunities for both to exchange perspectives and learn from each other. The analytics and pathways of the PNLP serving this community are further enriched through the participation and interaction of these learners leading to expanded inclusion capacity of the community. The normal distributions with high standard deviation described in this section are not the result of uninformed compromise where different biases cancel each other out. They are the result of continuously improving societal wisdom that emerges through multi-perspective reflective discourse supported by inclusive adaptive learning that aims for IPPD.

Our model for predicting institutional change allows for informed discourse between a radical paradigm shift (distributed networks of diverse integrative learners supported by PNLPs) and the gradual change processes embedded in existing institutions. By institutional change, we mean both change within organizations and change in the wider realm of societal knowledge. This calls for institutions to abandon a one-size-fits-all mentality when imagining their internal organization. For example, universities can promote the coexistence of traditional disciplinary departments with interdisciplinary centers and cross-sector transdisciplinary communities of practice. Each paradigm will come with its own customized learning, discovery, personnel, budget, and assessment structures. Although such disruption may increase entropy within organizations momentarily, our model proposes that over time these separate paradigms will fuse into one coherent, expansive, and dynamic paradigm.

In short, what we are describing in this report is not a new model that replaces existing institutions. We see networks of adaptive learning as a model that can thrive alongside existing institutions and attract collaborators throughout society. We propose that distributed networks of integrative learners should be based on practitioners who embody or aspire to the pluralistic knowledge in action principles of this report. Such practitioners exist already within our institutions and are looking for opportunities to advance adaptive and 
integrative learning within a different epistemological context. We see increased demand among young people for a more inclusive and sustainable knowledge economy. We have a unique opportunity to scale the training of adaptive learners and, in the process, mature adaptive learning mechanisms. Advancement of adaptive lifelong learning at scale can provide a disruptive paradigm that promotes a calibration of knowledge practices toward an inclusive, collaborative, and sustainable knowledge economy. 


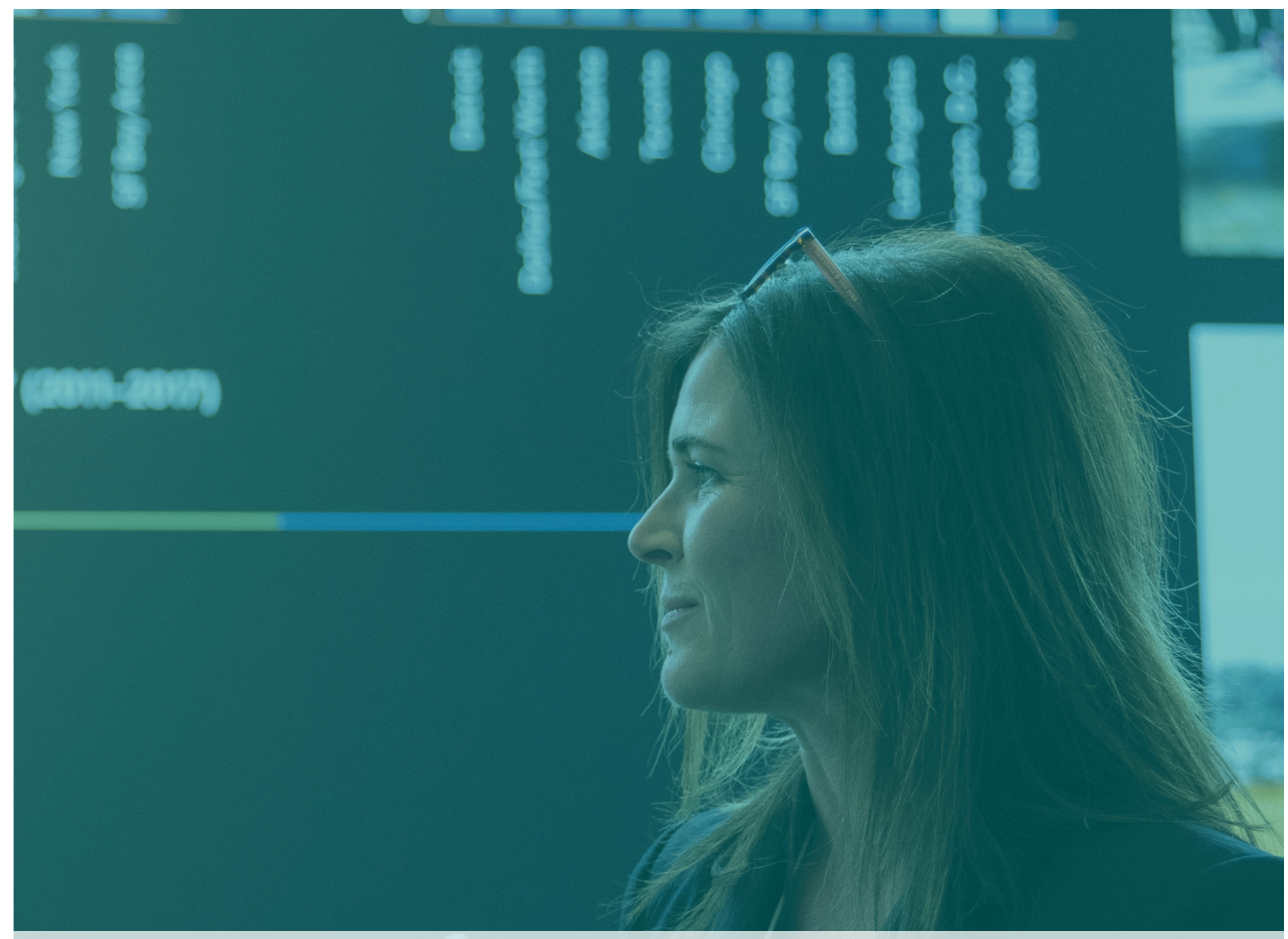

Working Groups

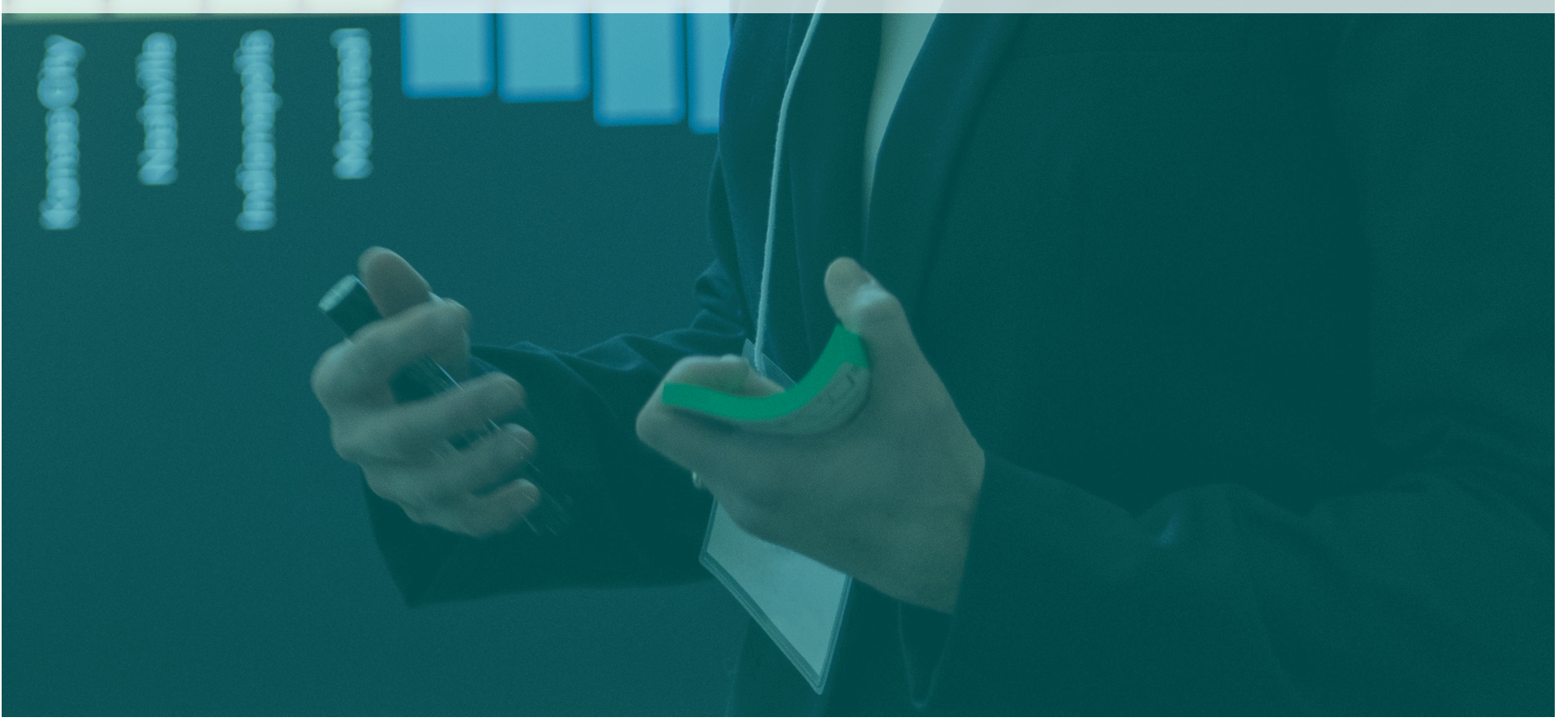




\section{WORKING GROUPS}

$\mathrm{I}$ n August 2020, we will be launching a series of working groups with learners, educators, and professionals across sectors ( $\mathrm{K}-12$, Higher Education, Industry, etc.). Organized around specific themes, these groups will explore, critique, and evolve the recommendations of this report. We envision working groups as opportunities for participatory assessment of the report as well as bridges to form partnerships for actionable items such as grant-funded pilot programs and new education modules, tools, and platforms. Although working groups will begin virtually, we anticipate the possibility of holding in-person workshops in the spring of 2021. The insights gained from these events will be analyzed and incorporated into a digital book on Inclusive and Integrative Point of Need Learning to be published by Virginia Tech Publishing in the second half of 2021. At that time we will also start the implementation of a Point of Need Learning Platform for Inclusive and Sustainable Industry 4.0

Participation in working groups is open through application. The participant lists given below are therefore continuously updated. If you are interested in participating, please contact the CalhounCenteratcchei@vt.edu

\section{Proposed working groups include:}

1. From School, to Manufacturing Employment, to Lifelong Learning (with a focus on pathways in advanced manufacturing)

Coordinator: Amy Arnold

Current Participants: Dave Hare, Kristin Wingfeld, Chip Blankenship, Robert Smith, Lisa McNair

This working group will leverage knowledge from a number of initiatives mentioned in Chapter III to (i) bring together people and entities that have successful experiences in these types of learning pathways, (ii) leverage ongoing work in places like the Academies of Louisville and FAME for developing adaptive pathways in high school curricula that can lead directly to successful employment in advanced manufacturing for learners from various backgrounds, and (iii) begin to define a point-of-need approach for lifelong learning in advanced manufacturing that can provide upskilling and career development opportunities to all levels of workers. This group will synergize with the Future Talent Council Advisor Boards on the Future of Talent in Manu- 
facturing and Employer \& Educator Relationships.

2. Adaptive and Integrative Learning in Global Academia - the International Academic Forum (IAFOR), the Association of Public and Land-grant Universities (APLU), and the Future Talent Council (FTC)

Coordinators: Joseph Haldane, Shari Garmise, John Flato, Jared Keyel

Current Participants: Daniel Kjellsson, Paul Heilker, Dale Whitaker, Juliet Greenwood, Rebecca Clark-Stallkamp, Marianna Savoca, Peter Sforza

This working group will engage a diverse group of educators and scholars from around the world with a focus on the IAFOR, APLU and FTC networks. The group will gather emerging practices in developing adaptive and integrative professional and personal development (IPPD) curricula across the globe and form partnerships for the exchange of lessons learned and/or coordination of efforts across institutions. The group will also look into faculty and staff development issues as well as technology development issues for delivering adaptive lifelong learning. The group will focus on the enabling technologies discussed in Chapter III and the combinations of gradual and transformative change discussed in Chapters $I I I$ and $I V$.

3. Adaptive and Integrative $\mathbf{K}-\mathbf{1 2}$ Preparation in Underserved Areas-Trusting the Young Learner

Coordinators: Owen Cardwell, Chrystal Harris, Chris Glover, Scott Bess, Karen Eley Sanders, Amy Arnold

Current participants: To be determined
This working group will bring together people and entities that have successful experiences in implementing adaptive and integrative learning in $\mathrm{K}-12$ with a focus on underserved areas. The goal is to make recommendations and build partnerships for scaling this work. The group is also planning a workshop on collaborative self-discovery exercises that can expose young learners to an adaptive learning framework, help them discover their strengths, and allow them to have some ownership of the adaptive learning process by connecting these strengths to future aspirations through customized pathways. This working group will bring together two focus groups of $5010^{\text {th }}$ grade students from Newport News, Virginia and Lynchburg, Virginia.

4. Cross-Sector Summit on Adaptive Learning for an Inclusive Workforce at the Intersection of Humans and Technology

Coordinators: Renee Schlechta, Michael Richey, Jay Chance, Shahab Sagheb, Amy Arnold, Catherine Amelink

Participants: By invitation

In manufacturing and engineering industries, several key technologies are impacting the workforce's knowledge development. These include robotics and automation; industrial Internet of Things and advanced sensing; digital twins (corresponding data packages for each design and part); cyber security for production systems; augmented and virtual reality, e.g., for inspection tasks; and additive manufacturing technologies; among others. Taken in total, these technologies are posed to transform manufacturing capabilities, enabling greater operational flexibility (in the form of reconfigurable production assets), strategic 
flexibility (in the form of granular, data-driven business intelligence), and advanced knowledge management (in the form of knowledge graphs and data lakes).

The development and implementation of these technologies within a systems context of the five $P$ s (People, Peace, Planet, Prosperity and Partnership) can facilitate much needed socioeconomic sustainability. This summit will focus on the structuring of partnerships that can coordinate the commitment of significant resources towards sociotechnical systems approaches that increase manufacturing capability and flexibility while also advancing inclusive and equitable growth of human capital. The summit will bring together experts from industry, academia, government, and community to explore training and production systems that leverage cyber-human intelligence to tackle these complex goals. The summit will also explore the potential of cross-sector Point of Need Learning Platforms (PNLP), as presented in this report, for educating, reskilling, and upskilling all related members of the current and future workforce to utilize and leverage these technologies. Since PNLPs advance targeted domain-specific skills while also leveraging and advancing diverse domain-general and life skills, they can become a key mechanism for inclusively enhancing the professional and personal development of human capital and driving the five $P$ s of Sustainable Development Goals. The summit will be hosted at the Boeing Leadership Center in St. Louis, Missouri.

5. Integrating IPPD Adaptive Learning in Current Higher Education StructuresCalhoun Discovery Program

Coordinators: Lisa McNair, Amy Arnold,
Jared Keyel, Thanassis Rikakis, Shahabedin Sagheb, Mike Kretser, Alkan Soysal, Robert Smith, James Ivory, Chip Blankenship, Joan Banks-Hunt

This working group will focus on a threeyear assessment of the Calhoun Discovery Program (CDP) as a pilot for an IPPD-based adaptive learning curriculum within existing structures in higher education.

6. An Inclusive Workforce Development Workshop with Virginia Mayors-Focus on Industry 4.0

Coordinators: Anne Khademian, Scott Weimer, Jared Keyel

Current participants: To be determined

The overarching goal of this working group is to ask mayors across cities of varied sizes and demographics to identify (i) current skills, built through both formal training and life experiences, that exist in their community; (ii) current and future skills needed in their community; and (iii) training mechanisms (including learning mechanisms and support structures) that can leverage existing skills to train an inclusive workforce for the future in their city. The working group will focus on mapping diverse "knowledge-in-action" skills that exist in current cities to an inclusive Industry 4.0 workforce.

7. Institutional Partnerships with Local Employers in Rural Settings

Coordinator: Catherine Amelink

Contributor: United Way of Southwest Virginia

Current participants: To be determined 
Starting in the summer of 2020, this working group will explore how student internships with local employers in a rural setting coupled with project-based classroom work provided by local employers can help to provide opportunities for adaptive learning and help to further expand this model to other communities and learning contexts such as community colleges.

\section{Transdisciplinary Relational Knowledge for} Integrative Development and Revaluing the Humanities and Arts

Coordinators: Sylvester Johnson, Ico Bukvic, Catherine Amelink, Thanassis Rikakis, Roger Reynolds

Current participants: To be determined

This working group will explore structured trans-sector, transdisciplinary discourse as a relational context for advancing inclusive definitions of knowledge and promoting adaptive and integrative learning. The working group will also explore how transdisciplinarity as a relational context for IPPD can bring forward and revalue humanities and arts as applied learning experiences that develop critical domain-general and life skills in tandem with inclusive collective intelligence.

\section{Towards a Point of Need Platform for Inclu- sive and Sustainable Industry $\mathbf{4 . 0}$}

Coordinators: Thanassis Rikakis, Sylvester Johnston, Jenna Joo, Randy Swearer, Robert Smith, Mike Kretser, Anne Khademian, Kimberly Carlson, David Tegarden, Michael Richey, Chip Blankenship, Andrew McCoy, Mukul Kumar, Ronan Mac Domhnaill, Tazio Grivetti, David Tinnaple, Jared Keyel, Amy Arnold
Current participants: To be determined

This working group will leverage work in all other working groups to draft a model of a PNLP that can advance an inclusive approach to workforce training and overall sustainable development for Industry 4.0. The group will address:

- A systems approach that advances pointof-need learning that places technology development within the five Sustainable Development Goals of Industry 4.0.

- Dynamic cross-sector workforce analytics that explore domain specific, domain general, and life skills involved in competencies for Industry 4.0 and Sustainable Development.

- Cross-sector development of modular, just-in-time training content that leverages knowledge mapping of existing integrative skills of all types of learners to emerging Industry 4.0 needs.

- An Industry 4.0 credentialing system that is owned by the learner and tracks and details all Industry 4.0 related experiences and knowledge of each learner from various activities in work, education, and community interaction.

- Technologies and computational tools for supporting a PNLP for Industry 4.0 with a focus on Industry 4.0 enabling technologies as discussed in Chapter III.

- Cross-sector collaborations to reduce cost and increase access.

- Applications of Industry 4.0 PNLP to smart construction or construction 4.0. 


\section{Appendix A:}

The Calhoun Discovery Program A Pilot IPPD curriculum

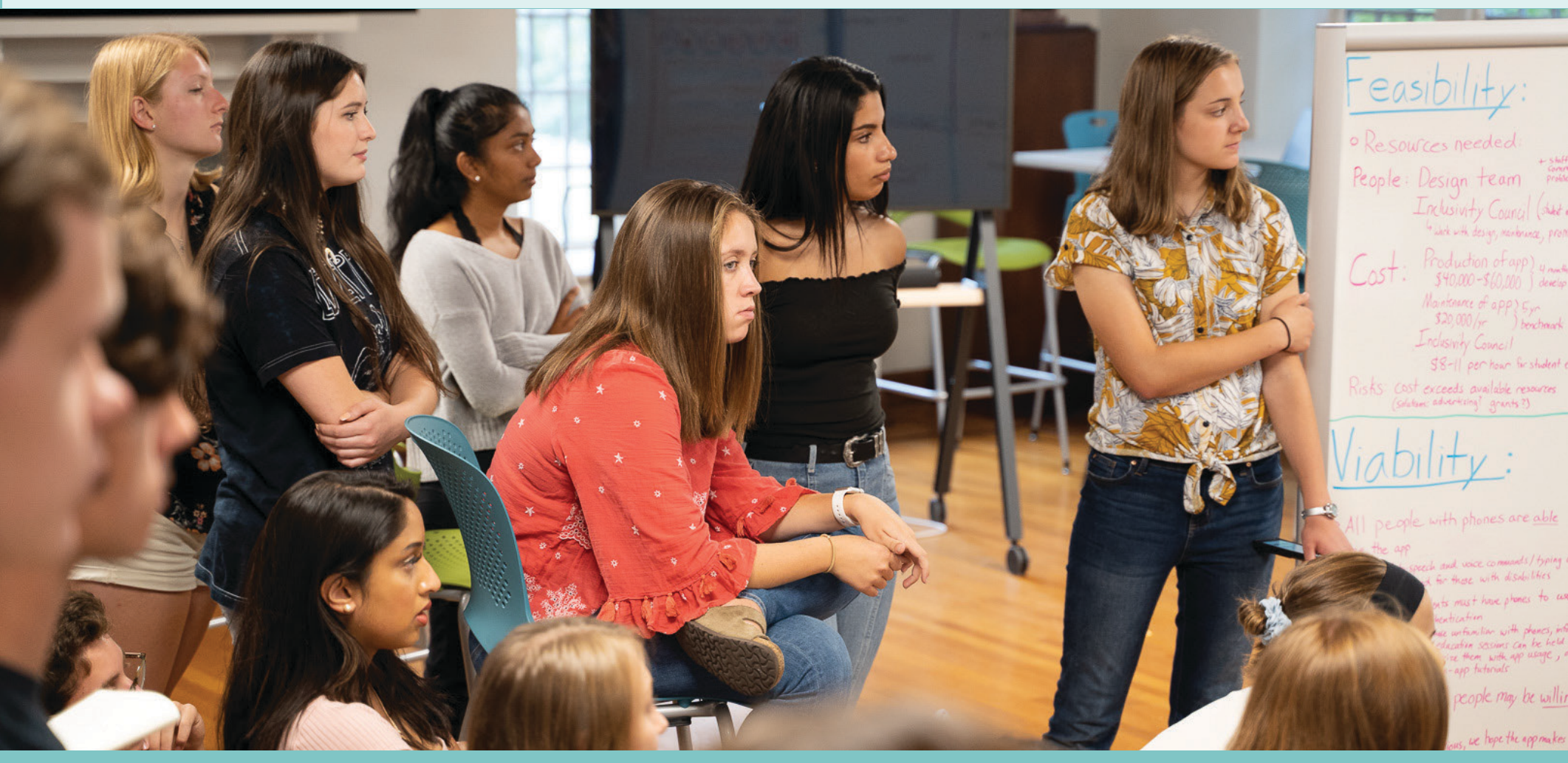




\section{APPENDIX A}

\section{The Calhoun Discovery Program-A Pilot IPPD Curriculum}

\section{Author: Thanassis Rikakis}

Co-authors: Lisa McNair, Shahabedin Sagheb, Alkan Soysal, Mike Kretser, Robert Smith, Neal Henshaw

Contributors: Michelle Kovac, Paul Knox, Paul Heilker, Tom Martin, Akshay Sharma, Lara Khansa, Mark Embree, Sylvester Johnson, James Ivory, Anne-Lise Velez, Nikki Lewis, Luke Lester, Chip Blankenship, John Tracy, Amy Arnold, Les Duffeld, Howard Haines

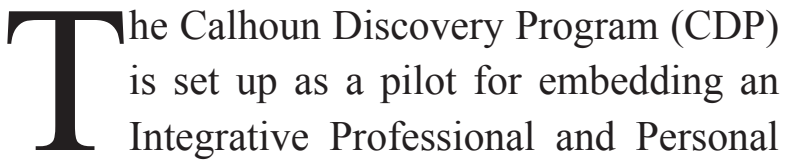
Development (IPPD) curriculum, as outlined in this report, within existing institutional structures at Virginia Tech. The goal of the program is to help prepare integrative, lifelong learners who:

- Can move easily across knowledge domains and pick up diverse new skills in a just-in-time approach,

- Can connect their specialized knowledge to complex collaborative contexts for problem setting and problem solving,

- Use complex relational and collaborative contexts for self-discovery and personal fulfillment, and

- Connect personal fulfillment to advancing an equitable and sustainable society.

The CDP helps learners develop these competencies through integrative development of domain- specific, domain-general, and life skills. The connectivity and integration of these skills are supported by:
- Inclusive social learning that includes a highly structured collective intelligence component,

- Learning experiences that connect domain-specific skills to domain-general skills,

- Learning experiences that connect domain-general skills to life skills,

- Coordination of learning across experiences so as to facilitate integration of different skills within the learner, and

- A co-creation approach, between instructors, partners, and students, spanning all of the CDP learning experiences.

CDP instructors aim to develop a student's self-authorship for the purpose of carrying independence in tandem with collective awareness over a lifetime of learning, while also developing the complex networks of skills necessary for integrative professional and personal development within diverse relational contexts (Baxter Magolda, 1999). Using the strategies outlined earlier in the report can aid students in finding their voices, engaging in content more meaningfully, and realizing they may always adapt transferable skills 
to new settings. The curriculum asks the instructor to meet the students where they are, regardless of what development stage they may be exhibiting (Kegan, 1994), by welcoming them and asking for their input. As mentioned in Chapter II, we recommend validating the students (Baxter Magolda, 1999) by acknowledging what they already have in their repertoire and respecting their diverse ways of knowing (Chickering \& Reisser, 1993). This is done in addition to lessening what Moore (1993) describes as transactional distance, "the psychological and communication space between the teacher and learner" (p. 22). Secondly, CDP course design values the learners' experience (Baxter Magolda, 1999; Brown, Collins, \& Duguid, 1989). This is done by connecting the learning to students' life experiences or situating a problem in a real-life context, as well as providing alternative options for students to advance. Including students' experiences in the learning environment aids in their ability to connect new information and engage in interdependent learning (Baxter Magolda, 1999). Lastly, all voices, including student-to-student and student-to-instructor, collaborate to construct shared meaning (Baxter Magolda, 1999). Students participate more when the instructor engages in dialogue rather than lecture (Shor \& Freire, 1987). A related strategy that fosters a co-creation paradigm is for the instructor to take on the role of 'guide on the side' by physically moving to the students' location and guiding the discussion rather than giving away all knowledge (Baxter Magolda, 1999). These strategies are devised to enable students to realize that they play a necessary role in knowledge creation.

As proposed in this report, inclusive, collective learning can help develop life skills (communication, collaboration, versatility, complex thinking, and creativity) that are critical for success in the $21^{\text {st }}$ century knowledge economy. To realize an inclusive relational context, the CDP aims to attract learners with many different life experiences as well as instructors from academia and industry with different areas of specialization. Thanks to significant industry and philanthropic support, all CDP students receive tuition scholarships and additional grants for experiential learning. Admission to the CDP is based on a holistic review of GPA, learning skills exams, essays, portfolios of work, as well as interviews that explore the interests of the students in adaptive and collaborative learning. In the first two years, this approach has produced gender-balanced cohorts with $25 \%$ of the students being from underserved and/or underrepresented backgrounds.

The CDP invited ten programs at the university to engage based on their expressed interest in combining disciplinary learning with collaborative experiential learning that spans professional and personal development. Students applying to the CDP choose paths in business information technology, business management, computational modeling and data analytics, electrical and computer engineering, industrial design, industrial and systems engineering, communication, environmental policy and planning, smart and sustainable cities, and creative technologies.

Additionally, the CDP invited institutional partners from industry and the non-profit sectors. Qualifiers for engagement include (a) interest in supporting an integrated approach to personal and professional development of students; (b) commitment to an inclusive workforce; and (c) willingness to embed experts from their companies into the program as visiting faculty. In the first year, Boeing, General Electric, Caterpillar, and the non-profit Share Charlotte participated. More non-profit and industry partners will be added in the future. 
Recruiting this diverse set of students and institutional partners was critical for the CDP to achieve an inclusive social learning environment. The next step was to establish an inclusive transdisciplinary theme for the CDP that would facilitate the structuring of collective intelligence among the diverse participants. The selected theme needed to achieve four goals in parallel:

1. Engage the specific interests and abilities of all academic and industry participants regardless of disciplinary background or industry specialization;

2. Promote integrative development of domain-specific, domain-general, and life skills by the participants so as to allow them to tackle collaborative work within the theme;

3. Enable educators to employ a systems approach to collaborative sociotechnical innovation that could facilitate the connection of different individual knowledge to collective intelligence;

4. Engage a sociotechnical area of current importance so as to leverage the strengths and fulfill the mission of Virginia Tech as a land-grant institution.

As we began to structure a collaborative sociotechnical innovation theme for the program, it was important to consider the significant body of research over the past 15 years in engineering systems/design thinking approaches to collaborative technology innovation. The goal of the research is to systematize an integrative approach to collaborative innovation that addresses the technical components (feasibility) along with the business (viability) and design (desirability) components (De Weck et al., 2011; IDEO, n.d.). A further goal is to structure learning methodologies that train experts who can work in teams to implement these systems approaches (Miller, 2010). The CDP aims to build on this work while adding the component of sustainability (socioeconomic and environmental), thus emphasizing the societal impact of the program.

We refer to the four components of the CDP systems approach to collaborative sociotechnical innovation as sets. From an industry perspective, the four sets can represent the following simplified elements of a solution concept for a problem space: (1) desirability aligns with a definable real need from a use case; (2) feasibility aligns with a technical approach that exists and has some maturity; (3) viability aligns with how the technical approach can be manufactured reliably and repeatedly, is testable, and can be accomplished for a cost that is reasonable to the desirability constraint; and (4) sustainability aligns with a solution concept that embraces societal benefits such as being eco-friendly, policy compliant, regulation compliant, life-cycle cost supportable, and promotes inclusive economic prosperity. As shown in Figure A1, some elements of these four sets overlap. Systems approaches to sustainable sociotechnical solutions need to address the interrelations and interdependencies among all the key elements of the four sets through extensive collaboration of people with different experiences and knowledge.

The CDP chose to focus on the sociotechnical innovation theme of Industry 4.0 for Sustainable Development. The theme meets the goals of the CDP and interests of the participants while being well suited to the systems approach described above. Industry 4.0 is defined by five core technologies that have evolved into 13 enabling technologies (Habib \& Chissom, 2019), which are supporting five Sustainable Development Goals (SDG) for the year 2030 (United Nations General Assembly, 2015; World Economic Forum, 2016b). The 
Figure A1

\section{Integrating the Four Sets for Sociotechnical Innovation with the Participation of Students from 10 Different Programs}

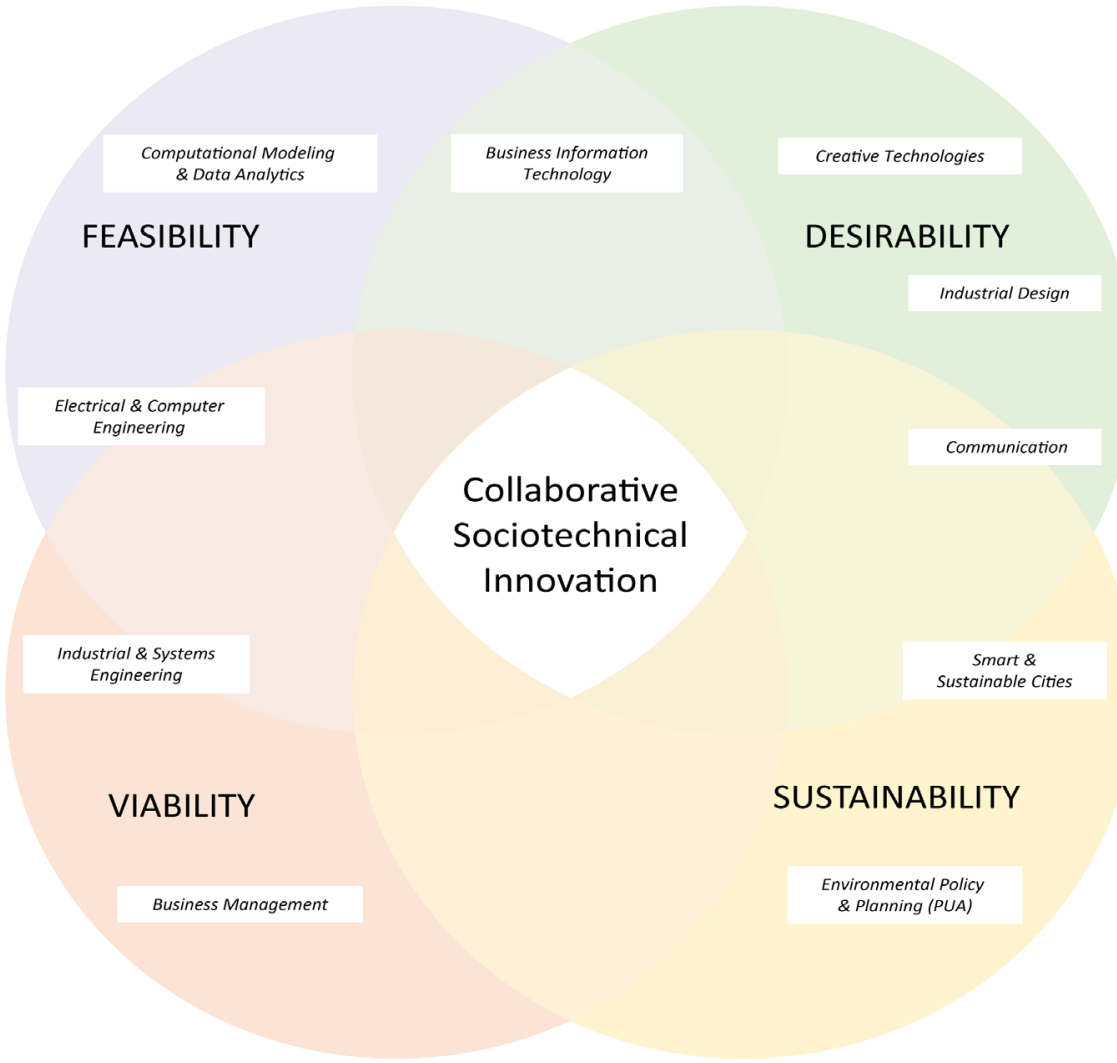

SDG outcomes require that technical development of the enabling technologies be placed in a systems context of the five $P$ s: People, Peace, Planet, Prosperity and Partnership. The World Economic Forum's discussion of Industry 4.0 elaborates further on the SDG by focusing on the productive coexistence of human and machines: Smart factories that take advantage of the Internet of Things while also advancing inclusive and equitable growth of human capital (World Economic Forum, 2016b). Implementation of such systems approaches to a technology-enabled, sustainable society requires the valuing of the technical, social, methodological, and personal competencies of the Fraunhofer Report model discussed in Chapter I (Hecklau et al., 2016). The complexity and dimensionality of the SDG requires that lifelong IPPD learners come together to generate collective intelligence and leverage that collective intelligence for further integrative development. Within the CDP systems model, exploration of the Industry 4.0 for Sustainable Development theme requires each individual participant to embody domain-specific proficiency along with domain-general knowledge across the four sets and mature life skills. This allows all participants to (1) have an integrative understanding of the problem space and (2) collaborate successfully with people that have significant expertise in different domain-specific elements of the four sets.

The CDP has chosen to concentrate on six 
components of the Industry 4.0 for Sustainable Development theme based on the particular interests of our faculty and partners. Around each component, we are developing a work cell: a hands-on lab in the university that hosts student, faculty, and partner activity that spans the four sets of the systems approach. The first four work cells focus on the maturation of a key enabling technology at the worker/machine interface:

1. Cyber Physical Systems-Smart Factory, Focus: Human Augmentation

\section{Design for Advanced Manufacturing}

3. Factory and Equipment Upgrade and Retrofitting

4. Semi-Automated Inspection, Focus: DroneBased Inspection

As enabling technologies mature, a Point-ofNeed Learning Platform (PNLP) will be required to educate and upskill all related members of the workforce in order to utilize and leverage the technologies. The PNLP advances targeted domain-specific skills while also leveraging and advancing diverse domain-general and life skills. It thus becomes a key mechanism for enhancing the professional and personal development of human capital and driving the SDG outcomes. It is highly likely that point-of-need learning may utilize an enabling technology, such as augmented reality, to provide a learning delivery system that is symbiotic with maturing the ecosystem (see Chapter II). An additional key element of the ecosystem required to support the SDG outcomes of Planet, Prosperity and Partnership is a stable supply chain. The supply chain includes the people, machines, and materials that allow the worker-machine interface to be realized. A collective intelligence approach to a sustainable supply chain for Industry 4.0 aims to create global partnerships, reduce the ecological footprint, promote sustainability for the planet through the use of enabling technologies, and bring prosperity to individuals throughout the ecosystem in an equitable and inclusive manner. With this in mind, we developed two more work cells that relate to all four enabling technologies:

5. Digital Thread and Supply Chain Synchronization

6. Inclusive Human Capital Development

A more detailed presentation of our systems approach to Industry 4.0 for Sustainable Development is provided in the Resources section.

A significant part of the learning process in the CDP throughout each year of study is realized through collaborative, hands-on projects connected to the work cells. Students are thus guaranteed real-world problems and real-world data as well as expert multidisciplinary, multi-sector supervision for their projects. All student projects embrace a systems approach and are realized by student teams with expertise that spans the four sets. Projects are offered at the concept, prototype, and applied level with multiple possible pathways between the different projects at each level. Students structure pathways of projects based on their emerging interests and through assistance from faculty and industry mentors. Through projects in students' chosen pathways, they gradually learn how to collaboratively understand complex problem spaces and embrace solutions spanning the four sets. Students realize collaborative projects through studio-based courses, internships, and externships. Senior capstones are realized in a similarly collaborative manner. Student teams realizing collaborative innovations in the work cells can be hired as individuals or teams to further implement these innovations within an industry partner organization after graduation. Alternatively, student teams can start their own venture 
that leverages their ideas and collaborative skills.

It is important to note that because work cell projects combine academic and industry experience, they bridge these two relational contexts for the students, thus further assisting their transition to the workforce. Industry and academia have teamed for decades to provide experiential learning opportunities. Industry has aligned collegiate hiring outcomes to students who participate in experiential learning. However, in a traditional experiential learning setting, students work in disciplinary-based teams that aim to improve or develop a discipline-specific capability for a product. For example, a cohort of aerospace engineering students will develop a drone for a Design, Build, Fly program or a cohort of mechanical engineering students will improve the mechanisms, structure, and engines for a car. In such situations, the outcome usually focuses on only one of the sets (i.e., feasibility). Because a student must have some knowledge within their discipline, their participation in these experiential learning opportunities requires them to be at least a second-year student, and often a third- or fourth-year student. More recently, we are seeing teams composed of students from different disciplines (i.e., engineering and business) covering two sets (i.e., feasibility and viability). But even in these contexts, the students predominantly perform work in their chosen disciplines.

The CDP shifts the paradigm by giving students experiential learning opportunities that are situated within a sociotechnical systems approach to building collective intelligence (the cross-sector context of Industry 4.0 for Sustainable Development work cells). The CDP thus brings together students, faculty, industry, and community partners to form transdisciplinary communities of practice (COP) in which members develop shared, relational knowledge around core practices (Barab et al., 2002; Wenger, 1998). Every experience in the program is designed to engage all components of sociotechnical innovation, which means that it also engages many different types of domain-specific knowledge. The CDP embeds students in such experiences throughout their studies, expecting them to produce systems-level solutions at every level. The students can see how different domain-specific expertise can complement each other within a collective intelligence context. They also learn, in practical terms, how to connect domain-general knowledge to different types of domain-specific knowledge. They realize that such connectivity requires that every participant embody both domain-specific and domain-general knowledge and that, in many cases, they need to possess working knowledge of the domain-specific knowledge of their peers. Furthermore, students realize the critical role of life skills in dealing with complexity and ambiguity of sociotechnical systems in a collaborative manner that leads to collective intelligence. This CDP relational knowledge framework advances personal knowledge along with an ever-expanding overlap of skills among participants, as well as greater awareness of systems approaches and increasing collective intelligence ability by all members. The overall social learning at the CDP also incorporates structured and unstructured informal exchanges between program participants from different disciplines and different backgrounds. All participants (students, faculty, industry partners) engage together as learners in a co-creation paradigm.

In parallel with their collaborative projects, all students follow one of the ten disciplinary curricula that participate in the CDP. Each disciplinary curriculum has a fairly fixed plan through first-and second-year courses, but by the third-year students are expected to branch out into different pathways, 
which further enhances the students' self-discovery process. For example, students in electrical and computer engineering can choose one of eight possible concentrations after their second year. Additionally, all students in CDP are assigned an honors faculty mentor with experience in transdisciplinary work and expertise in the student's chosen discipline. The mentor works with the student on integrating the domain-specific skills arising from their discipline with the domain-general and life skills that are emphasized in the collaborative projects.

The structuring of the general education expe- rience of the CDP assists learners' integration of domain-specific, domain-general, and life skills within a social learning context. A one-credit general education module is offered on each key element of the four sets. Each module is taught in a manner that maps the domain-general knowledge associated with the elements of the sets to the domain-specific knowledge of participating disciplines. Each module is also designed to map to one of the four domain-general skills of the Virginia Tech Pathways general education model: quantitative thinking, discourse, social science, and design/arts. For example, the module on hardware-software interface is mapped to feasibility and to quantitative

Figure A2

\section{The CDP Curriculum Promotes Collective Intelligence for Systems Approaches to Sociotechnical Innovation (Image by Shahab Sagheb and Emily Harmon)}

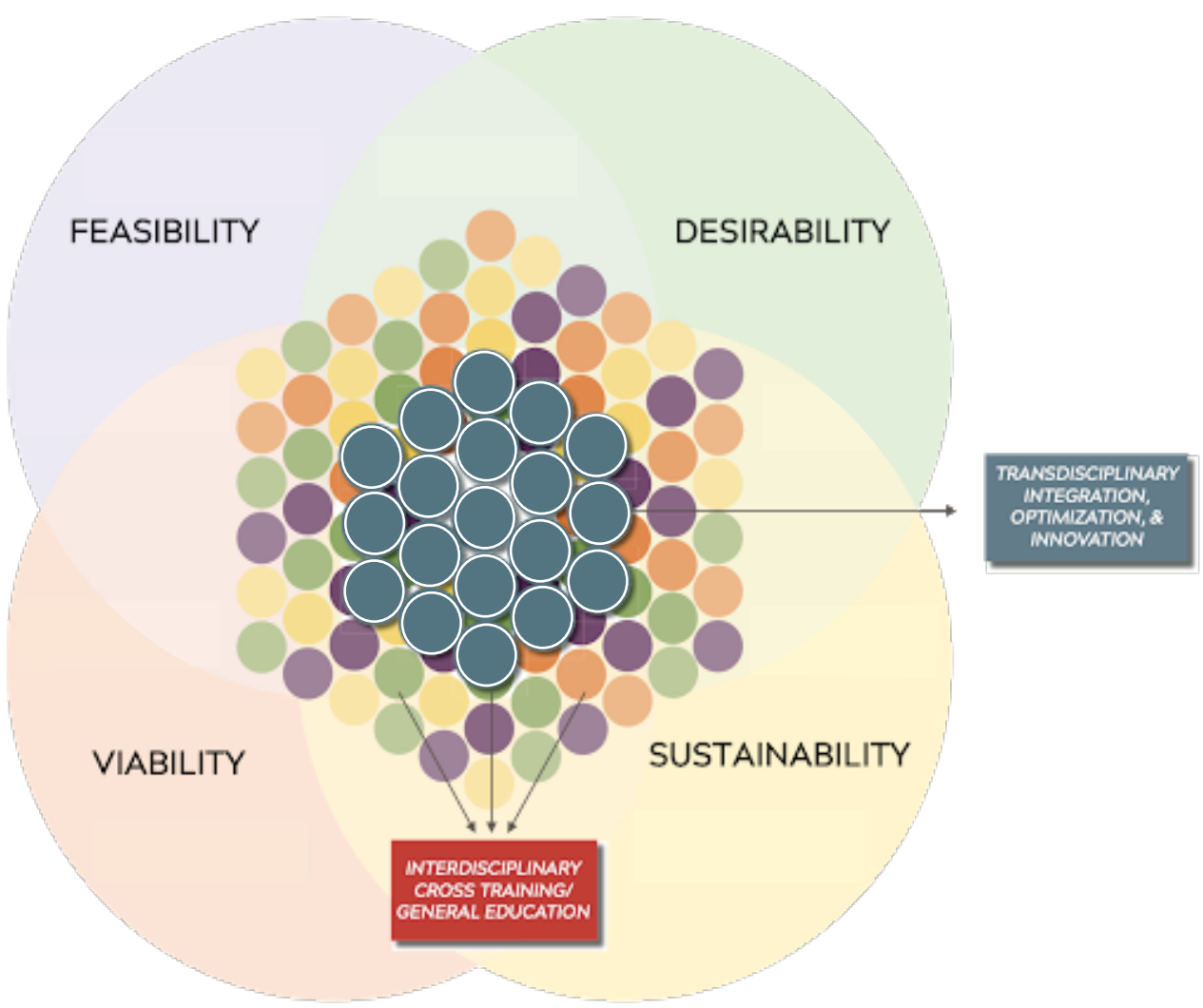


thinking. All modules are offered asynchronously and utilize interactive content applications and as needed meetings with peers and instructors. As the students are realizing collaborative Industry 4.0 for Sustainable Development projects and advancing in their discipline, they discover which modules can help them develop domain-general skills that complement their domain-specific skills. This helps them solve complex problems through collaborating more effectively with students from other disciplines. Modules are offered at the novice, capable, and skilled levels. Novice-level modules have very few prerequisites given that the students are generally relying on the transfer of previously learned knowledge from their domain-general skills (rather than on disciplinary preparation). If a novice-level module sparks the interest of a particular student to learn more about the concept, that student can complete relevant modules in the capable and skilled levels that gradually incorporate more domain-specific knowledge. This means that students are shaping their own pathway in a justin-time fashion by choosing the general education modules that complement their domain-specific knowledge and collaborative learning aspirations.

Figure A2 depicts how disciplinary preparation, general education, and collaborative experiential learning come together in the CDP as one systems-level experience that promotes collective intelligence for collaborative sociotechnical innovation. Figure A3 shows how this collective intelligence promotes and leverages IPPD of the learner that spans domain-specific, domain-general, and life skills. In Figure A3, skills are shown as circles of different size (denoting variable skill strength) that are connected through links of different strength denoted by width in the connector lines. Learning experiences (modules, collaborative projects, and disciplinary courses) are shown as triangles (novice level), squares (capable level) and polygons (skilled level) connected through multiple possible pathways. All students have a large hub of domain-specific skills from their discipline, which are then connected to domain-general skills by collaborative project experiences and mentoring. Students also have smaller hubs of domain-specific skills beyond their discipline. The CDP cross training modules leverage knowledge mapping to domain-general skills to support the development of the smaller domain-specific hubs. The overarching domain-general skill of the CDP is systems thinking, and this skill is deeply integrated across the feasibility, viability, desirability and sustainability sets of sociotechnical systems. Discourse, quantitative thinking, societal understanding and human experience, and design thinking are the other four domain-general skills associated with the CDP and Pathways general education. All CDP domain-general skills are strongly supported by the customized modular general education structure. Work-cell-based transdisciplinary and trans-sector collaborative projects facilitate the connection of life skills to domain-general skills. The CDP focuses on the key life skills of collaboration, communication, reflection and self-discovery, agility in complexity, leveraging diversity, and creativity. Figure A3 emphasizes the learner's skills thus denoting that integrative knowledge accumulates in the person and not in the curriculum. Given what we have outlined in this report, we expect the adaptive integrative approach of the CDP to lead each student in developing differentiated skill strengths and skill connectivity supported by varied collections of modules, projects, and courses. This variation cannot be shown in the figure due to limitations of a static image. In the Resources and Working Groups sections we discuss in detail the continuous and collaborative assessment and improvement process we are implementing in the CDP. 
APPENDIX A

Figure A3

\section{CDP Skill Connectivity and IPPD Facilitation by a Highly-Structured Collective Intelligence Context}

Collective Intelligence

Life Skills

Collaboration

Communication

Reflection and Self Discovery

Agility in Complexity

Creativity

Leveraging Diversity

Domain General Skills

Systems Thinking

Feasibility

Vesireability

Sustainability

Discourse

Society and Human Experience Quantitative Thinking

Design Thinking

Domain Specific Skills
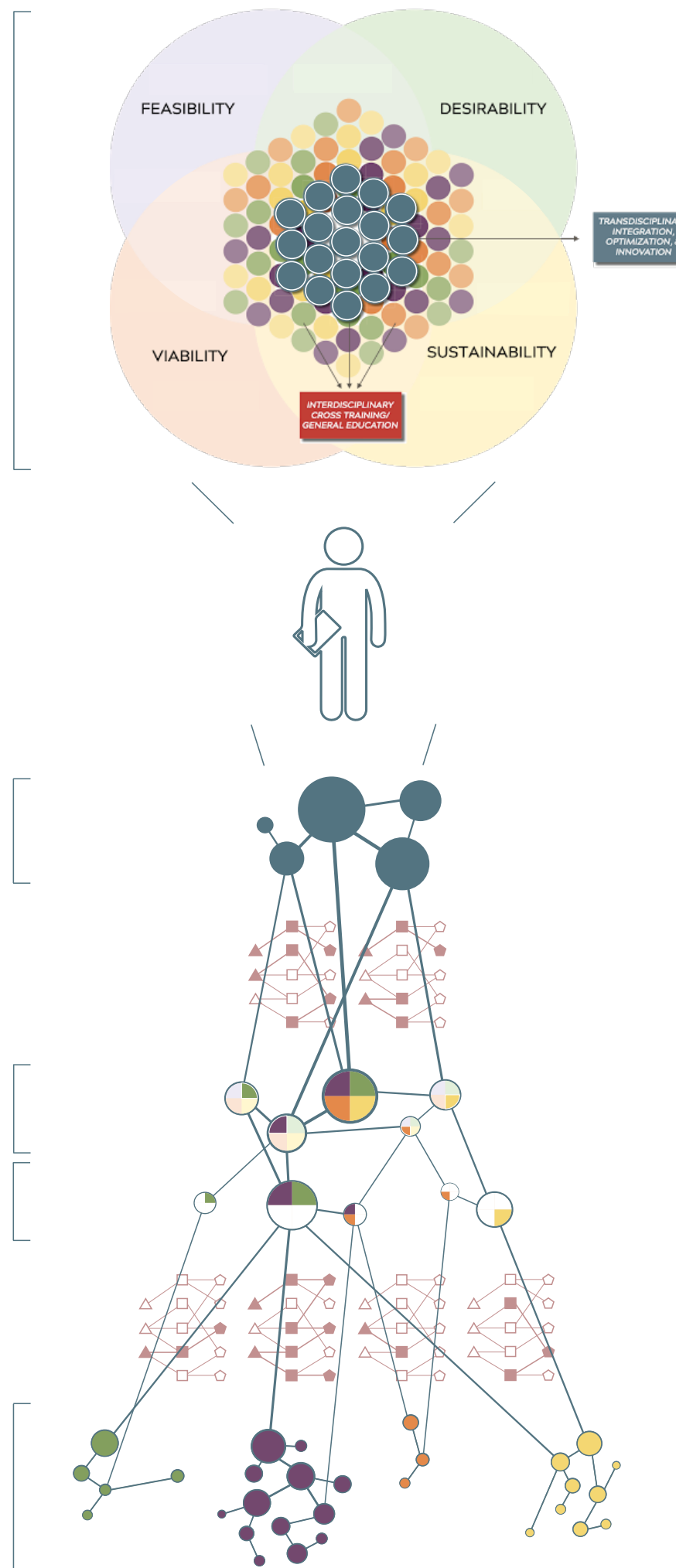


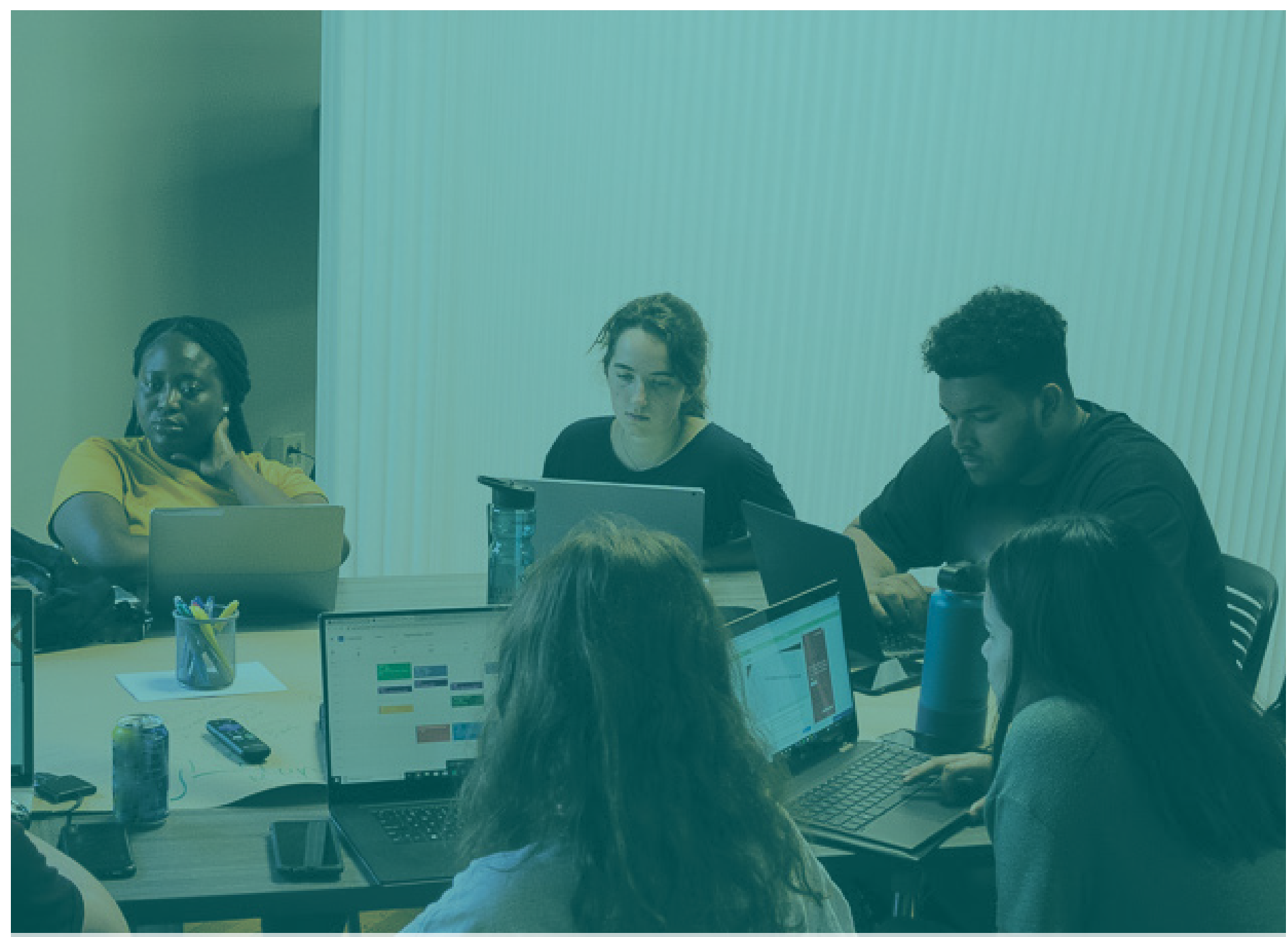

References

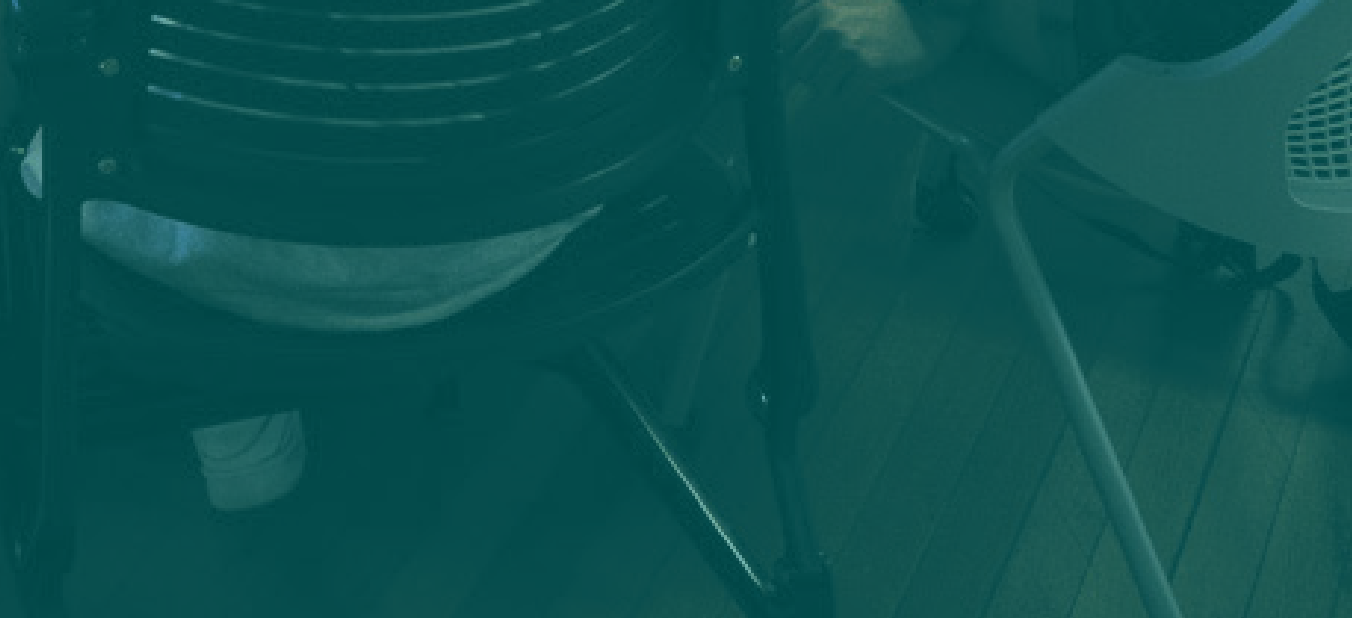




\section{REFERENCES}

Abes, E. S., Jones, S. R., \& McEwen, M. K. (2007). Reconceptualizing the model of multiple dimensions of identity: The role of meaning-making capacity in the construction of multiple identities. Journal of College Student Development, 48(1), 1-22.

Adelman, C., Ewell, P., Gaston, P., \& Schneider, C. G. (2014). The Degree Qualifications Profile: A learning-centered framework for what college graduates should know and be able to Do to earn the associate, bachelor's or master's Degree. Lumina Foundation for Education. https://www. luminafoundation.org/files/resources/dqp.pdf

Adler, R. (2015). Navigating continual disruption. Aspen Institute. https://csreports.aspeninstitute.org/ documents/NavigatingDistruption.pdf

Advanced Robotics for Manufacturing Institute. (n.d.). Driving the future of manufacturing through collaboration. https://arminstitute.org/about/

Agarwal, R., Chandrasekaran, S., \& Sridhar, M. (2016). Imagining construction's digital future. Our insights. http://www.mckinsey.com/industries/capital-projects-and-infrastructure/our-insights/ imagining-constructions-digital-future

Allison, S. T., \& Goethals, G. R. (2011). Heroes: What they do and why we need them. Oxford University Press.

Alperovitz, G. (2013). What then must we do? Straight talk about the next American Revolution. Chelsea Green Publishing.

Alturi, V., Dietz, M., \& Henke, N. (2017, September). Learning innovation in the digital age. McKinsey Quarterly, (3). https://www.mckinsey.com/business-functions/organization/ our-insights/learning-innovation-in-the-digital-age

Amelink, C.T., \& Nicewonger, T. (2019, October). Advancing integrative learning opportunities through transdisciplinary communities. American Association for Colleges and Universities, Transforming STEM Higher Education, Chicago, IL.

American School Counseling Association. (2015). State-by-state student-to-counselor ratios report: A 10-year trend. https://www.schoolcounselor.org/asca/media/asca/Publications/ratioreport.pdf

American Montessori Society. (2020). https://amshq.org/ 
REFERENCES

Anderson, E. C. (2005). Strengths-Based educating: A concrete way to bring out the best in studentsand yourself: The confessions of an educator who got it right-finally! Educational Horizons, 83(3), 180-189. https://files.eric.ed.gov/fulltext/EJ685057.pdf

Anderson, L. W., \& Krathwohl, D. R. (2001). A taxonomy for learning, teaching, and assessing: A revision of Bloom's taxonomy of educational objectives. Longman.

Anderson, J. R., Reder, L. M., \& Simon, H. A. (1996). Situated learning and education. Educational Researcher, 25(4), 5-11. https://doi.org/10.3102/0013189X025004005

Aoun, J.E. (2017). Robot-proof: higher education in the age of artificial intelligence. MIT Press.

Argyris, C. \& Schön, D. A. (1978). Organizational learning. A theory of action perspective. Addison-Wesley Pub. Co.

Association of American Colleges and Universities. (2011). The LEAP vision for learning: outcomes, practices, impact, and employers'views. Association of American Colleges and Universities.

Association of American Colleges and Universities. (2020). VALUE: What is value? https://www.aacu. org/value

Association of Public \& Land Grant Universities (APLU). (2019). University-community student success partnerships. https:/www.aplu.org/members/commissions/urban-serving-universities/ student-success/cog.html

Association of Public \& Land Grant Universities (APLU) \& Coalition of Urban Serving Universities (USU). (n.d.). USU initiatives. https://www.aplu.org/members/commissions/urban-serving-universities/student-success

Association of Public \& Land Grant Universities (APLU) \& Coalition of Urban Serving Universities (USU). (2019). Delivering 21st century skills [White paper]. https://www.aplu.org/members/ commissions/urban-serving-universities/usu-publications/APLU_USU_21stCentury_.pdf

Autor, D.H. (2013). The "Task Approach" to labor markets: An overview. Journal for Labour Market Research, 46(3), 185-199. https://doi.org/10.2139/ssrn.2211349

Autor, D.H. (2015). Why are there still so many jobs? The history and future of workplace automation. Journal of Economic Perspectives, 29(3), 3-30. https://doi.org/10.1257/jep.29.3.3

Autor, D. H., Levy, F., \& Murnane, R. J. (2003). The skill content of recent technological change: An empirical exploration. The Quarterly Journal of Economics, 118(4), 1279-1333. https://doi. org/10.1162/003355303322552801 
REFERENCES

Autor, D.H., \& Price, B. (2013). The changing task composition of the US Labor Market: An update of Autor, Levy, and Murnane [Working paper].

Avis, J. (2002). Social capital, collective intelligence and expansive learning: Thinking through the connections, education, and the economy. British Journal of Educational Studies, 50(3), 308326. https://doi.org/10.1111/1467-8527.t01-1-002051

Balcar, J., Homolová, E., Karásek, Z. et al. (2011). Transferable skills across economic sectors: Role and importance for Employment at European level. Publications Office of the European Union.

Baldwin, T. T., \& Ford, J. K. (1988). Transfer of training: A review and directions for future research. Personnel Psychology, 41(1), 63-105. https://doi.org/10.1111/j.1744-6570.1988.tb00632.x

Balsamo, A. (2010). Working the paradigm shift: Educating the technological imagination. In D. Araya $\&$ M. A. Peters (Eds.), Education in the creative economy: Knowledge and learning in the age of innovation (pp. 423-446). Peter Lange Publishing.

Bandura, A. (1986). Social foundations of thought and action. Prentice Hall.

Bandura, A. (1997). Self-efficacy: The exercise of control. Freeman.

Bandura, A. (2001). Social cognitive theory: An agentic perspective. Annual Review of Psychology, 52(1), 1-26. https://doi.org/10.1111/1467-839X.00024

Banerji, S. (2007). Report: Employers say college graduates lack essential skills to succeed in today's global Economy. Diverse Issues in Higher Education, 23(26), 18.

Barab, S. A., Barnett, M., \& Squire, K. (2002). Developing an empirical account of a community of practice: Characterizing the essential tensions. The Journal of the Learning Sciences, 11(4), 489-542. https://doi.org/10.1207/S15327809JLS1104_3

Bartlett, W., \& Rees, T. (2000). The variable contribution of guidance services in different types of learning societies. In F. Coffield (Ed.), Differing visions of a learning society (pp. 139-166). Policy Press.

Baxter Magolda, M. B. (1999). Creating contexts for learning and self-authorship: Constructive-developmental pedagogy. Vanderbilt University Press.

Basken, P. (2020, April 23). From crisis, US researchers see prospect of durable gains: Partnership approach during pandemic raises hopes of bursting scientific silos. Times Higher Education. https:/www.timeshighereducation.com/news/crisis-us-researchers-see-prospect-durable-gains\# 
REFERENCES

Bedwell, W. L., Salas, E., \& Fiore, S. M. (2011). Developing the 21st century (and beyond) workforce: A review of interpersonal skills and measurement strategies. In NRC Workshop on Assessing 21st Century Skills. https://www.academia.edu/998931/Developing the 21 st_Century and Beyond_Workforce_A_Review_of_Interpersonal_Skills_and_Measurement_Strategies

Benner, P. (2004). Using the Dreyfus model of skill acquisition to describe and interpret skill acquisition and clinical judgment in nursing practice and education. Bulletin of Science, Technology \& Society, 24(3), 188-199. https://doi.org/10.1177/0270467604265061

Bennington College. (n.d.). Field Work Term. https://www.bennington.edu/academics/field-work-term

Bhattacharyya, S., Junot, M., \& Clark, H. (2013). Can you hear us? Voices raised against standardized testing by novice teachers. Creative Education, 4(10), 633-639. https://doi.org/10.4236/ ce. 2013.410091

Blair, P. Q., \& Deming, D. J. (2020). Structural increases in skill demand after the Great Recession (No. w26680). National Bureau of Economic Research. Interactive Media in Education, 1, 1-25. https://ssrn.com/abstract $=3522329$

Bleizner, R., Grant, A., \& Rikakis, T. (2016). Envisioning Virginia Tech Beyond Boundaries: A 2047 Vision. http://hdl.handle.net/10919/79633

Bliss, T. J., \& Smith, M. (2017). A brief history of open educational resources. In R. S. Jhangiani \& R. Biswas-Diener (Eds.), Open: The philosophy and practices that are revolutionizing education and science (pp. 11-28). Ubiquity Press.

Bloom, B. S. (1956). Taxonomy of educational objectives, handbook I: The cognitive domain. David McKay Co. Inc.

Bloom, B. S. (1984). The 2 sigma problem: The search for methods of group instruction as effective as one-to-one tutoring. Educational Researcher, 13(6), 4-16. https://doi. org/10.3102/0013189X013006004

Boeing. (2020). Our values. https://www.boeing.com/principles/values.page

Bohn, D. (2019, February 24). Microsoft's Hololens 2: A \$3,500 mixed reality headset for the factory, not the living room. The Verge. https://www.theverge.com/2019/2/24/ 18235460/microsoft-hololens-2-price-specs-mixed-realityar-vr-business-work-features-mwc-2019

Boulet, G. (2015, October 17). The difference between knowledge and skills: Knowing does not make you skilled. eLearning Industry. https://elearningindustry.com/difference-between-knowledgeand-skills-knowing-not-make-skilled 
REFERENCES

Brown University. (n.d.). The open curriculum. https://www.brown.edu/academics/undergraduate/ open-curriculum

Brown, J. S., Collins, A., \& Duguid, P. (1989). Situated cognition and the culture of learning. Educational Researcher, 18(1), 32-42. https://doi.org/10.3102/0013189X018001032

Brown, A., \& Keep, E. (Eds.). (2000). Review of vocational education and training research in the United Kingdom. Office for Official Publications of the European Communities.

Bruner, J. (1990). Acts of meaning. Harvard University Press.

California Polytechnic. (2017). Cal Poly launches world's first university-based cloud innovation center powered by Amazon Web Services. Cal Poly News. https://calpolynews.calpoly.edu/news_releases/2017/october/amazon

Cardone, T. (2018). Embracing customization in higher education: Leveraging personal learning design to promote design thinking and self-authorship. About Campus, 23 (4), 11-18. https://doi. org/10.1177/1086482218817533

Carnegie Mellon Robotics Academy. (2020). CS-STEM network. CS2N. https://www.cs2n.org/

Carnegie Mellon University. (2019). Advanced robotics for manufacturing (ARM) partners with Carnegie Mellon University's NREC and CMRA to grow a skilled, technical workforce. National robotics engineering center. https://www.nrec.ri.cmu.edu/nrec/media/news-stories-pages/ news-stories-2019/cmra-arm-smart.html

Carnegie Mellon University. (n.d.). The future of manufacturing is here. Advanced manufacturing. https://www.cmu.edu/advanced-manufacturing/

Carnegie Mellon University. (n.d.). Undergraduate programs. Computer science department. https:// csd.cmu.edu/academic/undergraduate/bachelors-curriculum-admitted-2018

Carroll, J.B. (1993). Human cognitive abilities: A survey of factor-analytic studies. Cambridge University Press.

Carayannis, E. G. (2014). Developed democracies versus emerging autocracies. Journal of Innovation and Entrepreneurship, 3(12), 1-23. https://doi.org/10.1186/s13731-014-0012-2

Carayannis, E. G., \& Campbell, D. (2019). Smart quintuple helix innovation systems: How social ecology and environmental protection are driving innovation, sustainable development and economic growth. Springer.

Chatterjee, D. K. (2019). Human rights in honors education [Paper presentation]. Honors Education in Research Universities, University of Utah, Salt Lake City, United States. 
REFERENCES

Chickering, A. W., \& Reisser, L. (1993). Education and identity. Jossey-Bass Inc.

Clark, R. E., \& Voogel, A. (1985). Transfer of training principles for instructional design. Educational Communication and Technology, 33(2), 113-123.

Clifton, D. O., Anderson, E., \& Schreiner, L. A. (2002). StrengthsQuest. The Gallup Organization.

Coffield, F. (1999). Breaking the consensus: Lifelong learning as social control. British Educational Research Journal, 25(4), 479-499. https://doi.org/10.1080/0141192990250405

Coffield, F. (Ed.). (2000). Differing visions of a learning society: Research findings (Vol. 1). Policy Press.

Coghlan, D., \& Brydon-Miller, M. (Eds.). (2014). The SAGE encyclopedia of action research. Sage.

Collins, A. (2006). Cognitive apprenticeship. In K. R. Sawyer (Ed.), The Cambridge handbook of the learning sciences (pp. 47-60). Cambridge University Press.

Collins, A., \& Halverson, R. (2018). Rethinking education in the age of technology: The digital revolution and schooling in America. Columbia University-Teacher's College Press.

Collins, R. (2002). Credential inflation and the future of universities. In S. Brint (Ed.) The future of the city of intellect (pp. 23-46). Stanford University Press.

Costa, A., \& Kallick, B. (2014). Dispositions: Reframing teaching and learning. Corwin.

Costa, H. M., Nicholson, B., Donlan, C., \& Van Herwegen, J. (2018). Low performance on mathematical tasks in preschoolers: the importance of domain-general and domain-specific abilities. Journal of Intellectual Disability Research, 62(4), 292-302. http://doi.org/10.1111/jir.12465

Council, S. S. R. (2018). To secure knowledge: Social science partnerships for the common good. https://www.ssrc.org/to-secure-knowledge/

Creative Commons (CC). (2019). Education/OER. https://creativecommons.org/about/program-areas/ education-oer/

Crow, M. M., \& Dabars, W. B. (2020). The fifth wave: The evolution of American higher education. Johns Hopkins University Press.

Darbellay, F. (2015). Rethinking inter- and transdisciplinarity: Undisciplined knowledge and the emergence of a new thought style. Futures, 65, 163-174. http://dx.doi.org/10.1016/j.futures.2014.10.009 
REFERENCES

Davies, J. S., \& Spicer, A. (2015). Interrogating networks: Towards an agnostic perspective on governance research. Environment and Planning C: Government and Policy, 33(2), 223-238. https:// doi.org/10.1068/c11292

Deci, E. L., \& Ryan, R. M. (2008). Facilitating optimal motivation and psychological well-being across life's domains. Canadian Psychology/Psychologie Canadienne, 49(1), 14. https://doi. org/10.1037/0708-5591.49.1.14

Dede, C. (2019). The 60 year curriculum: Developing new educational models to serve the agile labor market. The evolution: A destiny solutions illumination. https://evolllution.com/revenue-streams/professional development/the-60-year-curriculum-developing-new-educational-models-to-serve-the-agile-labor-market/

Democracy at Work Institute. (2018). State of the sector: US worker cooperatives in 2017. Journal of Participation and Employee Ownership, 2(3), 190-201. https://doi.org/10.1108/JPEO-09-2019$\underline{0023}$

Derivatives. (2019, June 19). In Wikipedia. https://en.wikipedia.org/wiki/Time derivative

Derrida, J. (2004). Eyes of the university: Right to philosophy 2. Stanford University Press.

De Weck, O. L., Roos, D., \& Magee, C. L. (2011). Engineering systems: Meeting human needs in a complex technological world. Mit Press.

Dewey, J. (1906). The child and the curriculum. University of Chicago Press.

Dewey, J. (1910). How we think. D.C. Heath \& Co. Publishers.

Dewey, J. (1934). Art as experience. Routledge.

Dewey, J. (1938). Experience and education. Collier.

Dewey, J. (1966). Democracy and Education. Free Press.

Dewey, J. (1964) What psychology can do for the teacher. In R. Archambault (Ed.), John Dewey on education: Selected writings. Random House.

Dierking, L. D., \& Falk, J. H. (2016). 2020 Vision: Envisioning a new generation of STEM learning research. Cultural Studies of Science Education, 11(1), 1-10. https://doi.org/10.1007/s11422$\underline{015-9713-5}$

Donovan, S. (2015). Multi-agency science and technology priorities for the FY 2017 budget. Office of the President. 
REFERENCES

Dourish, P. (2001). Where the action is: The foundations of embodied interaction. MIT Press.

Dreyfus, H. L., \& Dreyfus, S. E. (1986). Mind over machine: The power of human intuition and expertise in the era of the computer. Free Press.

Duncan, C. M. (2001). Social capital in America's poor rural communities. In S. Saegert, J. P. Thompson, \& M. R. Warren (Eds.), Social capital and poor communities (pp. 60-88). Russell Sage.

Duncan-Andrade, J. M. R., \& Morrell, E. (2008). The art of critical pedagogy: Possibilities for moving from theory to practice in urban schools (Vol. 285). Peter Lang.

DuPre, C., \& Williams, K. (2011). Undergraduates' perceptions of employer expectations. Journal of Career and Technical Education, 26(1), 8-19. https://doi.org/10.21061/jcte.v26i1.490

Eagle, N., Macy, M., \& Claxton, R. (2010). Network diversity and economic development. Science, 328, 1029-1031. https://doi.org/10.1126/science.1186605

EdPlus (2018). Who we are. Arizona State University. https://edplus.asu.edu/who-we-are

Eraut, M. (1985). Knowledge creation and knowledge use in professional contexts. Studies in Higher education, 10(2), 117-133. https://doi.org/10.1080/03075078512331378549

Eraut, M. (2004). Transfer of knowledge between education and workplace settings. In H. Rainbird, A. Fuller, \& H. Munro (Eds.), Workplace learning in context (pp. 201-221). Routledge.

Ericsson, K.A., Krampe, R.T., \& Tesch-Römer, C. (1993). The role of deliberate practice in the acquisition of expert performance. Psychological Review, 100(3), 363-406. https://doi. $\underline{\operatorname{org} / 10.1037 / / 0033-295 X .100 .3 .363}$

ESSENCE (2016). Planning, monitoring and evaluation framework for research capacity strengthening. ESSENCE on Health Research. World Health Organization. https://www.who.int/tdr/publications/Essence frwk 2016 web.pdf

Etherington, Cait. (2018, April 22). New Gallup study finds student satisfaction is above average at $W G U$. ELearningInside News https://news.elearninginside.com/new-gallup-study-finds-student-satisfaction-average-wgu/

Fadel, C., Bialik, M., \& Trilling, B. (2015). Four-dimensional education. Center for Curriculum Redesign.

Feuerstein, R., Rand, Y., Hoffman, M. B., \& Miller, R. (1980). Instrumental enrichment: An intervention program for cognitive modifiability. University Park Press. 
REFERENCES

Florida, R. (2002). The rise of the creative class: And how it's transforming work, leisure, community and everyday life. Basic Books.

Flowers, W. (2009, May 8). Engineer of the future 2.0. Summit on transforming engineering education. https://www.youtube.com/watch?v=F84LtXvLTtA

Foucault, M. (1969). L’Archéologie du savoir. Éditions Gallimard.

Ford, J. K., Smith, E. M., Weissbein, D. A., Gully, S. M., \& Salas, E. (1998). Relationships of goal orientation, metacognitive activity, and practice strategies with learning outcomes and transfer. Journal of Applied Psychology, 83(2), 218. https://doi.org/10.1037/0021-9010.83.2.218

Furrer, C., \& Skinner, E. (2003). Sense of relatedness as a factor in children's academic engagement and performance. Journal of Educational Psychology, 95(1), 148. https://doi.org/10.1037/0022$\underline{0663.95 .1 .148}$

Galaleldin, M., \& Anis, H. (2017). Impact of makerspaces on cultivating students' communities of practice. Conference Proceedings from the 2017 ASEE Annual Conference \& Exposition. https:// www.asee.org/public/conferences/78/papers/20041/view

George Mason University. (2019). NOVA ADVANCE. https://www2.gmu.edu/admissions-aid/advance

Georgia State University. (2020). GPS advising. Student success programs at Georgia State. https://success.students.gsu.edu/gps-advising/

Georgia Tech Commission on Creating the Next in Education. (2018a). Deliberate innovation, lifetime education. Georgia Tech Office of the Provost. https://provost.gatech.edu/sites/default/files/documents/deliberate innovation_lifetime_education.pdf

Georgia Tech Commission on Creating the Next in Education (2018b). Initiative 1: Whole-person education. Georgia Tech Office of the Provost. https://provost.gatech.edu/educational-innovation/ reports/lifetime-education/initiatives/whole-person-education

Georgia Tech Commission on Creating the Next in Education (2018c). Whole-person development. In Creating the next in education, supplement (pp. 1-6). https://provost.gatech.edu/commission-creating-next-education

Ginda, M., Richey, M. C., Cousino, M., \& Börner, K. (2019). Visualizing learner engagement, performance, and trajectories to evaluate and optimize online course design. PLoS One, 14(5), 1-19. https://doi.org/10.1371/journal.pone.0215964

Gnedenko, B. V., Kolmogorov, A. (1954). Limit distributions for sums of independent random variables. Addison-Wesley Publishing Company. 
REFERENCES

Goel, A. K., \& Polepeddi, L. (2016). Jill Watson: A virtual teaching assistant for online education. Georgia Institute of Technology.

Goldrick-Rab, S. (2016). Paying the price: College costs, financial aid, and the betrayal of the American dream. University of Chicago Press.

Goldstein, I. L., \& Ford, J. K. (2002). Training in organizations. Wadsworth.

Grabher, G., \& Stark, D. (1997). Organizing diversity: Evolutionary theory, network analysis and postsocialism. Regional Studies, 31, 533-544. https://doi.org/10.1080/00343409750132315

Green, T., \& Parnell, A. (2017). Comprehensive student record project: Final report. American Association of Collegiate Registrars and Admissions Officers (AACRAO) and the Association of Student Personnel Administrators (NASPA). https://www.aacrao.org/docs/default-source/ signature-initiative-docs/clr/comprehensive-student-record-project-final-report-9 2017---pubversion.pdf

Grinnell College. (n.d.-a). First year tutorial. Academics. https://www.grinnell.edu/academics/experi$\underline{\text { ence/tutorial }}$

Grinnell College. (n.d.-b). Grinnellians map their own academic journeys. Academics. https://www. grinnell.edu/admission/why-grinnell/academics

Guattari, F. (1972). Psychoanalysis and transversality. Semiotext(e).

Guest, D. (1991, September 17). The hunt is on for the Renaissance man of computing. The Independent.

Habib, M. K., \& Chimsom, C. (2019). Industry 4.0: Sustainability and design principles. 2019 20th International Conference on Research and Education in Mechatronics (REM) (pp. 1-8). IEEE.

Hall, B. L., \& Tandon, R. (2017). Decolonization of knowledge, epistemicide, participatory research and higher education. Research for All, 1(1), 6-19. https://doi.org/10.18546/RFA.01.1.02

Harnecker, C. (2007). Workplace democracy and collective consciousness. Monthly Review, 59(6), 27-40. https://doi.org/10.1521/siso.2009.73.3.309

Haveman, R.H., \& Smeeding, T.M. (2006). The role of higher education in social mobility, The Future of Children, 16(2), 125-150. https://doi.org/10.1353/foc.2006.0015

Hart, R. A. (2016). Falling short? College learning and career success. NACTA Journal, 60(1), 1-6.

Heales, C., Hodgson, M., \& Rich, H. (2017). Humanity at work: MONDRAGON, a social innovation ecosystem case study. The Young Foundation. 
REFERENCES

Hecklau, F., Galeitzke, M., Flachs, S., \& Kohl, H. (2016). Holistic approach for human resource management in industry 4.0. Procedia CIRP, 54(1), 1-6. https://doi.org/10.1016/j.procir.2016.05.102

Hein, G. (2009). Learning science in informal environments: People, places, and pursuits. Museums \& Social Issues, 4(1), 113-124.

Hermans, J., \& Lentz, B. (2013). Equilibria and kinetics of biological macromolecules. Wiley Online Library.

Herzog, S. M., \& Hertwig, R. (2009). The wisdom of many in one mind: Improving individual judgments with dialectical bootstrapping. Psychological Science, 20(2), 231-237. https://doi. org/10.1111/j.1467-9280.2009.02271.x

Hevner, A., \& Chatterjee, S. (2010). Design science research in information systems. In Design research in information systems (pp. 9-22). Springer.

Hlatshwayo, S., \& Spence, M. (2014). Demand and defective growth patterns: The role of the tradable and non-tradable sectors in an open economy. American Economic Review, 104 (5), 272-77. https://doi.org/10.1257/aer.104.5.272

Holmes, W., Bialik, M., \& Fadel, C. (2019). Artificial intelligence in education: Promises and implications for teaching and learning. Center for Curriculum Redesign.

Hoffman, R. R., Ward, P., Feltovich, P. J., DiBello, L., Fiore, S. M., \& Andrews, D. H. (2014). Accelerated expertise: Training for high proficiency in a complex world. Psychology Press.

Holt, E., Shaurette, M. and Chasek. C. (2018). A Comparison of construction management and engineering student learning styles, 2016 American Society of Engineering Education, 2016 Annual Conference \& Exposition.

Hope, D., \& Martelli, A. (2019). The transition to the knowledge economy, labor market institutions, and income inequality in advanced democracies. World Politics, 71(2), 236-288. https://doi. org/10.1017/S0043887118000333

Hutchins, E. (1995). Cognition in the wild. MIT Press.

IDEO. (n.d). Design thinking defined. IDEO Design Thinking. https://designthinking.ideo.com/

Is it still possible to pay for college? (2019). New York Times. https://www.nytimes.com/interactive/2019/09/19/opinion/paying-college-tuition.html 
REFERENCES

Jackson, Y., \& McDermott, V. (2015). Unlocking student potential: How do I identify and activate students'strengths? ASCD.

Jantsch, E. (1972). Inter- and transdisciplinary university. Higher Education, 1(1), 7-37. https://doi. org/10.1007/BF00145222

Jassel, P. K., \& Clark, H. (2016). The evolution of a new learning economy. In K. Winters (Ed.), The New learning economy and the rise of the working learner: An anthology of recent evidence (pp. 14-22). ACT Foundation and ACT Center for Equity in Learning. https://pages2.act.org/riseofworkinglearners.html\#_ga=2.135915894.610323121.1567628866-2066686857.1567628866

Jefferson County Public Schools. (n.d.). Academies of Louisville. JCPS. https://www.jefferson.kyschools.us/academies-louisville

Jensen, E. (1998). Teaching with the brain in mind. Association for Supervision and Curriculum Development.

Johnson, W., \& Bouchard Jr, T. J. (2005). The structure of human intelligence: It is verbal, perceptual, and image rotation (VPR), not fluid and crystallized. Intelligence, 33(4), 393-416. https://doi. org/10.1016/j.intell.2004.12.002

Jonassen, D., Cernusca, D., \& Ionas, G. (2007). Constructivism and instructional design: The emergence of the learning sciences and design research. In R. A. Reiser \& J. V. Dempsey (Eds.), Trends and issues in instructional design and technology (2nd ed., pp. 45-52). Pearson.

Joo, J., \& Spies, R. R. (2019, November 7). Aligning many campuses and instructors around a common adaptive learning courseware in introductory statistics: Lessons from a multi-year pilot in Maryland. https://doi.org/10.18665/sr.312073

Journeys. (2019). Your learning map for endless possibilities. https://journeysmap.com/

Kadel, R. S., Gazi, Y., Harmon, S., Goel, A., \& Courville, T. (2019). Toward a Road Map for scalable advanced learning ecosystems (SALES). International Journal on Innovations in Online Education, 3(1). https://doi.org/10.1615/IntJInnovOnlineEdu.2019030903

Kegan, R. (1994). In over our heads: The mental demands of modern life. Harvard University Press.

Kelly, K. (2016). The inevitable: Understanding the 12 technological forces that will shape our future. Viking.

Kinghorn, J. R., \& Womack-Smith, W. (2013). Nontraditional honors. Journal of the National Collegiate Honors Council, 14(1), 15-21. 
REFERENCES

Klein, J. T. (2008). Evaluation of interdisciplinary and transdisciplinary research: a literature review. American Journal of Preventive Medicine, 35(2), S116-S123. https://doi.org/10.1016/j.amepre.2008.05.010

Knight, D. (2013). Curricular and organizational features of undergraduate interdisciplinary programs. Innovative Higher Education, 38(2), 143-158. https://doi.org/10.1007/s10755-012-9232-1

Knowledge Media Institute \& The Open University. (2018). Researching the potential of blockchains. OpenBlockchain. Knowledge Media Institute, The Open University, UK. Retrieved from http:// blockchain.open.ac.uk

KnowledgeWorks. (2020). Thought Leadership Resources. https://knowledgeworks.org/resources/

Knudsen, H., Busck, O., \& Lind, J. (2011). Work environment quality: the role of workplace participation and democracy. Work, Employment and Society, 25(3), 379-396. https://doi. org/10.1177/0950017011407966

Koedinger, K., McLaughlin, E. A., \& Stamper, J. C. (2014, May). Data-driven learner modeling to understand and improve online learning: MOOCs and technology to advance learning and learning research. Ubiquity, 3. https://dl.acm.org/citation.cfm?id=2591682

Koestler, A. (1967). The ghost in the machine. Penguin Group.

Kohlberg, L. (1976). Moral Stages, Moralization: The Cognitive Developmental Approach. In T. Lickona (Ed.), Moral development and behavior. Holt, Rinehart, Winston.

Kohlberg, L. (1981). The philosophy of moral development. Harper \& Row.

Krathwohl, D. R., Bloom, B. S., \& Masia, B. B. (1956). Taxonomy of educational objectives: The classification of educational goals; Handbook II: Affective domain. David McKay Company, Incorporated.

Lattuca, L. R., \& Stark, J. S. (2011). Shaping the college curriculum: Academic plans in context. Wiley \& Sons.

Lillard, A. S., Heise, M. J., Richey, E. M., Tong, X., Hart, A., \& Bray, P. M. (2017). Montessori preschool elevates and equalizes child outcomes: A longitudinal study. Frontiers in psychology, 8 , 1783. https://doi.org/10.3389/fpsyg.2017.01783

Lin, S. W., Murphy, B., Clauer, E., Loewen, U., Neubert, R., Bachmann, G., Pai, M., \& Hankel, M. (2017). Architecture alignment and interoperability: An industrial internet consortium and plattform industrie 4.0 joint whitepaper. Industrial Internet Consortium. 
REFERENCES

Lopata, C., Wallace, N. V., \& Finn, K. V. (2005). Comparison of academic achievement between Montessori and traditional education programs. Journal of Research in Childhood Education, 20(1), 5-13. https://doi.org/10.1080/02568540509594546

Lu, W. F., Yang, J. K., \& Chu, H. T. (2017, April). Playing Mastermind game by using reinforcement learning. In 2017 First IEEE International Conference on Robotic Computing (IRC) (pp. 418421). IEEE.

Madhaven, K., \& Richey, M. (2016). Problems in big data analytics in learning. Journal of Engineering Education, 105(1), 6-14. https://doi.org/10.1002/jee.20113

Madni, A. M., Paulson, C., Spraragen, M., Richey, M. C., Nance, M. L., \& Vander Wel, M. (2015, October). Model-based optimization of learning curves: Implications for business and government [Conference paper]. INCOSE International Symposium, 25(1) 1070-1084.

Madrigal, A. (2017, October 12). What Facebook Did to American democracy and why it was so hard to see it coming. The Atlantic. https://www.theatlantic.com/technology/archive/2017/10/whatfacebook-did/542502

Mahiri, J. (1998). Shooting for excellence: African American and youth culture in new century schools. National Council of Teachers of English.

Manyika, J., Lund, S., Chui, M., Bughin, J., Woetzel, J., Batra, P., Ko, R., \& Sanghvi, S. (2017, November). What the future of work will mean for jobs, skills, and wages. McKinsey \& Company. https://www.mckinsey.com/featured-insights/future-of-work/jobs-lost-jobs-gained-what-the-future-of-work-will-mean-for-jobs-skills-and-wages

Maslow, A. H. (1968). Toward a psychology of being. Van Nostrand.

Matusovich, H., Carrico, C., Harris, A., Sheppard, S., Brunhaver, S., Streveler, R., \& Lester, M. B. M. (2019). Internships and engineering: Beliefs and behaviors of academics. Education+ Training, 61(6), pp. 650-665.

McAfee, A., \& Brynjolfsson, E. (2017). Machine, platform, crowd: Harnessing our digital future. W. W. Norton \& Company.

McKenzie, Lindsay. (2019). Seeking a shared global standard for digital credentials. Inside Higher Ed. https://www.insidehighered.com/digital-learning/article/2019/04/24/mit-and-8-other-universities-partner-shared-digital-credential

Miller, R. (2010). From the ground up: Rethinking engineering education for the 21st century [Conference paper]. Symposium on Liberal Education, Union College, New York. 
REFERENCES

Mooney, C. G. (2013) An introduction to Dewey, Montessori, Erikson, Piaget \& Vygotsky (2nd Ed.). Redleaf Press.

Moore, M.G. (1993). Theory of transactional distance. In D. Keegan (Ed.), Theoretical principles of distance education (pp. 22-38). Routledge.

Muro, M., Maxim, R., \& Whiton, J. (2019). Automation and artificial intelligence: How machines are affecting people and places. Brookings Institute. https://www.brookings.edu/research/automa$\underline{\text { tion-and-artificial-intelligence-how-machines-affect-people-and-places/ }}$

Nagel, T. (1986). The view from nowhere. Oxford University Press.

National Academy of Engineering. (2005). Educating the engineer of 2020: Adapting engineering education to the new century. National Academies Press.

National Academy of Science. (2004). Facilitating interdisciplinary research. National Academies Press.

National Association of Colleges and Employers (NACE). (2017). Career readiness defined. https:// www.naceweb.org/career-readiness/competencies/career-readiness-defined/

National Nanotechnology Initiative. (2015). A nanotechnology-inspired grand challenge for future computing. Nano.gov. http://www.nano.gov/futurecomputing

National Research Council. (2000). How people learn: Brain, mind, experience, and school: Expanded edition. National Academies Press.

National Research Council. (2009). Surrounded by science: Learning science in informal environments. National Academies Press.

National Research Council (U.S.). (2013). Education for life and work: Developing transferable knowledge and skills in the 21st Century. National Academies Press.

National Science Board (NSB). (2019). The skilled technical workforce: crafting America's science \& engineering enterprise. National Science Foundation. https://www.nsf.gov/nsb/publications/2019/nsb201923.pdf

National Science Foundation. (2018). Boeing, National Science Foundation announce partnership for workforce development and diversity in STEM. https://www.nsf.gov/news/news summ. isp?cntn id $=296700$

National Society for Minorities in Honors. (n.d.). http://www.nsfmih.org/ 
REFERENCES

Nicewonger, T., \& Amelink C. (2019, April 30). Expanding transdisciplinary capacity: Creating connections across STEM and Non-STEM Disciplines. National Alliance for Broader Impacts. Tuscon, AZ.

Nicolescu, B. (2002). Manifesto of transdisciplinarity. SUNY Press.

Niemiec, C. P., \& Ryan, R. M. (2009). Autonomy, competence, and relatedness in the classroom: Applying self-determination theory to educational practice. Theory and research in Education, 7(2), 133-144. https://doi.org/10.1177/1477878509104318

Northeastern University. (2015). Northeastern 2025. https://www.northeastern.edu/academic-plan/

Northeastern University. (2019). Lifetime learning membership. https://www.northeastern.edu/graduate/ admissions-information/lifetimelearning/

Northeastern University. (2020). Global Mission. GEO. https://www.northeastern.edu/geo/aboutus/mission/

Oakley, J. (2018). Intelligent cognitive assistants (ICA) workshop summary and research needs. National Science Foundation. https://www.nsf.gov/crssprgm/nano/reports/ICA2 Workshop_Report 2018.pdf

Organization for Economic Co-Operation and Development (OECD). (2018). The future of education and skills: Education 2030. http://www.oecd.org/education/2030-project/\#: : text=OECD\%20 Future $\% 20$ of $\% 20$ Education $\% 20$ and,Economic $\% 20 \mathrm{Co} \% 2$ Doperation $\% 20$ and $\% 20$ Development\&text $=$ The $\% 20$ Future $\% 20$ of $\% 20$ Education $\% 20$ and, in $\% 20$ and $\% 20$ shape $\% 20$ their $\% 20$ $\underline{\text { future }}$

Osborne, P. (2015). Problematizing disciplinarity, transdisciplinarity problematics. Theory, Culture \& Society, 32(5-6), 3-35. https://doi.org/10.1177/0263276415592245

Osterberg, L. G., Goldstein, E., Hatem, D. S., Moynahan, K., \& Shochet, R. (2016). Back to the future: what learning communities offer to medical education. Journal of Medical Education and Curricular Development. https://doi.org/10.4137/JMECD.S39420

Oxford Consortium. (2019). Oxford Consortium on Human Rights. https://www.oxfordconsortium.org

Page, S. E. (2007). The difference. Princeton University Press.

Pateman, C. (1970). Participation and democratic theory. Cambridge University Press.

Perkins, D. N., \& Salomon, G. (1989). Are cognitive skills context-bound? Educational Researcher, 18(1), 16-25. https://doi.org/10.3102/0013189X018001016 
REFERENCES

Piaget, J. (1954). The construction of reality in the child (M. Cook trans.). Basic Books.

Piaget, J. (1963). The origin of intelligence in children. Norton.

Pink, D. H. (2009). Drive: The surprising truth about what motivates us. Riverhead Books.

Plato, \& Richards, I. A. (1966). Plato’s republic. Cambridge University Press.

Polanyi, M. (1958). Personal knowledge: Towards a post-critical philosophy. University of Chicago Press.

Popović, K. (2014). The skills: A chimera of modern European adult education. In M. N. Gravani \& G. K. Zarifis, Challenging the European area of lifelong learning (pp. 17-29). Springer.

Popowitz, M., \& Dorgelo, C. (2018, February 13). University-led grand challenges. https://escholarship.org/uc/item/46f121cr

Posey, T. (2019). Different cultures cause me to hesitate. In G. Harper (Ed.), Diversity, equity and inclusion in honors education. Cambridge Scholars Publishing.

Purdue Global. (2020). Transfer students. Purdue University Global. https://www.purdueglobal .edu/ transfer-students/

Purdue Polytechnic High School. (n.d.). https://pphs.purdue.edu/about

Purdue University. (2019). A revolutionary school backed by a pioneering university.

Purdue University-Purdue Polytechnic Institute. (2020). Hands-on education. Real-world success. https://polytechnic.purdue.edu/

Prelec, D., Seung, S. H., \& McCoy, J. (2017). A solution to the single-question crowd wisdom problem. Nature, 541(7638), 532-535. https://doi.org/10.1038/nature21054

Reagans, R., \& Zukerman, E. (2001). Networks, diversity, and productivity: The social capital of corporate R\&D teams. Organizational Science, 12(4), 502-517. https://doi.org/10.1287/ orsc.12.4.502.10637

Reber, A. S. (1989). Implicit learning and tacit knowledge. Journal of experimental psychology: General, 118(3), 219-235. https://doi.org/10.1037/0096-3445.118.3.219

Rees, T. \& Bartlett, W. (1999a) Adult guidance services in the European learning society: A Scottish case study. Studies in the Education of Adults, 31(1), 21-34. https://doi.org/10.1080/02660830.1 $\underline{999.11661399}$ 
REFERENCES

Rees, T., \& Bartlett, W. (1999b). Models of guidance services in the learning society: The case of the Netherlands. In F. Coffield (Ed.), Why's the beer always stronger up north? Studies of lifelong learning in Europe (pp. 21-30). Bristol.

Reeve, J. (2002). Self-determination theory applied to educational settings. In E. L. Deci \& R. M. Ryan (Eds.), Handbook of self-determination research (pp. 183-203). University of Rochester Press.

Results. (2020). Achievable Dream Academies. https://achievabledream.org/our-program/results/

Rhodes, T. (2010). Assessing outcomes and improving achievement: Tips and tools for using rubrics. Association of American Colleges \& Universities.

Rhodes, T. (2019). The changing nature of work and careers: Higher education as a hub for establishing a lifelong learning System. Liberal Education, 105(3-4), 6-11.

Rikakis, T., Kelliher, A., Nicewonger, T., \& Swearer, R. (2019). Transdisciplinary and transsector knowledge ecosystems advance knowledge democracies [keynote presentation]. Proceedings of European Conference on Education 2019, London, UK.

Rikakis, T., Kelliher, A., Sundaram, H., \& Huang, J. B. (2018). Progressive cyber-human intelligence. ACM Interactions, (25)4.

Rothschild, J. \& Whitt, J. A. (1986). The Cooperative workplace: Potentials and dilemmas of organizational democracy and participation. Cambridge University Press.

Rothschild-Whitt, J. (1979). The collectivist organization: An alternative to rational-bureaucratic models. American Sociological Review, 44(4), 509-527. https://doi.org/10.2307/2094585.

Rothschild-Whitt, J. \& Whitt, J. A. (1986). Worker-owners as an emergent class: Effects of cooperative work on job satisfaction, alienation and stress. Economic and Industrial Democracy, 7, 297317. https://doi.org/10.1177/0143831X8673004

Ruijs, N. (2017). The effects of Montessori education: Evidence from admission lotteries. Economics of Education Review, 61, 19-34. https://doi.org/10.1016/j.econedurev.2017.09.001

Sa, C. (2008). 'Interdisciplinary strategies' in U.S. research universities. Higher Education, 55(5), 537-552. https://doi.org/10.1007/s10734-007-9073-5

Salomon, G., \& Perkins, D. N. (1989). Rocky roads to transfer: Rethinking mechanism of a neglected phenomenon. Educational psychologist, 24(2), 113-142. https://doi.org/10.1207/ $\underline{\mathrm{s} 15326985 \mathrm{ep} 2402 \_1}$

Salomon, G., \& Perkins, D. N. (1998). Chapter 1: Individual and social aspects of learning. Review of Research in Education, 23(1), 1-24. https://doi.org/10.3102/0091732X023001001 


\section{REFERENCES}

Samuels, E. (2015). How faculty understood their implementation of a cluster-hiring initiative. University of Michigan, Ann Arbor. https://deepblue.lib.umich.edu/handle/2027.42/113474

Sawyer, K. (2007). Group genius: the creative power of collaboration. Basic Books.

Schleicher, A. (2015). Why Rethinking the What of Education Matters So Much. In Fadel, C., Bialik, M. \& Trilling, B., Four-dimensional education: The competencies learners need to succeed (pp. 1-4) [Prologue]. Center for Curriculum Redesign.

Schmidt, M. (2017, July 3). Manufacturing's maker movement revolution. https://www.aem.org/news/ manufacturings-maker-movement-revolution/

Schneider, W. J., \& McGrew, K. S. (2012). The Cattell-Horn-Carroll model of intelligence. In D. Flanagan \& P. Harrison (Eds.), Contemporary intellectual assessment: Theories, tests, and issues (3rd ed., pp. 99-144). Guilford.

Schön, D. A. (1983). The reflective practitioner: How professionals think in action. Basic Books.

Schön, D. A. (1987). Educating the reflective practitioner. Josey-Bass.

Schuler, D., De Cindio, F., \& De Liddo, A. (2015, June). Encouraging collective intelligence for the common good: how do we integrate the disparate pieces? In Proceedings of the 7th International Conference on Communities and Technologies (pp. 157-159).

Semel, M. (2019). Partnership power: Essential museum strategies for today's networked world. Rowan \& Littlefield.

Senge, P. (1990). The fifth discipline: The art \& practice of the learning organization. Random House Business.

Senge, P. M., Cambron-McCabe, N., Lucas, T., Smith, B., \& Dutton, J. (2012). Schools that learn (updated and revised): A fifth discipline fieldbook for educators, parents, and everyone who cares about education. Crown Business.

Sepkowitz, K. (2020). Why is Covid 19 death rate so low in Germany? CNN Opinion. https://www. cnn.com/2020/03/24/opinions/germany-low-death-rate-for-coronavirus-sepkowitz/index.html

Shor, I., \& Freire, P. (1987). A pedagogy for liberation: Dialogues on transforming education. Bergin \& Garvey.

Shushok Jr, F., \& Hulme, E. (2006). What's right with you: Helping students find and use their personal strengths. About Campus, 11(4), 2-8. https://doi.org/10.1002/abc.173

Simon, H. A. (1957). Models of man: Social and rational. John Wiley and Sons, Inc. 
REFERENCES

Simonton, D. K. (2000). Creative development as acquired expertise: Theoretical issues and an empirical test. Developmental Review, 20(2), 283-318. https://doi.org/10.1006/drev.1999.0504

Snell, D., Gekara, V., \& K. Gatt. (2016). Cross-occupational skill transferability: Challenges and opportunities in a changing economy. National Center for Vocational Education Research (NCVER). https://www.ncver.edu.au/research-and-statistics/publications/all-publications/ cross-occupational-skill-transferability-challenges-and-opportunities-in-a-changing-economy

Spear, S. J. (2004). Learning to lead at Toyota. Harvard Business Review, 82(5), 78-86+151. https://hbr.org/2004/05/learning-to-lead-at-toyota

Spence, M., \& Hlatshwayo, S. (2012). The evolving structure of the American economy and the employment challenge. Comparative Economic Studies, 54(4), 703-738. https://doi.org/10.1057/ ces.2012.32

Spohrer, J. C. (2006). Services sciences, management, and engineering (SSME): An emerging multidiscipline. Proceedings of the frontiers in service conference. https://doi.org/10.1007/978-0-387$\underline{76578-5}$

Starbucks. (2020). Future leaders start here. Careers. https://www.starbucks.com/careers/working-at-starbucks/education

Sternberg, R. J. (2006). Recognizing neglected strengths. Educational Leadership, 64(1), 30-35.

Szreter, S. (1999). A new political economy for Labour: The importance of social capital. Political Economy Research Centre, University of Sheffield.

Tegarden, D. P., Tegarden, L. F., \& Sheetz, S. D. (2009). Cognitive factions in a top management team: Surfacing and analyzing cognitive diversity using causal maps. Group Decision and Negotiation, 18(6), 537-566. https://doi.org/10.1007/s10726-007-9099-1

Tenenbaum, J. B., Kemp, C., Griffiths, T. L., \& Goodman, N. D. (2011). How to grow a mind: Statistics, structure, and abstraction. Science, 331(6022), 1279-1285. https://doi.org/10.1126/science. 1192788

Thibodeaux, W. (2018). AI is awesome, blockchain is a powerhouse. But here's what combining them could do. Inc.com. https://www.inc.com/wanda-thibodeaux/ai-is-awesome-blockchain-is-apowerhouse-but-heres-what-combining-them-could-do.html

Thornton, T. (2013). Clinical judgment, tacit knowledge, and recognition in psychiatric diagnosis. In K. W. M. Fulford, M. Davies, R. G. T. Gipps, G. Graham, J. Z. Sadler, \& G. Stanghellini (Eds.), The Oxford handbook of philosophy and psychiatry. Oxford University Press.

Trilling, B., \& Fadel, C. (2009). 21st century skills: Learning for life in our times. John Wiley \& Sons. 
REFERENCES

Tschannen-Moran, M., \& Tschannen-Moran, B. (2011). Taking a strengths-based focus improves school climate. Journal of School Leadership, 21, 422-448. https://doi.org/10.1177\% $\underline{2 \mathrm{~F} 105268461102100305}$

Tsui, A. B. (2012). The dialectics of theory and practice in teacher knowledge development. In J. Hüttner, B. Mehlmauer-Larcher, S. Reichl, \& B.Schiftner (Eds.), Theory and practice in EFL teacher education: Bridging the gap (pp. 16-37). Multilingual Matters.

U.S. Bureau of Labor. (2020, June 18). Unemployment insurance weekly claims report. Bureau of Labor Statistics. https://www.dol.gov/newsroom/releases/eta/eta20200618

UNESCO. (2000, April 26-28). The Dakar framework for action: education for all-meeting our collective needs [paper]. World Education Forum, Dakar, Senegal.

UNESCO. (2019). Leave no one behind: Participation, equity and inclusion. UNESCO Institute for Lifelong Learning.

United Nations General Assembly. (2015). General assembly resolution 70/1. Transforming our world: the 2030 agenda for sustainable development-A/RES/70/1. United Nations.

United Way of Southwest Virginia. (n.d.). Ignite tech talent development program. https://unitedwayswva.org/technology-talent-development-program/

University of Central Florida. (n.d. -a). Direct connect to UFC. https://directconnect.ucf.edu/

University of Central Florida. (n.d. -b). Orlando's university. UCF downtown. https://www.ucf.edu/ downtown/

University of Detroit Mercy. (n.d.). Response to the U.S. Department of Education's request for information about promising and practical strategies to increase postsecondary success: Modular math at University of Detroit Mercy. www2.ed.gov/documents/college-completion/modu$\underline{\text { lar-math.doc }}$

University of Waterloo. (n.d. -a) Co-op programs. Undergraduate programs. https://uwaterloo.ca/future-students/co-op

University of Waterloo. (n.d. -b) Steps to careers in health and medicine. Undergraduate programs. https:/uwaterloo.ca/future-students/careers-health

University of Waterloo. (2019). Our differentiators. https://uwaterloo.ca/about/differentiators

Van Herwegen, J., Costa, H. M., Nicholson, B., \& Donlan, C. (2018). Improving number abilities in low achieving preschoolers: Symbolic versus non-symbolic training programs. Research in 
REFERENCES

developmental disabilities, 77, 1-11. https://doi.org/10.1016/j.ridd.2018.03.011

Virginia Tech. (2017). The Myers-Lawson School of Construction. https://www.mlsoc.vt.edu/

Vygotsky, L. S. (1978). Mind in society. Harvard University Press.

Walsh, J. D. (2020, May 11). The coming disruption: Scott Galloway predicts a handful of elite cyborg universities will soon monopolize higher education. Intelligencer. New York Magazine. https:// nymag.com/intelligencer/2020/05/scott-galloway-future- of-college.html

Wan, C. Y., \& Schlaug, G. (2010). Music making as a tool for promoting brain plasticity across the life span. The Neuroscientist, 16(5), 566-577. https://doi.org/ 10.1177/1073858410377805

Wayne State University. (2019a). Lumina convening shines as Spotlight on Wayne State, Detroit. Today@Wayne. https://today.wayne.edu/news/2019/04/24/lumina-convening-shines-a-spotlighton-wayne-state-detroit-31628

Wayne State University. (2019b). Program partners. C2 Pipeline. https://c2pipeline.wayne.edu/ partners/program-partners

Weber, L. (2019). Why companies are failing at reskilling. The Wall Street Journal. https://www. wsj.com/articles/the-answer-to-your-companys-hiring-problem -might-be-right-under-your$\underline{\text { nose- } 11555689542}$

Weise, M. R., Hanson, A. R., Salisbury, A. \& Qu, K. (2019). On-ramps to good jobs: Fueling innovation for the learning ecosystem of the future. Strada Institute for the Future of Work and Entangled Solutions. https://go.stradaeducation.org/on-ramps

Weise, M. R., Hanson, A. R., Sentz, R., \& Saleh, Y. (2018). Robot-ready: Human skills for the future of work. Strada Education Network. https://www.stradaeducation.org/press-release/robot-ready-labor-market-analysis-finds-human-skills-in-high-demand/

Wenger, E. (1998). Communities of practice: Learning, meaning, and identity. Cambridge University Press.

Wenger, E. (2000). Communities of practice and social learning systems. Organization, 7(2), 225. https://doi.org/10.1177/135050840072002

Whitney, P. (2010). Learning in the creative economy. In D. Araya \& M. A. Peters (Eds.), Education in the creative economy: knowledge and learning in the age of innovation (pp. 448-467). Peter Lange Publishing.

Wilber, K., Patten, T., Leonard, A., \& Morelli, M. (2012). Integral life practice: A 21 st century blueprint for physical health, emotional balance, mental clarity, and spiritual awakening. Shambha- 
REFERENCES

la Publications.

Wolff, R.D., \& Resnick, S.A. (2012). Contending economic theories: neoclassical, keynesian, and marxian. The MIT Press.

Woolfolk, A. W., \& Margetts, K. (2013). Educational psychology (3rd ed.). Pearson Australia.

World Data Lab. (2019). World poverty clock. http://worldpoverty.io/

World Economic Forum. (1990). The world competitiveness report. World Economic Forum.

World Economic Forum. (2016a). The future of jobs: Employment, skills and workforce strategy for the fourth industrial revolution. World Economic Forum.

World Economic Forum. (2016b). Mastering the Fourth Industrial Revolution. World Economic Forum. http://www3.weforum.org/docs/WEF_AM16_Report.pdf

World Economic Forum. (2017). Accelerating workforce reskilling for the Fourth industrial revolution: An agenda for leaders to shape the future of education, gender and work. World Economic Forum.

World Economic Forum \& Boston Consulting Group (BCG). (2018). Towards a reskilling revolution: A future of jobs for all. World Economic Forum.

Xenakis, I. (1971). Formalized music: thought and mathematics in composition. Indiana University Press.

Zarya, V. (2017). What do 65\% of the most powerful women have in common? Sports. Fortune. https:// fortune.com/2017/09/22/powerful-women-business-sports/

Zucker, L., \& Hicks, T. (2019). Alternative assessments, unintended consequences: The promise and peril of digital badges. Transformations: The Journal of Inclusive Scholarship and Pedagogy, 29(1), 113-123. https://doi.org/10.1353/tnf.2019.0008 


\section{Other Image Credits}

Appendix Figures A1 and A2 by Emily Harmon and Shahab Sagheb

\section{Photo Credits}

Executive Summary photo by Boeing

Introduction photo by Thinkabit Lab, Virginia Tech

Chapter I photo by Calhoun Discovery Program, Virginia Tech

Chapter II photo by Erica Corder for Virginia Tech

Chapter III photo by Pixabay

Chapter IV photo by Calhoun Discovery Program, Virginia Tech

Working Groups photo by Erin Williams for Virginia Tech

Appendix A photo by Calhoun Discovery Program, Virginia Tech

References photo by Calhoun Discovery Program, Virginia Tech 

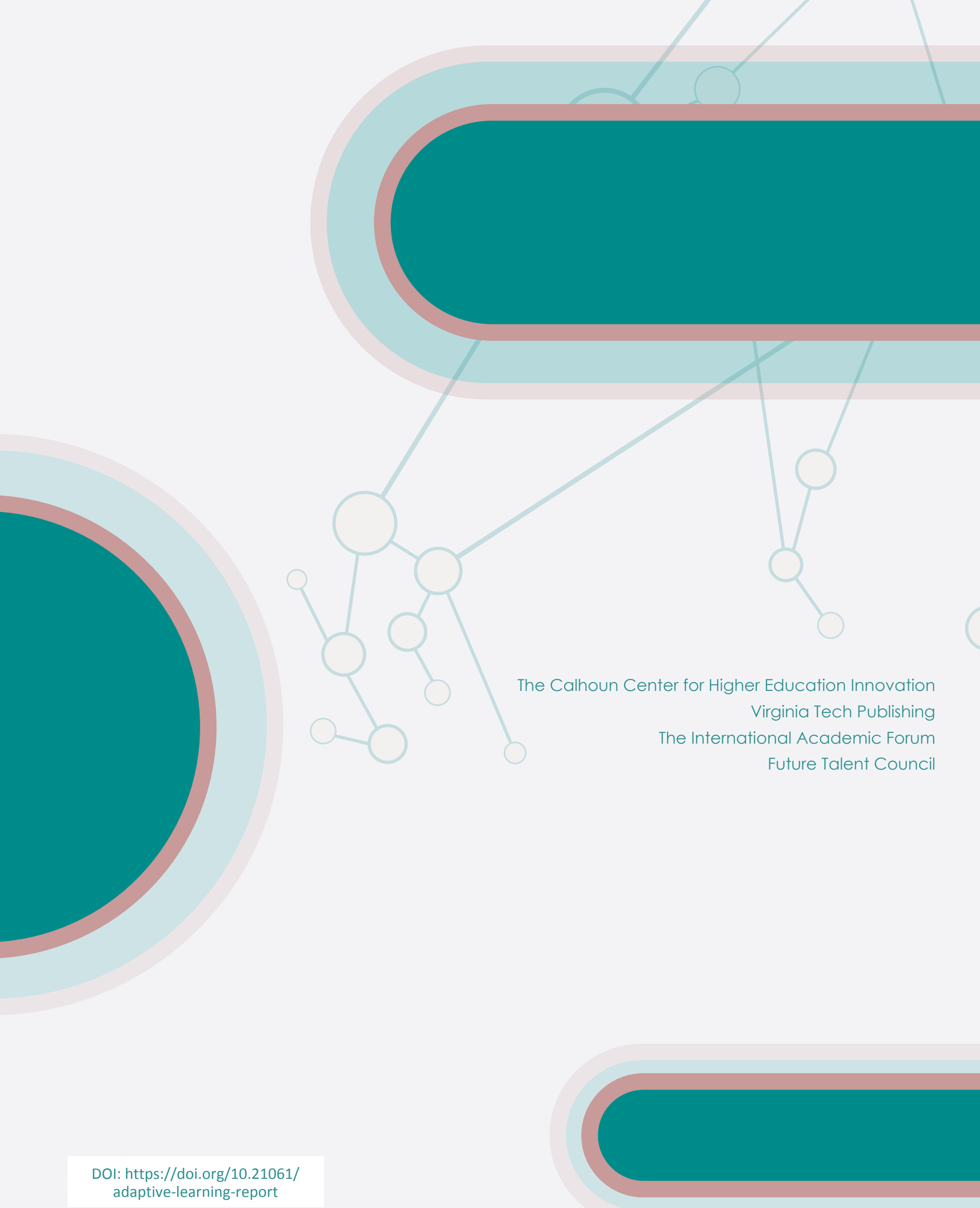